\title{
PARENTAL ATTITUDES TOWARD NEWBORN SCREENING FOR DUCHENNE/BECKER MUSCULAR DYSTROPHY AND SPINAL MUSCULAR ATROPHY
}

by

\section{Molly Frances Wood}

BA, Rutgers University, 2009

\author{
Submitted to the Graduate Faculty of \\ the Graduate School of Public Health in partial fulfillment \\ of the requirements for the degree of \\ Master of Science
}

University of Pittsburgh 


\section{UNIVERSITY OF PITTSBURGH \\ GRADUATE SCHOOL OF PUBLIC HEALTH}

This thesis was presented

by

Molly Frances Wood

It was defended on

April 6, 2012

and approved by

Robin E. Grubs, Ph.D., CGC, Assistant Professor, Co-Director of the Genetic Counseling Program, Department of Human Genetics, Graduate School of Public Health, University of Pittsburgh

Elizabeth Anne Gettig, M.S., CGC, Associate Professor, Co-Director of the Genetic Counseling Program, Department of Human Genetics, Graduate School of Public Health, University of Pittsburgh

M. Michael Barmada, Ph.D., Associate Professor, Department of Human Genetics, Graduate School of Public Health, University of Pittsburgh

Thesis Director: Paula Clemens, M.D., Associate Professor, Department of Neurology, School of Medicine, University of Pittsburgh 
Copyright (C) by Molly Frances Wood

2012 


\title{
PARENTAL ATTITUDES TOWARD NEWBORN SCREENING FOR DUCHENNE/BECKER MUSCULAR DYSTROPHY AND SPINAL MUSCULAR ATROPHY
}

\author{
Molly Frances Wood, M.S.
}

University of Pittsburgh, 2012

\begin{abstract}
A sensitive and specific screen for Duchenne muscular dystrophy (DMD) has been clinically confirmed, but the acceptability of adding DMD to the newborn screening (NBS) program has been controversial due to a lack of evidence that early diagnosis improves clinical outcome. With promising new gene therapies currently in clinical trials, it is reasonable to consider NBS for DMD for early pharmaceutical intervention. It is our objective to assess parents' attitudes toward the acceptability of including DMD, the milder and allelic Becker muscular dystrophy (BMD), and spinal muscular atrophy (SMA) in the NBS panel, as well as to determine which factors (early diagnosis, family planning, parent-child bonding, anxiety, decision regret, time to prepare) are the most influential in parents' opinions.
\end{abstract}

Methods: Two cohorts were recruited separately and surveyed about their attitudes toward NBS for DMD/BMD/SMA. Expectant parents were recruited with no regard to family history and their opinions were compared to those of parents of children with DMD, BMD, or SMA.

Results: Of the 65 parents of children with DMD, BMD, or SMA that were surveyed, 63 (97\%) supported NBS for DMD/BMD/SMA, either as a mandatory screen or with parental permission. Of the 400 expectant parents surveyed, 369 (92.5\%) would have their child screened at birth for an incurable, life-shortening disease such as DMD/BMD/SMA. Expectant parents, especially 
those who would choose to have their child screened, viewed the benefits of early diagnosis $(58.9 \%)$ as the most influential factor in their decision.

Conclusions: There is strong support for NBS for DMD/BMD/SMA in both cohorts, which is not contingent on further therapeutic development. The consideration of including non-treatable diseases in NBS should include consideration of parental opinions on the beneficence of screening. Although there is currently no direct medical benefit to early diagnosis in DMD/BMD/SMA, parents responded that early diagnosis could have other, less tangible benefits. Parental opinions, along with promising clinical trials, make the implementation of an optional screen ideal for DMD, BMD, and SMA.

Public Health Importance: NBS is the foremost intersection of genetics and public health. It is imperative to involve public opinion when assessing the acceptability of adding a potentially controversial disease to a standard panel. 
TABLE OF CONTENTS

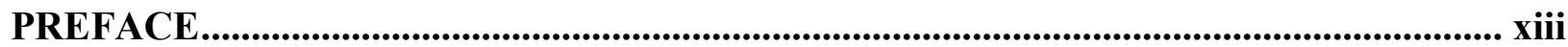

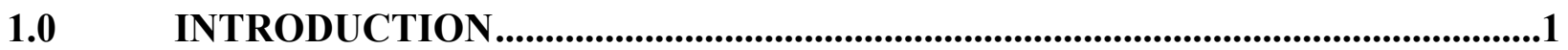

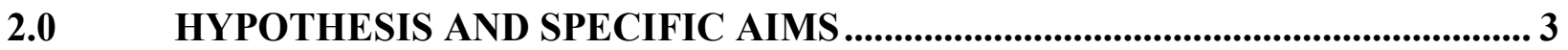

2.1.1 Specific Aim 1........................................................................................................ 3

2.1.2 Specific Aim 2 2..................................................................................................... 3

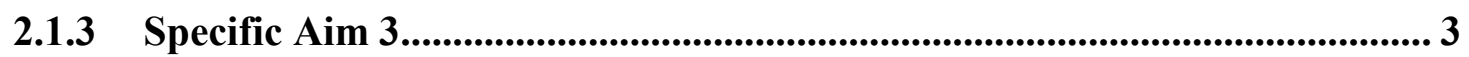

2.1.4 Specific Aim 4...................................................................................................... 4

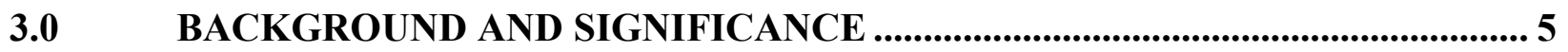

3.1 DUCHENNE MUSCULAR DYSTROPHY ........................................................ 5

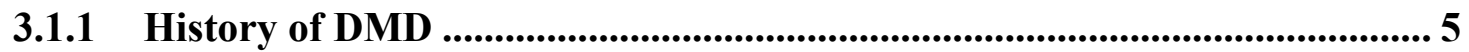

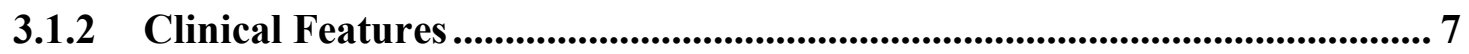

3.1.3 Diagnosis.............................................................................................................. 8

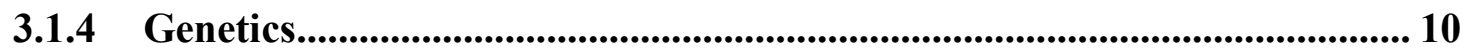

3.1.5 Management...................................................................................................... 14

3.1.5.1 Neuromuscular Interventions .............................................................. 14

3.1.5.2 Orthopedic Interventions ......................................................................... 15

3.1.5.3 Rehabilitation Interventions ................................................................ 16

3.1.5.4 Pulmonary Interventions.......................................................................... 16 
3.1.5.5 Cardiac Interventions ........................................................................... 16

3.1.5.6 GI/Nutrition/Swallowing Interventions .............................................. 17

3.1.5.7 Psychological Interventions................................................................. 17

3.1.6 Emerging Therapeutics....................................................................... 18

3.2 BECKER MUSCULAR DYSTROPHY .......................................................... 20

3.2.1 Clinical Features .......................................................................................... 20

3.2.2 Diagnosis .............................................................................................................. 21

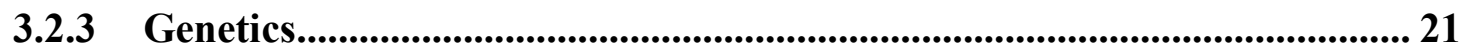

3.2.4 Management..................................................................................................... 22

3.3 SPINAL MUSCULAR ATROPHY ................................................................... 22

3.3.1 Clinical Features ................................................................................................... 23

3.3.2 Diagnosis...................................................................................................................... 24

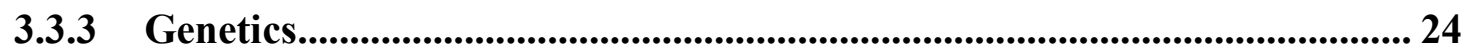

3.3.4 Management......................................................................................................... 26

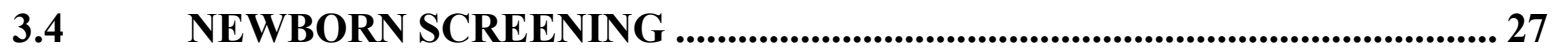

3.4.1 Phenylketonuria ..................................................................................................... 28

3.4.2 Wilson and Jungner Criteria ............................................................................. 28

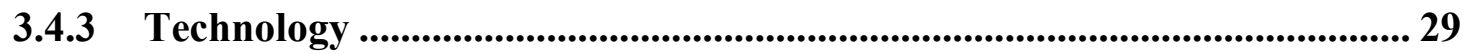

3.4.4 Mandatory vs. State-specific NBS ................................................................... 30

3.5 HISTORY OF NBS FOR DMD/BMD/SMA …................................................... 30

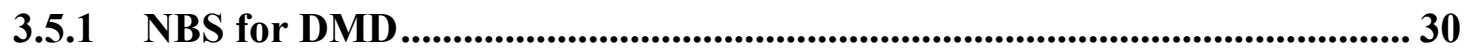

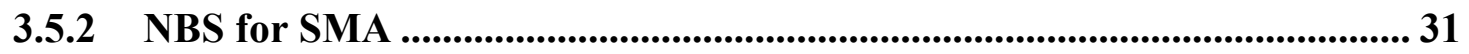

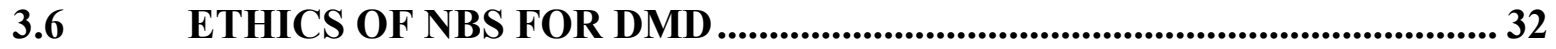




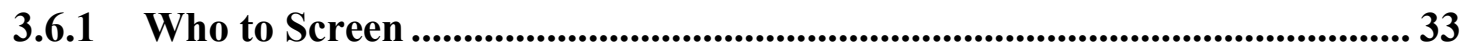

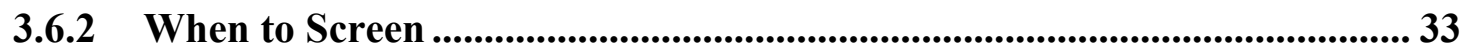

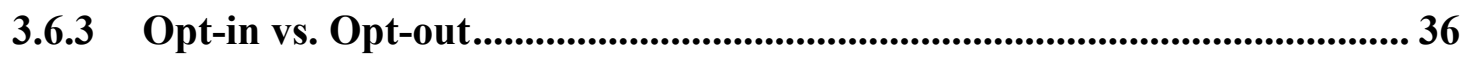

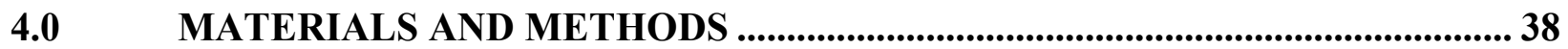

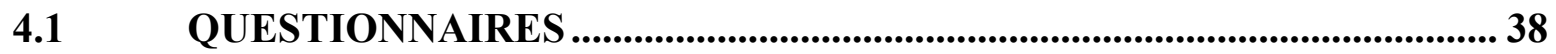

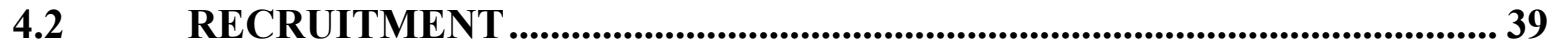

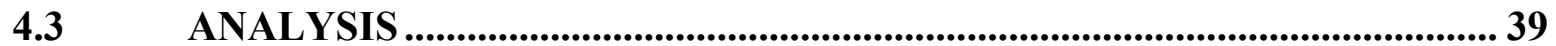

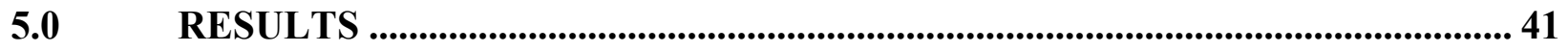

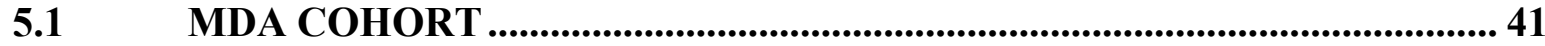

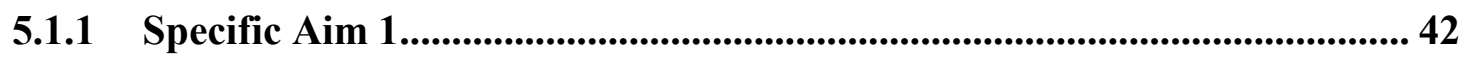

5.1.2 Additional Comments............................................................................. 47

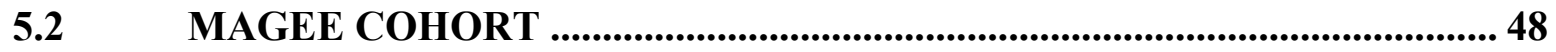

5.2.1 Specific Aim 2................................................................................................. 49

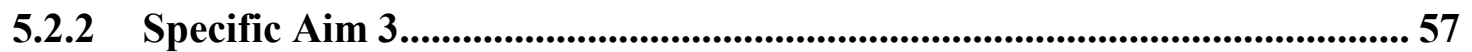

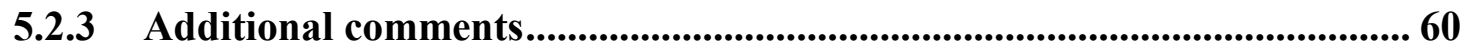

5.3 HOW DO THE MDA AND MAGEE COHORTS COMPARE?................. 62

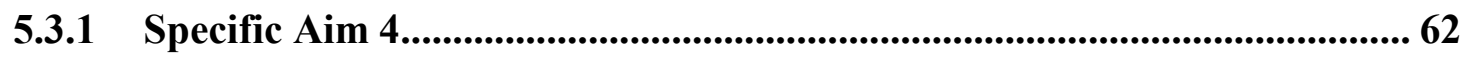

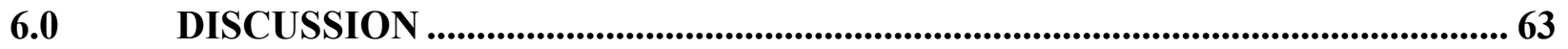

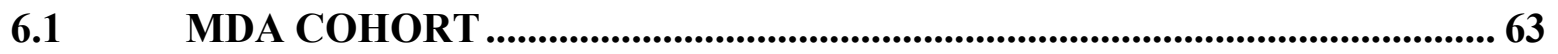

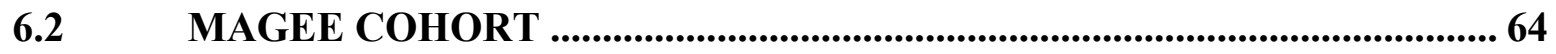

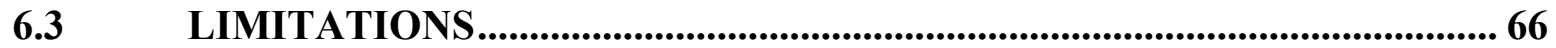

6.4 IMPLICATIONS FOR RE-IMPLEMENTING OPT-IN, OR INITIATING

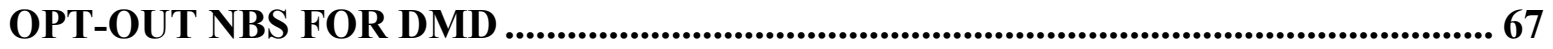




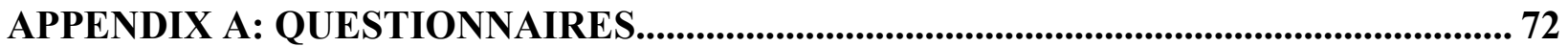

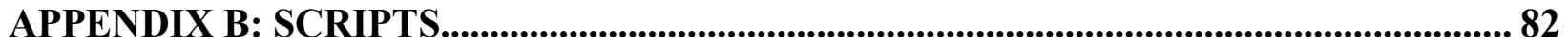

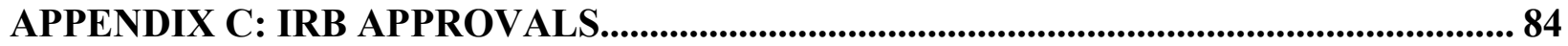

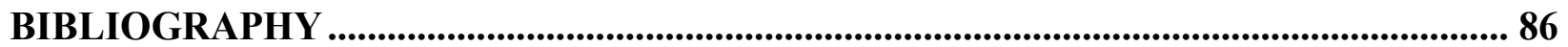




\section{LIST OF TABLES}

Table 1: Prior family history in the MDA cohort, stratified by disease. ................................ 41

Table 2: MDA parents' opinions on NBS for DMD/BMD/SMA...................................... 42

Table 3: Selected comments from parents of children with DMD, BMD, or SMA.................. 48

Table 4: The most influential factors for expectant parents who would screen their child, compared to the most influential factors for expectant parents who would not screen their child.

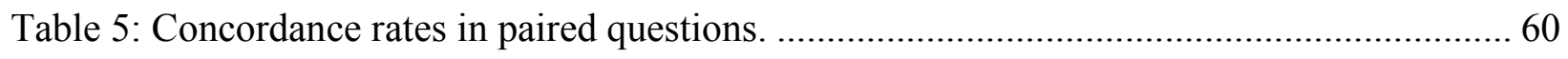

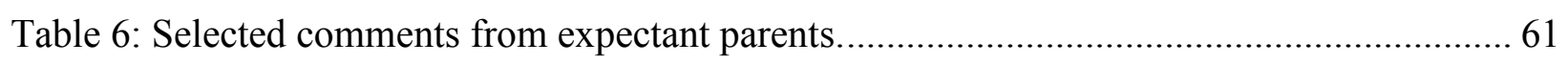

Table 7: Comparison of NBS support in MDA and Magee cohorts...................................... 62 


\section{LIST OF FIGURES}

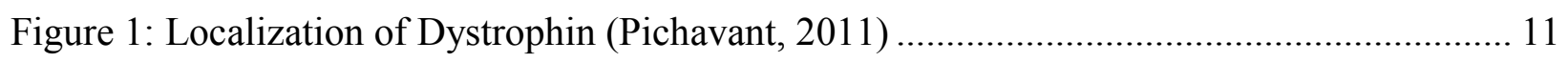

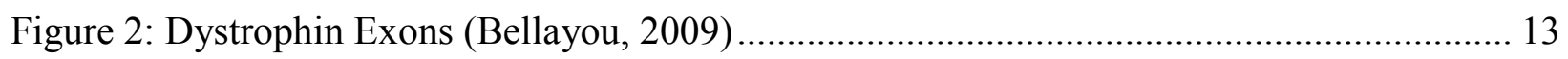

Figure 3: Support for NBS among parents of children with DMD/BMD/SMA...................... 43

Figure 4: Parental support for NBS stratified by child's diagnosis.................................... 44

Figure 5: Parental support for NBS stratified by the presence or absence of a family history..... 45

Figure 6: Parental support for NBS stratified by parental age........................................... 46

Figure 7: Parental support for NBS stratified by the number of children a parent has............... 47

Figure 8: Awareness of NBS in expectant parents. ....................................................... 50

Figure 9: Awareness of NBS in expectant parents with and without prior children. ................. 51

Figure 10: Expectant parents' opinions on the necessity of screening for genetic diseases........ 52

Figure 11: Expectant parents' opinions on whether screening for genetic disease is wrong. ...... 53

Figure 12: Support for NBS among expectant parents. ................................................... 54

Figure 13: Support for NBS among expectant parents with and without personal knowledge of a

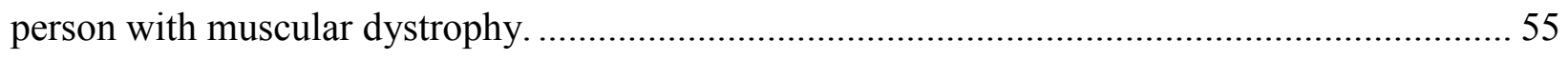

Figure 14: Support for NBS among expectant parents with and without personal knowledge of a

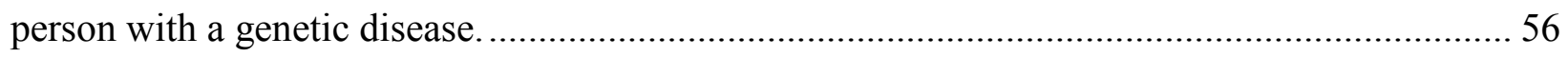


Figure 15: Support for NBS among expectant parents with and without knowledge of a person (such as a celebrity, athlete, or politician) with a genetic disease.

Figure 16: Factors that play a primary role in expectant parents' opinions of NBS for

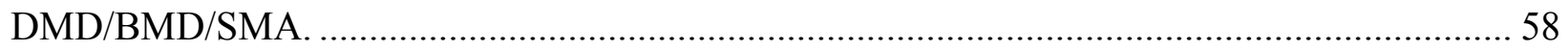

Figure 17: Factors that play a primary role in expectant parents' opinions of NBS for $\mathrm{DMD} / \mathrm{BMD} / \mathrm{SMA}$, stratified by whether an expectant parent would choose to screen his/her child...... 59 


\section{PREFACE}

There are innumerable people who have been a part of this journey, and words are inadequate to express my gratitude toward them.

My advisor and committee chair, Paula Clemens, has my eternal thanks for her insight, advice, and admirable patience, as well as for her careful and thoughtful edits throughout the writing process. Her mentorship and guidance made this thesis possible.

I am indebted to the rest of my committee for their constant support. Mike Barmada's good humor and love for teaching made data analysis as painless as possible. Robin and Betsy have provided a constant example of what it means to be a counselor in all aspects of life, and I can only hope to continue my career with as much grace.

Through this project, I have interacted with many amazing people, including Kate Hughes and Lauren Hache, and I am thankful for their gentle guidance in navigating the professional world.

Lastly, I am grateful for friends and family who have kept me sane and grounded throughout this process; for my mother, who taught me everything I know about how to be a compassionate human being; and for Chris, whose unfaltering faith, love, and kindness constantly inspire me and give me strength. 


\subsection{INTRODUCTION}

Duchenne muscular dystrophy (DMD) is an X-linked neuromuscular disease that causes progressive proximal muscle weakness, respiratory and cardiac complications, and early death. DMD affects approximately 1 in 3500 male births and is the most common form of muscular dystrophy. Becker muscular dystrophy (BMD) is an allelic disease with a similar but slower progression and affects approximately 1 in 17,500 male births. Spinal muscular atrophy (SMA) is an autosomal recessive neurodegenerative disease that is characterized by the degeneration of motor neurons in the spinal cord, resulting in progressive muscle weakness and paralysis. SMA affects approximately 1 in 6000-10,000 live births.

There is significant interest in including DMD/BMD/SMA in the newborn screening (NBS) program among families affected by these diseases as well as the medical teams that care for them. Traditionally, however, NBS is reserved for diseases in which the child clearly benefits from early diagnosis and medical intervention, and this improvement in outcome has not been reliably shown in DMD, BMD, or SMA. Promising clinical trials involving gene therapy for DMD especially have recently rekindled interest in NBS for DMD/BMD/SMA. It is the goal of this study to assess the acceptability of NBS for DMD/BMD/SMA among expectant parents and parents of children with DMD, BMD, or SMA. This study analyzed parental support for a NBS program for $\mathrm{DMD} / \mathrm{BMD} / \mathrm{SMA}$ and compared parental support between expectant parents and parents of children who have these diseases. 
In addition to assessing the acceptability of NBS for DMD/BMD/SMA, this study aims to determine what factors influence parents' opinions on this complex issue. During the implementation of an optional NBS for DMD in Wales, Parsons et al. (2002) did a psychosocial study into parents' opinions of screening and found several themes regarding the perceived advantages and disadvantages of NBS for DMD. This study used three of the most popular advantages (reproductive choice/family planning, time to prepare, and early diagnosis) and three of the most popular disadvantages (decision regret, parent-child bonding, and anxiety) to determine which factors are the most influential in parents' opinions toward NBS for DMD/BMD/SMA. 


\subsection{HYPOTHESIS AND SPECIFIC AIMS}

\subsubsection{Specific Aim 1}

Specific Aim 1: To assess how parents of children with DMD, BMD, or SMA feel about adding DMD/BMD/SMA to the NBS program.

Hypothesis: Parents of children with DMD, BMD, or SMA will be in favor of adding $\mathrm{DMD} / \mathrm{BMD} / \mathrm{SMA}$ to the mandatory NBS program because of their previous experience with the diagnostic process.

\subsubsection{Specific Aim 2}

Specific Aim 2: To assess how expectant parents feel about adding DMD/BMD/SMA to the NBS program.

Hypothesis: Expectant parents will be in favor of adding DMD/BMD/SMA to the NBS program, because of the advantages of early diagnosis.

\subsubsection{Specific Aim 3}

Specific Aim 3: To assess what factors influence expectant parents' feelings about NBS for DMD/BMD/SMA. 
Hypothesis: The most influential factor in expectant parents' feelings about NBS for $\mathrm{DMD} / \mathrm{BMD} / \mathrm{SMA}$ will be time to prepare, because of the emotional experience of these diagnoses.

\subsubsection{Specific Aim 4}

Specific Aim 4: To compare the opinions of expectant parents and parents of children with DMD, BMD, or SMA regarding NBS for DMD/BMD/SMA.

Hypothesis: Parents of children with DMD, BMD, or SMA will be more likely to support NBS for DMD/BMD//SMA than expectant parents, because of their personal investment in these specific diseases. 


\subsection{BACKGROUND AND SIGNIFICANCE}

\subsection{DUCHENNE MUSCULAR DYSTROPHY}

Duchenne muscular dystrophy (DMD) is a neuromuscular disease that causes progressive proximal muscle weakness, respiratory and cardiac complications, and eventually, death. DMD is the most common muscular dystrophy in children, and affects approximately 1 in 3500 male births (Emery, 1991).

\subsubsection{History of DMD}

Duchenne muscular dystrophy is named for C.B. Duchenne de Boulogne, but credit for the first clinical description goes to the English physician Charles Bell, who in 1830 described an 18year-old man with gradual muscular weakness of the lower extremities and no associated findings to suggest a spinal cord disease (Tyler, 2003). In 1851 Edward Meryon gave an unequivocal clinical and pathological description of DMD through a paper presented to the Royal Medical and Chirurgical Society of London. Although Meryon initially believed the spinal cord to be cause of the disease, after performing an autopsy on one of his patients, he was the first to suggest that defective nutrition of the muscles was the true cause (Tyler, 2003).

In 1861, Duchenne described his first patient, seen in 1858, as having "hypertrophic paraplegia of infancy of cerebral origin." However, in 1868, he revised his clinical name to 
"pseudo-hypertrophic muscular paralysis," and described 6 principal diagnostic features (as quoted in Tyler, 2003) which still apply today:

1. "Decrease in strength, at the beginning of the disease, usually in the muscles of the lower limbs.

2. Lordosis and spreading of the lower limbs on standing and walking.

3. Excessive development of volume, during a second stage, either of some or all of the weakened muscles.

4. Progressive course of the disease, during a third stage, with worsening of the paralysis and with its generalization if it was limited to the inferior members.

5. Decrease or abolition of electromuscular contractility in an advanced stage of the disease.

6. Absence of fever, sensory disturbance, and impairment of the functions of the bladder and intestine during the entire course of the disease."

William Richard Gowers, an English neurological clinician, was the first to propose that there was an inherited component to DMD and described its pattern in 1879 (Tyler, 2003). He observed that DMD tends to affect several members of the same family and most commonly affects boys, with affected girls seeming to have a milder presentation at a later age (Tyler, 2003). Regarding family history, Gowers noted that "the disease is never to be heard of on the side of the father; always when antecedent cases have occurred, they have been on the side of the mother," - something Gowers referred to as unilateral inheritance (Tyler, 2003). He concluded, 
"the congenital tendency is exclusively due to the maternal element in the embryo." (Tyler, 2003).

\subsubsection{Clinical Features}

Individuals with DMD typically present between the ages of 3-5 years with a delay in the achievement of motor milestones, as well as a reduced ability to run and jump (Bushby, 2010). Proximal muscle weakness leads to difficulty when rising from the floor, resulting in the classical Gowers' sign. The average age of diagnosis is 5 years old, when there is a distinct divergence from their peers in physical ability (Bushby, 1999). Meryon and Duchenne referred to the pseudo-hypertrophy associated with DMD, especially in the calf and deltoid muscles, which is typically present by ages 5-6 years (Engel, 2004). While still ambulatory, proximal muscle weakness causes boys with DMD to have a distinct posture, characterized by thrown back shoulders, spinal lordosis, and a wide stance (Pearce, 2000). Tenuous balance leads to a wide, abnormal gait, and with no way to recover, affected boys often fall (Doglio, 2011). Uneven weakness of agonist and antagonist muscles leads to contractures in approximately $70 \%$ of affected boys (Engel, 2004).

As muscle weakness progresses, the course of DMD can be divided into 5 stages: presymptomatic, early ambulatory, late ambulatory, early non-ambulatory, and late nonambulatory (Bushby, 2010). The transition between ambulatory and non-ambulatory stages typically occurs between ages 10-12 years, at which point boys with DMD become wheelchairdependent for mobility (Manzur, 2009). In the later stages of disease, boys with DMD are prone

to progressive kyphoscoliosis, dilated cardiomyopathy (DCM), and respiratory insufficiency. It 
is not the primary muscle weakness, but complications from respiratory insufficiency and especially cardiac failure that most often directly cause death (Eagle, 2002).

Dystrophin deficiency in cardiac muscle leads to DCM. As the ventricles fill, cardiac muscles must stretch, and in the absence of dystrophin, damage occurs (Kaspar, 2009). This damage starts an inflammatory response pathway, leading to fibrosis, which makes the cardiac muscle less flexible and leads to DCM (Kaspar, 2009).

There are also well-documented cognitive and psychological problems associated with DMD, in approximately 33-50\% of cases (Giliberto, 2004; Manzur, 2009; Bushby, 2010). Cognitive delays include both overall impaired intelligence and specific learning disabilities, most often in verbal areas such as verbal short-term memory and phonological language processing (Mehler, 2000; Giliberto, 2004). There is an increased risk for behavioral and developmental disorders, including attention-deficit hyperactivity disorder, obsessivecompulsive disorder, and autism (Bushby, 2010).

\subsubsection{Diagnosis}

Evaluation for DMD is typically considered when abnormal muscle function is observed in a male child. This could include using the arms to rise from the floor combined with a wide stance, known as Gowers' sign, or a waddling gait with or without toe walking (Drousiotou, 1998; Bushby, 2010). Often, there is an associated frequency of falling, in addition to difficulty running or climbing stairs. Other earlier signs of DMD typically seen in retrospection include delayed motor milestones such as walking, or a delay in language development (Bushby, 2010).

The first step for diagnosing DMD is often to test serum creatine kinase (CK) levels. CK is an enzyme that is used as a marker for muscle damage (Zellweger, 1975). Although serum CK 
level is a sensitive indicator of disease, it is not specific for DMD. An elevated CK could indicate myocardial infarction, rhabdomyolysis, or other muscular dystrophies (Engel, 2004). Typically, the CK levels in patients with DMD are at least ten-fold higher than normal (Zatz, 1991).

Once DMD is suspected, confirmation of the diagnosis may include muscle biopsy or genetic testing, depending on the clinical situation, availability of genetic testing, and resources available to the testing center. Genetic testing is mandatory after a positive muscle biopsy, but a muscle biopsy is not always required after a positive genetic test (Bushby, 2010). Immunocytochemistry and immunoblotting for dystrophin are used to diagnose DMD by muscle biopsy. DMD is distinguished from other milder dystrophinopathies by the complete absence of dystrophin expression in muscle in DMD. If dystrophin is present, a muscle biopsy can provide information about the amount and size of the dystrophin protein (Bushby, 2010).

Genetic testing is necessary even after diagnosis of DMD through muscle biopsy because the exact mutation type and location provides information about expected prognosis, availability of future mutation-specific therapies, and familial implications (Bushby, 2010). Typically, deletion/duplication testing is done first, recognizing that between $55-75 \%$ of mutations will be detected. If no mutation is found through deletion/duplication testing, gene sequencing will detect an additional $20-35 \%$ of mutations, including smaller deletions and insertions. Knowing the exact endpoints and location of a deletion or duplication is key in understanding the effect of the mutation on the reading frame of the gene, which is the most important predictive factor in phenotypic variability among the dystrophinopathies (Bushby, 2010). 


\subsubsection{Genetics}

DMD follows an X-linked recessive pattern of inheritance. Each child born to a female carrier has a $50 \%$ chance of inheriting the mutation; male children will be affected with DMD and female children will be carriers. Almost all DMD patients are male, but infrequently, the disease is manifested in girls with a structurally altered or absent $X$ chromosome (Engel, 2004). Female carriers most often do not show symptoms of DMD, but they are at risk for cardiac complications later in life, and in rare cases, may have a similar phenotype to affected males (Holloway, 2008; Engel, 2004).

Approximately 2/3 of cases are inherited in this manner (Engel, 2004). The remaining 1/3 of DMD diagnoses are a result of a de novo mutation in the affected child. This is explained by a high spontaneous mutation rate in the dystrophin gene, estimated to be 1 in 10,000 (Emery, 1991).

DMD is caused by mutations in the dystrophin gene, located at Xp21 (Hoffman, 1987). The dystrophin gene is the largest in the human genome, and makes up $0.1 \%$ of the genome (Koenig, 1988). It is comprised of 2.4 million base pairs, which encode a 14 thousand base (or $14 \mathrm{~Kb}$ ) messenger RNA that comprises 79 exons, and is translated to generate a 3,685 amino acid protein (Koenig, 1988). Dystrophin is found in skeletal, cardiac, and smooth muscles, as well as the retina, cerebral cortex, lung, and kidney. Small amounts of dystrophin can also be detected in the placenta, liver, spleen, and cultured lymphoblastoid cells (Chelly, 1988).

Dystrophin connects the muscle filament actin to the dystrophin-associated glycoprotein complex (DGC). The DGC then connects the muscle fiber membrane (sarcolemma) to the extracellular matrix, as shown in Figure 1 (Manzur, 2009; Muntoni, 2003). When functioning 
correctly, it is therefore thought that dystrophin plays a role in stabilizing the sarcolemma as well as protecting it from the damage associated with contraction (Davies, 2006; Manzur, 2009).

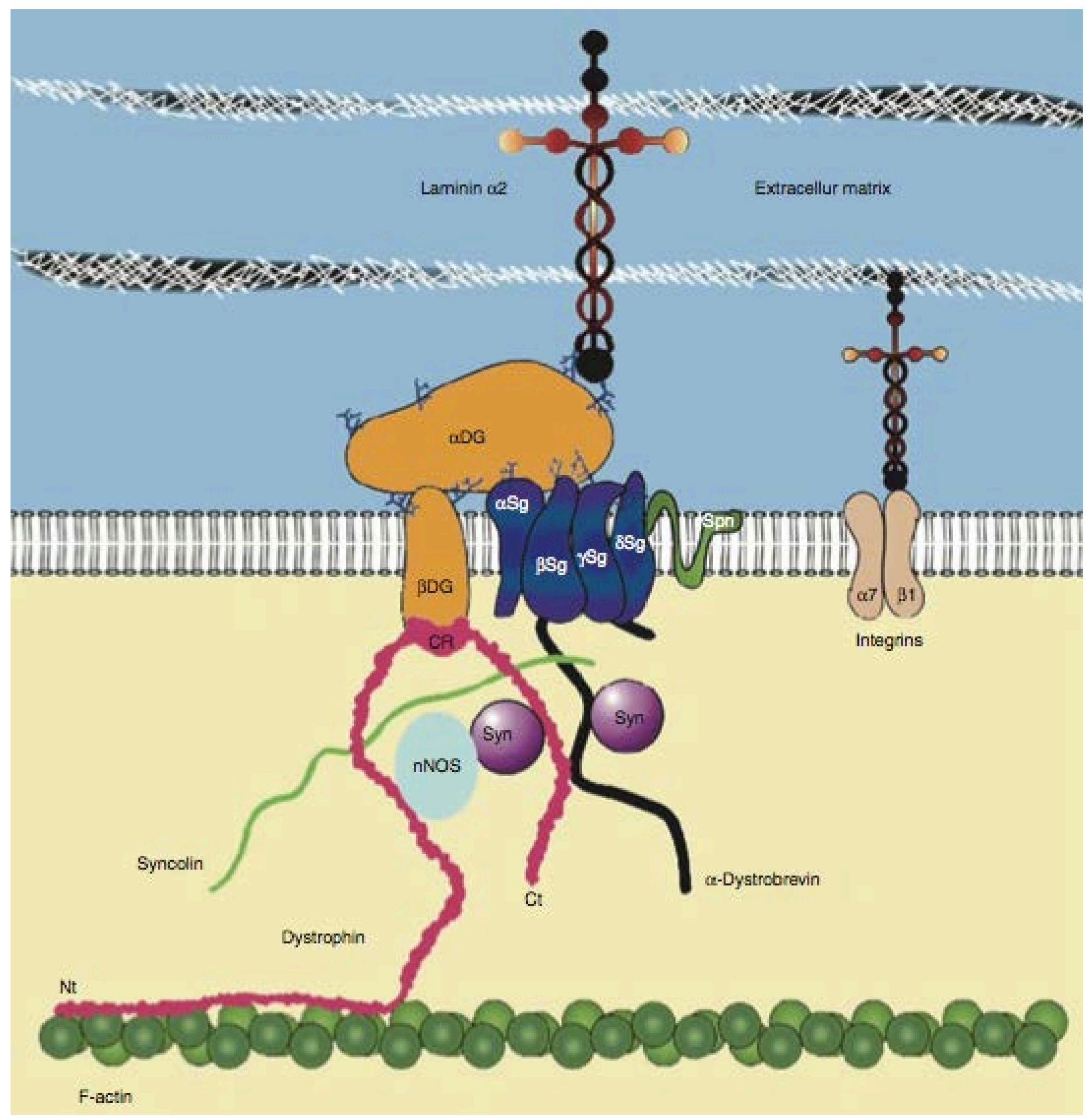

Figure 1: Localization of Dystrophin (Pichavant, 2011)

The localization of dystrophin within the muscle fiber. Dystrophin connects the muscle filament actin to the dystrophin-associated glycoprotein complex, located in the sarcolemma. 
Dystrophin protein is made up of 4 domains: an actin-binding domain at the 5' end, a central rod domain, a cysteine-rich domain, and a carboxy (C)-terminal domain at the 3' end (Koenig, 1988). Of these 4 domains, the most critical are the actin-binding and C-terminal domains; the central rod domain can be shortened and still retain function (Ervasti, 2007). Mutations that shorten this central rod domain without affecting the function of the actin-binding or C-terminal domains may cause a milder phenotype, known as Becker muscular dystrophy (BMD), discussed below (Engel, 2004). The most influential determining factor of whether a mutation preserves the function of these critical regions is whether the mutation results in a shift of the transcript reading frame. In large measure, in-frame deletions result in BMD and out-offrame deletions result in DMD (Monaco, 1988). However, there are exceptions to this 'reading frame rule.' In-frame mutations that occur in critical regions of the dystrophin gene such as the actin-binding or C-terminal domains can result in a DMD phenotype (Muntoni, 2003; Manzur, 2009). To some extent, some out-of-frame mutations can be compensated for by alternative splicing isoforms, resulting in a BMD phenotype (Muntoni, 2003; Manzur, 2009).

The most common dystrophin mutations are large deletions, spanning multiple exons. Figure 2 illustrates the dystrophin exons. Rectangular blocks represent exons that begin and end with whole codons, and blocks with arrows pointing to the right or left represent exons that begin or end on the second or third nucleotide. Exons that begin and end with the same codon position can be deleted without shifting the reading frame; likewise, if an exon that begins and ends with different codon positions is deleted, the reading frame is lost, along with downstream translation. Multiple exons can be deleted and still preserve the reading frame, if the beginning of the first exon and the end of the last exon coincide with the same relative nucleotide position within the 
codon. The idea of skipping additional exons to restore the reading frame is the basis of a promising new therapy for DMD, discussed in more detail below.

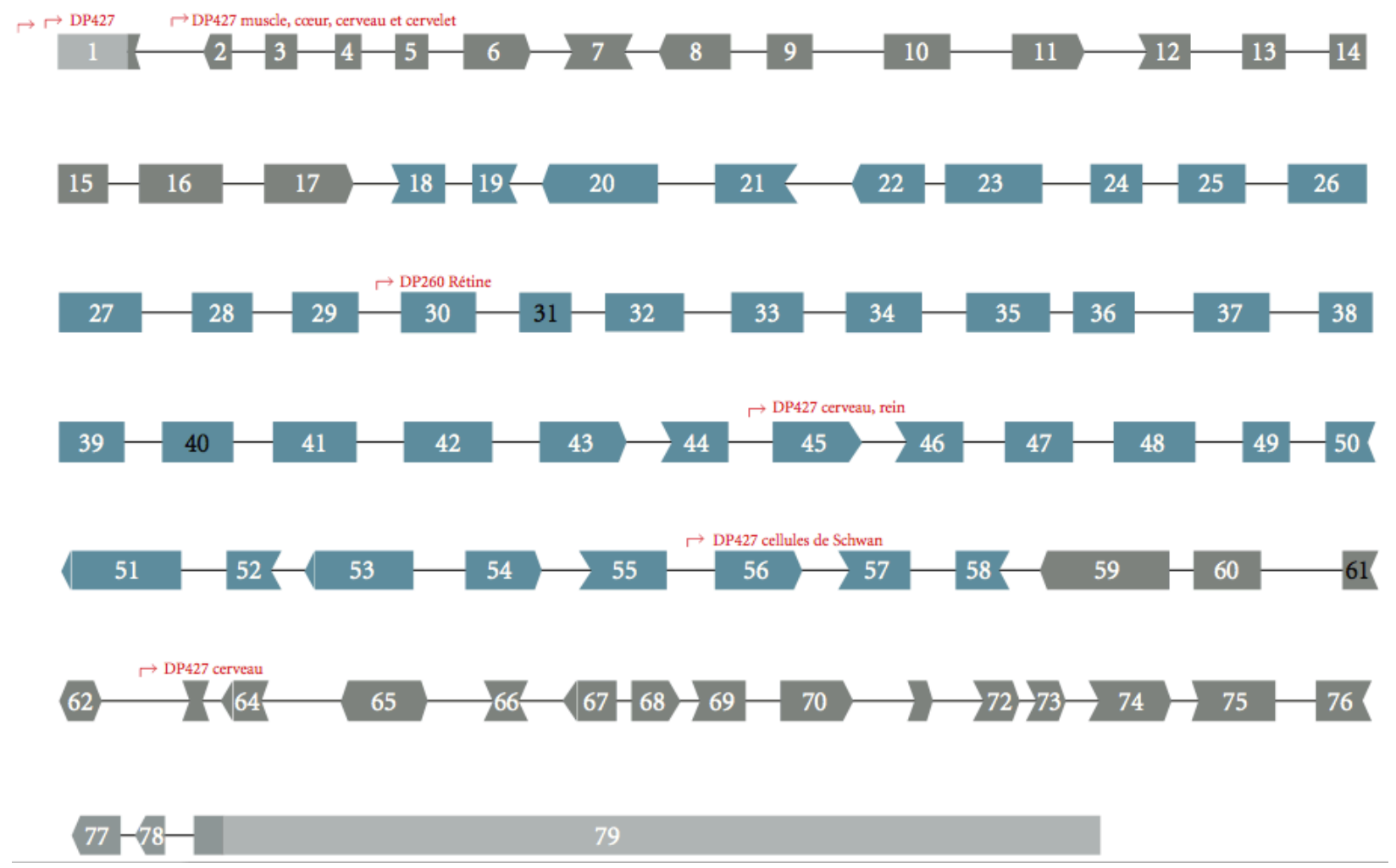

Figure 2: Dystrophin Exons (Bellayou, 2009)

Dystrophin exons, numbered 1-79. Rectangular pieces represent exons that begin and end at codon boundaries. Arrows pointing to the right or left represent exons that end on the second and third positions of the codon, respectively.

There are four full-length and four truncated transcripts from the dystrophin gene; each transcript has a different promotor (Engel, 2004). Each full-length dystrophin isoform is cell-type specific, and includes isoforms for muscle cells, cortical cells, Purkinje cells, and lymphoid cells. The four truncated variants of dystrophin have intronic promotors, and are named for their estimated molecular masses: Dp260, Dp140, Dp116, and Dp71 (Engel, 2004). Different 
deletions in the dystrophin gene result in the interruption of different dystrophin isoforms, and this may contribute to the clinical variability within both DMD and BMD.

\subsubsection{Management}

There is no cure for DMD; current management for boys with DMD provides prophylactic and symptomatic treatment and involves a team of specialists, including (but not limited to) neurologists, rehabilitation specialists, cardiologists, pulmonologists, pediatricians, orthopedic surgeons, and primary care physicians (Bushby, 2010). Principle interventions available can be broken down into the following categories: neuromuscular, orthopedic, rehabilitation, pulmonary, cardiac, GI/nutrition/speech, and psychosocial.

\subsubsection{Neuromuscular Interventions}

Neuromuscular management and therapies primarily revolve around the initiation and timing of glucocorticoids, a type of corticosteroid. Currently, glucocorticoids are the only medication available to slow the decline in muscle strength and function in DMD (Bushby, 2010). Glucocorticoids prolong ambulation and reduce the risk for progressive scoliosis as well as stabilize pulmonary function variables after ambulation is lost (Yilmaz, 2004; Manzur, 2009). The two most widely used glucocorticoids are prednisone and deflazacort.

Timing the initiation of glucocorticoids is an individual decision, and should take into account age, current functional state, and risk factors for complications (Bushby, 2010). Side effects of early steroid treatment include excessive weight gain and behavioral abnormalities (Merlini, 2003; Manzur, 2008). It is the current recommendation that glucocorticoids should be 
initiated once the gain in motor milestones has plateaued, but before motor function begins to decline (Bushby, 2010).

Other supplements have been used, including coenzyme Q10, carnitine, certain amino acids, and anti-oxidants such as fish oil, vitamin E, and green-tea extract, but there is no strong evidence for the efficacy of these supplements (Bushby, 2010).

\subsubsection{Orthopedic Interventions}

Braces and orthoses are most helpful in prolonging ambulation in patients with DMD, which in turn results in a better outcome and reduced incidence of scoliosis (Hsu, 1993; Manzur, 2009). Knee ankle foot orthoses (KAFOs) may prolong ambulation by as much as 18 months to 2 years by assisting standing (Kinali, 2007; Manzur, 2009). Although KAFOs are not as effective as iliotibial band (ITB) surgical resection, progressive casting may be the best alternative in individuals for whom surgery is not a viable option (Do, 2002; Main, 2007).

Surgical interventions are sometimes necessary for the orthopedic consequences of DMD. In the case of scoliosis, surgical spinal fusion is best tolerated when an individual still retains good respiratory function and has started a more rapid progression of the scoliosis (Van Opstal, 2011). Patients and their families are often satisfied with the results of spinal fusion, due to a more comfortable sitting posture, reduction in pain, and better quality of life (Takaso, 2010).

Contractures can also be released surgically. This can include hip, knee, elbow, or ankle contractures. It is important to release contractures to maintain or regain upright positioning as well as slow the progression of scoliosis (Griffet, 2011). Studies have shown that while surgery can increase ankle dorsiflexion in the short term, contractures recur, and individuals who did not undergo surgery retained better functionality (Rose, 2010). 


\subsubsection{Rehabilitation Interventions}

Individuals with DMD are sensitive to contraction-induced muscle damage, so a balance must be maintained between muscle use and disuse (McDonald, 2002). Overall, low-intensity exercises are recommended while still ambulatory, and mobilizing passive or actively-assisted exercises are recommended for non-ambulatory patients (Jansen, 2010). Physical training and physiotherapy are especially effective in combination with corticosteroid use (Manzur, 2009; Jansen, 2010).

\subsubsection{Pulmonary Interventions}

Complications result from a progressively diminishing respiratory reserve, including sleep apnea and hypoxemic events (Manzur, 2009). Several interventions have recently been implemented, including non-invasive ventilation (NIV). NIV is able to correct hypoventilation during sleep and does not require tracheostomy. Cough-assist devices supplement lowered forced vital capacity (FVC) and the regular use of a cough-assist device is effective in decreasing the incidence of pulmonary complications such as pneumonia.

\subsubsection{Cardiac Interventions}

Because of improvements to the pulmonary management of individuals with DMD, the prevalence of DCM is becoming an increasing cause of mortality (Spurney, 2011). It is important to consider early preventative treatment for cardiac failure, which includes prophylactic ACEinhibitors and beta-blockers, although timing is still controversial (Manzur, 2009). Cardiac condition can be monitored through electrocardiogram (EKG), echocardiogram, cardiac MRI, CT imaging, and PET scans and assessment should be done annually until an abnormality is 
found (Kaspar, 2009). Medication should be started by the earliest detection of DCM (Bushby, 2010).

\subsubsection{GI/Nutrition/Swallowing Interventions}

Obesity is a common concern in ambulatory patients taking corticosteroids (Marigne, 2011). It is important to regularly monitor weight gain and offer dietary advice in order to reduce the complications of obesity (Martigne, 2011). Conversely, in late nonambulatory patients, weight loss is a concern as difficulties with chewing, swallowing, or aspiration appear (Martigne, 2011). Nutritional supplementation and eventual gastrostomy insertion are commonly used interventions for the cachexia that can accompany the late stages of DMD (Seguy, 2002).

\subsubsection{Psychological Interventions}

Because of the various psychosocial issues associated with DMD, it is important to consider psychological assessments at critical times, including at the time around diagnosis, before entering school, and after a change in function (Bushby, 2010). Assessments should include evaluation of emotional adjustment/coping, neurocognitive and neuropsychological function, and speech and language. Psychosocial wellbeing should be evaluated in the patient, siblings, and parents (Pangalila, 2011; Bushby, 2010).

Several interventions for psychosocial support are available, and need to be individualized to the specific needs of the patient and family. Psychotherapy can involve parental management training when the child has externalizing behaviors such as aggression, or individual therapy for when the child has internalizing behaviors such as depression. Group therapy is available to improve social skills, as well as family therapy for difficulties in adjustment and coping, and applied behavior analysis for children with autism spectrum 
disorders (Bushby, 2010). Medications can be prescribed for comorbidities such as ADHD and OCD, as well as for depression, anxiety, and emotional dysregulation (Bushby, 2010).

There are also interventions and activities that convey psychological benefit outside of psychotherapy and pharmaceuticals. Increasing awareness of DMD among school personnel and peers, as well as an individualized education plan (IEP) can help maximize the child's potential in school as well as minimize the activities that may pose a risk for complications (Bushby, 2010.

\subsubsection{Emerging Therapeutics}

There are two main categories of emerging treatments for DMD that are currently being tested in clinical trials. The first is based on the premise of repairing or replacing the mutated dystrophin gene, and the second focuses on rescuing the translation of dystrophin (Partridge, 2011). The most promising method in this first category uses a single-stranded DNA virus (recombinant adeno-associated virus (AAV)) vector to provide a functional, yet truncated, copy of the dystrophin gene (Goyenvalle, 2011). The 14kb cDNA sequence of the dystrophin gene is too large for AAV vectors to carry, so minidystrophins and microdystrophins were designed that eliminated most of the central rod domain, expected to give a BMD-like dystrophin protein (Goyenvalle, 2012; Partridge, 2011). However, one drawback of AAV vector delivery is the potential for an immune response, which may require short-term immunosuppression during administration (Partridge, 2011).

The most promising therapy for rescuing translation is exon-skipping using antisense

oligonucleotides (AOs) (Nakamura, 2009; Partridge, 2011). These AOs are designed to bind to a specific region of mRNA post-transcription to alter splicing of the mRNA such that the mature 
transcript has an in-frame deletion, thus rescuing a dystrophin protein that retains both $\mathrm{N}$ - and $\mathrm{C}$ terminals (Fragall, 2011; Manzur, 2009). Depending on the dystrophin gene deletion location and its effect on reading frame, skipping an adjacent exon can restore the reading frame and potentially modify a DMD phenotype to enable a clinical course of a milder BMD phenotype (Nakamura, 2009; Aoki, 2010). Based on an analysis of the prevalence of specific deletions, skipping exon 51 would rescue the highest percentage of DMD deletions, and clinical trials testing exon 51 skipping strategies are currently showing promise (Lu, 2011; Brolin, 2011; Goemans, 2011). Drawbacks of exon-skipping include the requirement to design a different AO for the purpose of skipping each exon and the need for a constant supply of the $\mathrm{AO}$ in tissues producing dystrophin (Manzur, 2009). Delivery to relevant tissue is also an issue (Goyenvalle, 2011). A recent innovation combines these two most promising therapies into one, by using AAV vectors to transport exon-skipping AOs to the muscle (Goyenvalle, 2011; Goyenvalle, 2012).

Other therapeutics still under development include the induced increase in utrophin expression to supplement deficient dystrophin activity and the read-through of premature truncation mutations (Ervasti, 2007; Goyenvalle, 2011). Utrophin is highly homologous to dystrophin, but is expressed most in fetal development and expression declines in the newborn period (Ervasti, 2007). It is hypothesized that an approximately seven-fold increase in utrophin expression could compensate for a complete lack of dystrophin (Ervasti, 2007; Goyenvalle, 2011). 


\subsection{BECKER MUSCULAR DYSTROPHY}

Becker muscular dystrophy is a neuromuscular disease that resembles DMD, but is characterized by a slower progression and later onset. BMD and DMD are allelic disorders and there is a spectrum of severity (Engel, 2004). BMD is less common than DMD, and affects approximately 1 in 17,500 male births (Emery, 1991).

\subsubsection{Clinical Features}

Individuals with BMD typically present with lower limb weakness and calf pain with exercise in the earliest stages (Bushby, 1993). The average age of symptom onset is 12 years old, but there is significant variability. Severity can range from a DMD-like presentation to mild weakness and

exercise intolerance presenting in the $6^{\text {th }}$ decade (Yazaki, 1999). Almost $90 \%$ of affected individuals are symptomatic by age 20 years (Bushby, 1993).

The transition from ambulatory to non-ambulatory varies with clinical severity, but on average, individuals with BMD require a wheelchair for mobility in their 30's (Becker, 1962; Norman, 1990). Cognitive impairment is sometimes present and is more severe in early-onset cases (Engel, 2004; Bushby, 1993). There may be a correlation between cognitive impairment and mutations that interrupt the dystrophin isoforms expressed in CNS tissue (Giliberto, 2004; Muntoni, 2003). BMD can also shorten the expected lifespan, with the average age of death at 42 years old (Bradley, 1978; Emery, 1976).

DCM and other cardiac manifestations are the most common source of morbidity and mortality, and do not correlate with severity of skeletal muscle involvement (Melacini, 1996; Darras, 2011). Indeed, because of the slower skeletal muscle progression and the ability to lead 
an active lifestyle, cardiac symptoms are more apparent in individuals with BMD (Kaspar, 2009). In milder forms of BMD, DCM can be the first presenting symptom (Engel, 2004). DCM in BMD stems from a similar pathway as DCM in DMD, although fibrosis begins in the right, rather than left ventricle (Kaspar, 2009).

\subsubsection{Diagnosis}

The diagnostic process for BMD is similar to that of DMD. The hallmark of BMD is a partial dystrophin deficiency (Engel, 2004; Mehler, 2000; Anthony, 2011). Although 90\% of dystrophin

mutations follow the 'reading frame rule,' molecular testing cannot always predict phenotype, and it is therefore important to combine molecular testing with clinical observation and/or measurement of dystrophin levels on muscle biopsy (Manzur, 2009).

\subsubsection{Genetics}

BMD and DMD are allelic disorders, and BMD is also caused by a deficiency in dystrophin. BMD is therefore also inherited in an X-linked manner, with the same recurrence risks as DMD. As with DMD, maternal gonadal mosaicism has been reported in families with BMD (Voit, 1992), but it is difficult to estimate the prevalence. Men with BMD retain up to $70 \%$ of their fertility as compared to their unaffected brothers (Bushby, 1993). If an affected male has children, all daughters will be carriers of the dystrophin mutation, and no sons will inherit the mutation. 


\subsubsection{Management}

Management for BMD involves many of the same interventions as DMD, with some minor exceptions. In BMD, the primary source of mortality is heart failure due to DCM (Eagle, 2002; Kaspar, 2009). As in DMD, cardiac functioning should be monitored annually following diagnosis, and more often once an abnormality is identified (Finsterer, 2008; Kaspar, 2009). ACE-inhibitors and beta-blockers are available to slow the progression of DCM (Kaspar, 2009). Heart transplantation is also a viable option that has been successful, but individuals with BMD have an increased risk for anesthetic complications (Kaspar, 2009; Komanapalli, 2006). Treatment with glucocorticoids has not been studied in BMD and is not a routinely recommended therapy.

\subsection{SPINAL MUSCULAR ATROPHY}

The term "spinal muscular atrophy" (SMA) is used to describe a group of diseases characterized by the degeneration and eventual loss of cells in the spinal cord known as anterior horn cells (Engel, 2004; Wee, 2010). Most often, SMA refers to the most common disease in this group proximal SMA - which is further subdivided into four types based on clinical severity, as described in detail below (Engel, 2004; Wee, 2010). The incidence of SMA is between 1 in 6000 and 1 in 10,000 births (Su, 2011; Lorson, 2010; Pearn, 1978), making it the most common fatal autosomal recessive disorder (Prior, 2010). 


\subsubsection{Clinical Features}

SMA is a highly variable neuromuscular disease characterized by the degeneration of motor neurons in the spinal cord, resulting in progressive muscle weakness and paralysis (Prior, 2010).

SMA is divided into four subtypes based on clinical severity. SMA type I is the most severe, with onset of symptoms in the first six months of life. Children with SMA type I are unable to sit unassisted, and are not expected to live longer than two years without respiratory support (Wee 2010; Engel, 2004). SMA type II typically will present with symptoms in the first

year of life. While children with SMA type II can sit unassisted, they are unable to walk, and survival is variable (Wee 2010; Engel, 2004). People with SMA type III can walk without aid, and life span is not markedly reduced (Wee 2010; Engel, 2004). SMA type III is further divided into IIIa and IIIb, with age of onset before or after age 3, respectively (Engel, 2004). Adult SMA, or SMA type IV, has an age of onset after age 30 with variable severity (Engel, 2004).

The severe muscle weakness in SMA causes a number of orthopedic consequences, including the formation of contractures, spinal deformity, osteopenia, and pain (D'Amico, 2011). Daily functions are limited by physical ability. Feeding difficulties are often present and may require gastrostomy. The most significant source of mortality, however, is from respiratory distress. Although the diaphragm is spared in SMA, expiratory and intercostal muscles are weakened, making breathing difficult (D’Amico, 2011). This leads to recurrent chest infections, decreased respiratory function, impaired cough with poor secretion clearance, and eventually respiratory failure (Wang, 2007; D’Amico, 2011). 


\subsubsection{Diagnosis}

There is no substrate or biomarker to aid in the diagnosis of SMA. Diagnosis relies on clinical observation and molecular genetic testing (Ogino, 2004; D'Amico, 2011). SMA should be on the list of differential diagnoses when a severely weak child or hypotonic baby presents with normal attentiveness and cognitive function (Menezes, 2011; D'Amico, 2011). SMA-related weakness is typically proximal and symmetrical, and tendon reflexes are diminished or absent (Wang, 2007; D'Amico, 2011). There are no associated sensory abnormalities (Wang, 2007). In SMA type I, there may be feeding difficulties, a weak cry and cough, and impaired head control (D'Amico, 2011). Other diagnostic tests (including CK levels, electromyography (EMG), and nerve conduction studies) can help distinguish other neuromuscular diseases from SMA (Wang, 2007).

\subsubsection{Genetics}

SMA is inherited in an autosomal recessive pattern. It is estimated that the pan ethnic carrier frequency for SMA is between 1:25 and 1:66 (Hendrickson, 2009; Prior, 2010). All the subtypes of proximal SMA are caused by mutations in the survival motor neuron-1 (SMN1) gene (Lefebvre, 1995; Bürglen, 1996). The vast majority (95-98\%) of cases are caused by homozygous deletion of SMN1, with a small minority of cases caused by a heterozygous whole gene deletion / point mutation combination, which does not allow the SMN protein to function (Bürglen, 1996).

Although SMN1 is the gene that causes SMA, SMN2 is the most influential in determining prognosis, and therefore subtype. SMN1 and SMN2 are both located at 5q13; SMN1 is distal to SMN2. SMN1 and SMN2 are highly homologous, and the coding sequence differs by 
just one base pair in exon 7 (c.840C $>\mathrm{T}$ ) (Prior, 2010). This silent nucleotide change does not alter the amino acid sequence, but affects splicing (D'Amico, 2011). It is thought that this silent change either disrupts an exonic splicing enhancer (ESE) or creates an exonic splicing silencer (ESS) (Kashima, 2003; Lorson, 2010). Although the exact mechanism is not known, SMN2 is known to primarily produce a quickly-degraded RNA product lacking exon 7, called $\operatorname{SMN} \Delta 7$, although some amount of functional SMN protein is also produced (Lorson, 2010). SMA prognosis is correlated with the amount of SMN protein preserved. With the loss of both copies of SMN1, prognosis is directly correlated with the number of SMN2 copies an affected person has.

Copy number variation in SMN2 ranges from 0-3 in the general population, with 10-15\% of unaffected individuals having no copies (Ogino, 2002; Gerard, 2000; Prior, 2010). People with SMA must have at least 1 copy of SMN2, but there is still variability. 1-2 copies of SMN2 is most often associated with SMA type I; people with SMA type II typically have 3 copies; and the majority of people with SMA type III have 3-4 copies (Gerard, 2000; Mailman, 2002; Prior, 2010). This variability and overlap of SMN2 copy number between clinical presentations makes it difficult to predict prognosis based on SMN2 copy number alone (Wang, 2007).

Pan ethnic carrier screening for SMA has been recommended by the American College of Medical Genetics (ACMG), but is limited by the need for gene dosage testing (Prior, 2010). Approximately $9 \%$ of the population has 3 copies of SMN1, and logically, a carrier could have two copies of SMN1 on one chromosome, and no copies on the other. Gene dosage testing is not able to distinguish between an SMA carrier 2/0 genotype and a non-carrier 1/1 genotype, and might therefore miss up to $9 \%$ of carriers for SMA (Prior, 2010). 


\subsubsection{Management}

Management for SMA has historically been focused on palliative care and supportive therapy, and there is no known cure. Recently, guidelines outlining standard of care in SMA were published (Wang, 2007). Care for individuals with SMA should be coordinated by a neuromuscular specialist and include care through pulmonology, gastroenterology, orthopedics, and palliative care (Wang, 2007; D’Amico, 2011). Ultimately, the interventions pursued should be considered in the context of goals for quality of life for the patient, often as determined by his or her parents and family.

Pulmonary complications are the leading cause of mortality in the more severe types of SMA. This can include chest infections, respiratory failure, swallowing dysfunction, and reflux (D’Amico, 2011). Respiratory interventions include cough-assist devices, non-invasive ventilation (NIV), bi-level positive air pressure (BPAP), and eventually a tracheostomy (D’Amico, 2011). Other complications, such as feeding difficulties or obesity secondary to limited mobility, can be addressed through nutritional support and intervention, and a gastrostomy, if needed (Wang, 2007).

Interventions for muscle weakness and the associated orthopedic consequences should encourage standing or walking based on an individual's capability (Wang, 2007). Braces and splints can preserve range of motion while reducing pain (Wang, 2007). Supportive equipment, orthotics, and assistive technology should take into consideration the individual's primary posture and maximum ability (Wang, 2007). Scoliosis correction should be approached cautiously, with consideration given to a patient's respiratory function, as individuals with SMA have an increased risk for anesthetic complications (Wang, 2007; D’Amico 2011). 
Palliative care plays an important part in the clinical management of SMA. Especially in more severe types of SMA, therapies to extend the lifespan may decrease the overall quality of life (Wang, 2007). Appropriate support for grieving family members, including bereavement support and hospice care, is available. End of life care decisions are ideally made after sufficient time has passed since the initial diagnosis, but before an emergent situation arises (Wang, 2007).

\subsection{NEWBORN SCREENING}

Newborn screening (NBS) is a public health initiative established in the 1960s that aims to identify infants at a higher risk for certain disorders, who would benefit from early diagnosis and management (CDC, 2004). Most disorders identified by NBS are not outwardly apparent at birth, but would cause death or permanent disability if left untreated (Wilson, 1968; CDC, 2004). For this reason, it is important to identify those infants that are at a higher likelihood of having these disorders and begin treatment immediately.

As the name implies, NBS involves a screening test. By definition, NBS is not diagnostic, and many infants that screen positive will not have the disorder in question. These are known as "false positives." Likewise, NBS may miss some infants that do in fact have a given disorder. These are known as "false negatives." Ideally, a screening test would have very few false positives and no false negatives. False negatives lead to a delay in diagnosis for individuals that require treatment, causing harm. False positives increase the cost of a screening program, because all screen-positive infants undergo additional testing to determine those who have the disease in question. 


\subsubsection{Phenylketonuria}

The disease that first brought the need for population-wide screening to the public's attention was phenylketonuria (PKU). Patients with PKU lack phenylalanine hydroxylase (PAH), an enzyme that metabolizes phenylalanine into tyrosine (NIH, 2001; Blau, 2011). Phenylalanine is a common amino acid found in most protein-rich foods, such as milk, eggs, meat, and nuts. Without PAH, phenylalanine will accumulate and thus will be converted to phenylpyruvate, which can be detected in the urine (Blau, 2011). PKU, if left untreated, will lead to developmental delay, microcephaly, albinism, seizures, and mental retardation (Trefz, 2011). If phenylalanine intake is restricted through a modified diet started within weeks of birth and continued throughout adulthood, these disease characteristics can be avoided (NIH, 2001; Koch, 2002).

Dr. Robert Guthrie developed a test for PKU using only a drop of blood that was inexpensive, fast, and accurate (Bodamer, 2010). This became the first "newborn screen" used to screen all infants while still in the hospital, in order to start a modified diet as early as possible (Wilcken, 2008). Dried blood spots are still collected on Guthrie cards made of special filter paper (Bodamer, 2010).

\subsubsection{Wilson and Jungner Criteria}

After the development of a reliable population screen for PKU, screens for several other diseases were created (Bodamer, 2010). In 1968, the World Health Organization commissioned a book addressing the ethical principles and practices of screening newborns (Wilson and Jungner, 
1968). Wilson and Jungner developed a set of guidelines that could be followed addressing whether a disease should or should not be included in a NBS program:

1. "The condition sought should be an important health problem.

2. There should be an accepted treatment for patients with recognized disease.

3. Facilities for diagnosis and treatment should be available.

4. There should be a recognizable latent or early symptomatic stage.

5. There should be a suitable test or examination.

6. The test should be acceptable to the population.

7. The natural history of the condition, including development from latent to declared disease, should be adequately understood.

8. There should be an agreed policy on whom to treat as patients.

9. The cost of case-finding (including diagnosis and treatment of patients diagnosed) should be economically balanced in relation to possible expenditure on medical care as a whole.

10. Case-finding should be a continuing process and not a "once and for all" project." (Wilson and Jungner, 1968)

These criteria constitute the gold standard by which new potential NBS are judged.

\subsubsection{Technology}

Guthrie’s first PKU screen was a bacterial inhibition assay (Bodamer, 2010), but this has been replaced in many states by the development of tandem mass spectrometry (MS/MS), which can screen multiple samples for multiple diseases simultaneously (Naylor, 1999). Polymerase chain reaction (PCR) is used to screen for hemoglobinopathies (Jinks, 1989). A radioimmunoassay screens for congenital hypothyroidism through measurement of T4 levels (Sadler, 1978). 


\subsubsection{Mandatory vs. State-specific NBS}

Not all disorders are screened by NBS in every state. The American College of Medical Genetics recommends a core panel of 29 diseases, including 9 organic acidurias, 5 fatty-acid oxidation disorders, 6 amino acidurias, 3 hemoglobinopathies, and 6 other conditions (congenital hypothyroidism, congenital adrenal hyperplasia, biotinidase deficiency, classical galactosemia, cystic fibrosis, and hearing loss); almost all can be screened using MS/MS (Watson, 2006).

\subsection{HISTORY OF NBS FOR DMD/BMD/SMA}

\subsubsection{NBS for DMD}

In the mid-1970s, it was demonstrated that a screening test for DMD could be performed on the dried blood spots already collected through the established NBS program (Zellweger, 1975).

In newborns with DMD, CK activity levels are elevated (Zellweger, 1975). CK levels can also be elevated in other muscle conditions as well as for unrelated reasons, including muscle stress during birth. For this reason, testing newborn CK level detects all infants with DMD, but results in many false positive results (Drousiotou, 1998).

There have been several trials of NBS for DMD, and it is currently offered for newborn boys with parental consent in some countries, including Wales, Canada, and Belgium (Bradley, 1993; CDC, 2004). The German infant screening program recently ended in November 2011

(correspondence with G. Scheuerbrandt, 7 Dec 2011). Each of these programs was unique in their approach to screening. Germany screened only boys at 4-6 weeks of life, starting in March 
of 1977. This choice of when to screen reduced the rate of false positive results and encouraged autonomy in the decision to screen. The screen was voluntary, and required private payment of approximately \$20 (Scheuerbrandt, 2011).

There are currently 4 hospitals in the United States that offer optional NBS for DMD, through a CDC-funded research study conducted by investigators at the Columbus Children's Research Institute in Ohio (Mendell, 2012). In the past, NBS was offered in other parts of the United States, including parts of Pennsylvania (Pittsburgh), New York, Oregon, Iowa, and Texas, as well as parts of Brazil, France, New Zealand, and Puerto Rico (CDC, 2004).

\subsubsection{NBS for SMA}

There have been no population-wide NBS programs for SMA, although there has been a research trial that identified and confirmed 4 positive results in 40,103 screened babies (Prior, 2010).

Most commonly, NBS relies on substrate markers detected by MS/MS. DNA confirmation, when used, is primarily employed as a second-tier confirmation of first-tierpositive results (Prior, 2010). However, there is no biochemical marker for SMA; thus, DNA would be required as the first-tier substrate (Prior, 2010). An approach such as direct DNA testing for first-tier testing may be practical in the future for NBS, so it is reasonable to look into the ethics of a population-wide screen for SMA.

The carrier rate for SMA is estimated between 1:25 and 1:66, and SMA has an incidence between 1:6000 and 1:10,000 live births. In 2007, Pyatt et al. showed that it was possible to extract sufficient DNA from the standard NBS blood spots to effectively screen for SMA, with a sensitivity of $100 \%$ and a specificity of $99.5 \%$ (Pyatt, 2007). The sensitivity would be closer to 
95-98\% after accounting for the small percentage of affected people who do not have homozygous SMN1 deletions (Prior, 2010).

Treatment for SMA is currently palliative, but there are promising clinical trials ongoing and planned, including the rescue of the transcriptional product from SMN2. Similar to exonskipping in DMD, AOs would target SMN2 pre-mRNA to suppress exon 7 skipping (MacKenzie, 2012). Rather than producing SMN $\Delta 7$, functional SMN protein would be produced, and testing in mouse models has been promising (MacKenzie, 2012). NBS for SMA would allow enrollment in potential clinical trials as an infant. It is thought that in order to be most effective for the child, protein rescue must occur before damage to the anterior horn cells becomes irreversible. This requires clinical trial enrollment, and ultimately treatment, before symptoms present (Prior, 2010).

\subsection{ETHICS OF NBS FOR DMD}

The consideration of population-based NBS for DMD/BMD/SMA can be controversial. The primary source of this controversy is the lack of evidence that early detection of DMD/BMD/SMA will lead to a better outcome for the child. Recent promising developments in therapy for DMD especially have increased interest in creating a practical pathway for adding DMD to the NBS program. When focusing on DMD, several key issues include who to screen, when to perform screening, and whether NBS for DMD should be offered as a voluntary, optional screen. 


\subsubsection{Who to Screen}

In consideration of the practicality of including DMD in the currently established NBS program, it is important to assess who should be offered screening. As an X-linked condition, DMD almost exclusively affects males, so it is potentially feasible to screen only male infants rather than both males and females.

Screening only males would meet the Wilson and Junger screening goal of identifying infants that will become symptomatic and require treatment for their disease, recognizing that the occasional symptomatic female will be missed (Wilson and Jungner, 1968; Ross, 2006). This would allow the identification of the vast majority of infants that could be started on the current experimental therapies.

Screening both males and females offers the added benefit of identifying carrier females, and subsequently at-risk families before an affected male is conceived. However, not every carrier female will be detected by NBS, and this may provide false reassurance to a family if a girl is screen negative (Ross, 2006). From an ethical standpoint, there is no precedent for carrier screening of infants, and this is a decision that could be delayed until adulthood, when the individual can decide for him- or herself whether the information is valuable (Hiraki, 2006; Ross, 2002). The identification of a female carrier may also negatively impact the child's self-esteem and her relationships with others (Ross, 2006).

\subsubsection{When to Screen}

There is ongoing discussion on when screening for DMD would be most beneficial: at birth, at a later well-child appointment, or when symptoms present. The current approach is symptomatic 
diagnosis and treatment. There are many advantages to this approach, including the avoidance of insurance discrimination due to early disease identification. Additionally, symptomatic diagnosis is the responsibility of the individual, and therefore does not use public funding (Kemper, 2007). However, on average, approximately 2 years elapse from the time a parent first reports symptoms in an affected son until a diagnosis is made (Ross, 2006). In the past 20 years, efforts to increase pediatricians' recognition of DMD have not shortened this diagnostic odyssey (Ross, 2006).

NBS is a well-established public health initiative with structures and resources in place for infants who have a positive NBS test. Therefore, it is appealing to include more diseases in this infrastructure rather than to fund screening at a later time. Screening in the newborn period may also improve the physician's ability to treat DMD most effectively. Glucocorticoid treatment prolongs ambulation and improves quality of life, and the current recommendation is to begin corticosteroid treatment when boys with DMD have stopped gaining motor milestones, but before their motor skills have begun to decline (Mendell, 2012; Bushby, 2010). The average age of diagnosis for DMD is currently 5 years of age (Ciafaloni, 2009), but the loss of motor skills may have already begun before this age. An earlier diagnosis could lead to better medical management for the child (Mendell, 2012).

Another advantage to screening in the newborn period is the time gained with the early diagnosis, to prepare both emotionally and by practical measures for the challenge and long-term nature of caring for a patient with DMD. Parsons et al. (2002) conducted a psychosocial study in Wales in which parents of infants with a positive NBS test for DMD and children diagnosed with DMD after the newborn period were surveyed. The authors concluded that the majority of 
parents in both cohorts were in favor of the earlier diagnosis for the emotional and practical reasons mentioned above (Parsons, 2002).

There are also potential disadvantages to including DMD as part of the already established NBS program. Past screening trials have shown a high rate of enrollment, which raises the concern that enrolled parents may not have made an autonomous decision to participate. It could also be potentially confusing to present the NBS for DMD as an optional screen, when other NBS programs are essentially mandatory (Kemper, 2007). Additionally, there is the possibility of lingering doubt over the accuracy of a false positive result (Parsons, 2002), which occurred in 2 out of 20 parents of the cohort that tested positive on the primary screen, but were then found to be negative on secondary screen. However, this occurred when informed consent for NBS for DMD had not been optimal (Parsons, 2002). Researchers have also cited the possibility of anxiety or impaired bonding with infants who are identified as affected with DMD through NBS (Bradley, 1993). Overall, Parsons found no evidence of rejection from either assessment by a health visitor or mothers' responses to the rejection/protection index. There was also no difference in protectiveness during the first year of life (Parsons, 2002).

Screening for DMD at a later well-child appointment such as a 6- or 12-month checkup provides an alternative to screening newborns prior to hospital discharge. Separating the timing of screening for DMD from the state-mandated NBS program helps separate the goal of screening for an untreatable condition (preparation) from the goal of screening for a treatable condition (prevention). This separation in timing is also better suited for a voluntary, opt-in screen (Ross, 2006). However, this would separate screening from the established infrastructure of the current NBS program (Ross, 2006). By 6-12 months of life, CK levels in carrier females have often normalized, so identification of carrier females is less sensitive beyond the newborn 
period. Additionally, a population-wide screen performed later than the newborn period would be difficult, because not all children are seen reliably at well-child appointments.

\subsubsection{Opt-in vs. Opt-out}

Although the evidence is strong for the potential benefits of NBS for DMD, including a sensitive screen with almost no false negatives and minimal psychological harm, a compelling reason to include DMD in mandatory NBS remains a requirement. There is not yet a cure for DMD, and the benefits of early intervention are difficult to quantify. There is not a standardized treatment plan, and currently doctors and parents work together to make many decisions regarding treatments and the timing of treatments. The lack of a standardized and clearly beneficial treatment is the main reason why DMD does not meet the Wilson and Jungner screening criteria. For this reason, it is reasonable to consider a voluntary, opt-in NBS for DMD.

In consideration of the ethical challenge presented by NBS for DMD, Ross states that

“Overall, expanding NBS to DMD has potential benefits and risks and individual couples and families may decide differently on whether or not the benefit: risk ratio is positive... If one believes that it is reasonable for some parents to choose NBS for DMD and for other parents to refuse to test their children, then screening for DMD ought to be voluntary."

One of the most compelling arguments against an opt-in NBS for DMD while the baby is still in the hospital is that this is not the ideal time for a truly informed consent from the new parents. In Wales, there was an opt-in rate of 94\% to screen for DMD (Parsons, 2002). Opt-in rates are highest when requests are done in person, and when testing can be performed immediately (Bekker, 1993; from Ross, 2006). 
It is because of these ethical issues that we sought to assess parents' opinions toward screening for DMD/BMD/SMA. 


\subsection{MATERIALS AND METHODS}

In order to achieve the specific aims, two cohorts were surveyed regarding their attitudes toward NBS for DMD/BMD/SMA. The Muscular Dystrophy Association (MDA) cohort consisted of parents of children with DMD, BMD, or SMA. The Magee cohort consisted of expectant parents with no regard to family history. This study was approved by the University of Pittsburgh Institutional Review Board.

\subsection{QUESTIONNAIRES}

Two questionnaires were used in this research study (Appendix A). The questionnaire distributed to the MDA cohort was created by Edwin Naylor, Ph.D. to assess the acceptability of adding DMD to the NBS panel (Naylor, 1992), and was modified only to include SMA. This questionnaire was also distributed at one other center (Medical University of South Carolina), and took approximately 5 minutes to complete. The questionnaire distributed to the Magee cohort was solely used at the University of Pittsburgh Medical Center (UPMC), and took approximately 10 minutes to complete. Data from the independent survey was extrapolated to fit the original multicenter survey. 


\subsection{RECRUITMENT}

All participation for this research study was voluntary, and there was no compensation for participants. Parents of children with DMD, BMD or SMA were identified and approached during routine MDA clinic visits at Children's Hospital of Pittsburgh of UPMC or the adult neuromuscular clinic of UPMC. A scripted verbal consent (Appendix B.1) was read to every potential participant, and upon agreement, questionnaires were given to the parent(s) present. Additional surveys, along with a consent letter (Appendix B.1.1) were mailed to clinic families that were not seen in clinic during the recruitment period.

Expectant parents were recruited at Magee Women's Hospital of UPMC in Pittsburgh, PA. Potential participants were approached while waiting for hospital tours of the labor and delivery facilities at Magee Women's Hospital. Tours are given to expectant couples during the $2^{\text {nd }}$ or $3^{\text {rd }}$ trimester of pregnancy. A scripted verbal consent (Appendix B.2) was read to every potential participant, and upon agreement to participate in the study, questionnaires were given to expectant mothers and fathers. Questionnaires, but no identifying information from participants, were collected immediately upon completion.

\subsection{ANALYSIS}

All identifying information was removed from survey responses when relevant. Responses were then entered into two Excel spreadsheets. Chi-square values and corresponding p-values were calculated using the R-project statistical analysis program, an open-source computing language 
available through http://cran.r-project.org/. For the purposes of this study, significance was determined by a p-value less than 0.05 . 


\subsection{RESULTS}

\subsection{MDA COHORT}

A total of 65 parents, including 48 mothers and 17 fathers, were surveyed at the time of data analysis. Of these 65 parents, $14(21.5 \%)$ had one child, $19(29.2 \%)$ had two children, 16 $(24.6 \%)$ had three children, and $16(24.6 \%)$ had four or more children. Sixty-four parents reported their age range, of which 5 (7.8\%) were between 20-29 years, 14 (21.9\%) were between 30-39 years, and $45(70.3 \%)$ were 40 years or older.

Of these 65 parents, 51 (78.5\%) had a child with DMD, 9 (13.8\%) had a child with BMD, and $5(7.7 \%)$ had a child with SMA. Sixty-four parents reported if there was a prior family history of DMD/BMD/SMA, as shown in Table 1.

Table 1: Prior family history in the MDA cohort, stratified by disease.

\begin{tabular}{|c|c|c|c|c|}
\hline & DMD & BMD & SMA & Total \\
\hline Family history & 7 & 1 & 1 & $9(14.1 \%)$ \\
\hline No family history & 43 & 8 & 4 & $55(85.9 \%)$ \\
\hline
\end{tabular}




\subsubsection{Specific Aim 1}

The first specific aim was to assess how parents of children with DMD, BMD or SMA feel about adding DMD/BMD/SMA to the NBS program.

Overall, we found strong support for NBS among parents of children with DMD, BMD, or SMA. Thirty-seven out of 65 parents $(57.0 \%)$ believed that DMD, BMD, and SMA should be included in the mandatory NBS, and another 26 parents $(40.0 \%)$ believed screening should be offered to parents and performed after consent was given (Table 2). Therefore, the total level of support from parents of children with DMD, BMD, or SMA without any advances in treatment is $97.0 \%$.

Table 2: MDA parents' opinions on NBS for DMD/BMD/SMA.

\begin{tabular}{|l|c|}
\hline $\begin{array}{l}\text { Newborn babies should be screened for } \\
\text { muscular dystrophy and spinal muscular } \\
\text { atrophy: }\end{array}$ & Number (Percentage) \\
\hline "Yes, as a routine procedure" & $37(57.0 \%)$ \\
\hline "Yes, but only if treatable" & $1(1.5 \%)$ \\
\hline "Yes, but only with parent consent" & $26(40.0 \%)$ \\
\hline "No" & $1(1.5 \%)$ \\
\hline
\end{tabular}

This trend of parental support for NBS is further supported by the number of parents who would have future children screened at birth for DMD/BMD/SMA (Figure 3). Sixty-three out of 65 parents responded to this question. Of these, $54(85.7 \%)$ said they would want future children screened, $3(4.8 \%)$ would not want future children screened, and $6(9.5 \%)$ were not sure. 


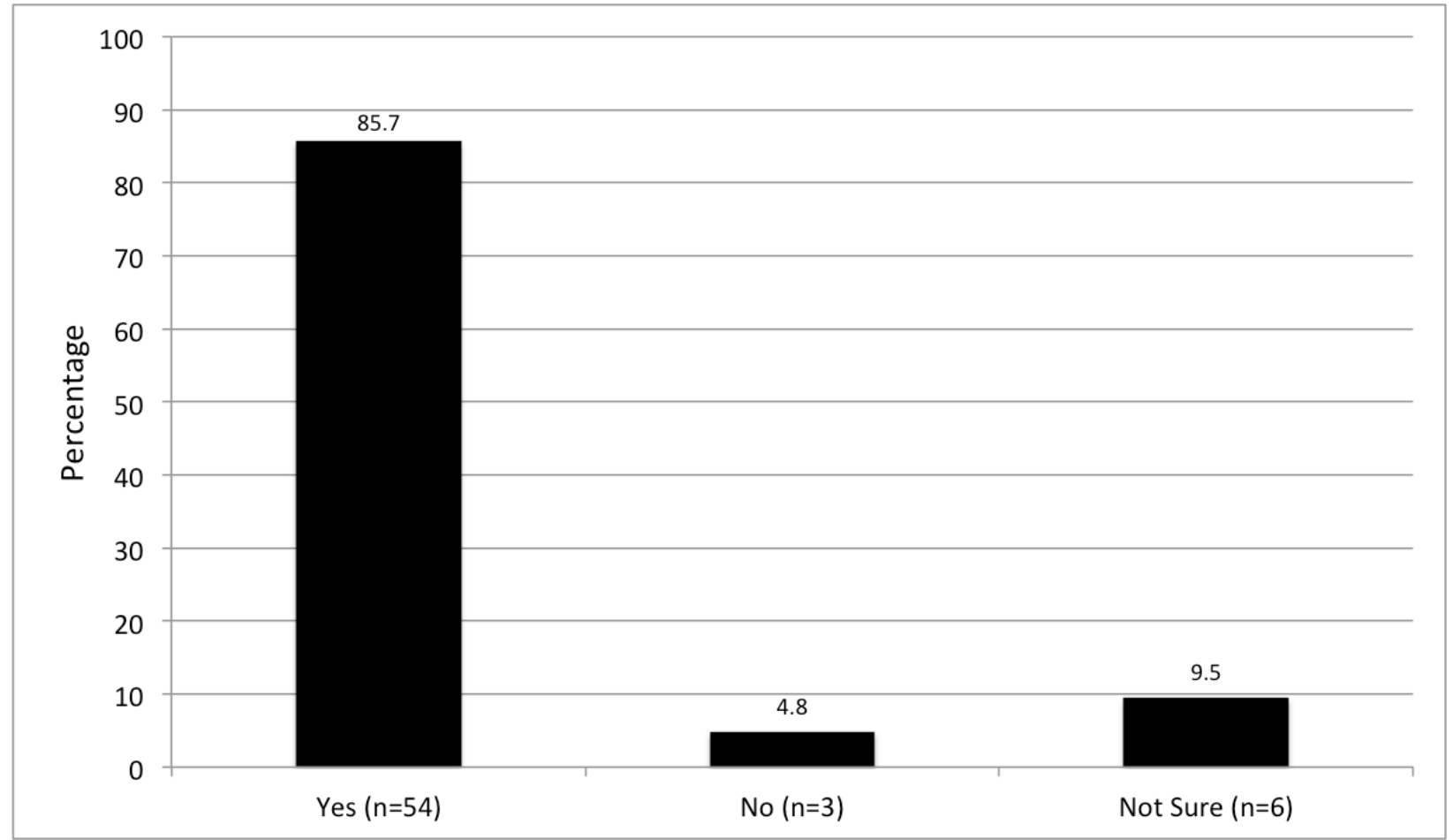

Figure 3: Support for NBS among parents of children with DMD/BMD/SMA.

Parents responded to the question, "Would you want future children screened for muscular dystrophy and spinal muscular atrophy?" with responses, "Yes," "No," and "Not sure."

This support does not significantly change with the child's diagnosis $(p=0.157)$, the presence of a family history of DMD/BMD/SMA $(p=0.389)$, parent's age $(p=0.294)$, or number of children ( $\mathrm{p}=0.448)$, as calculated by Fisher's exact test (Figures 4, 5, 6, and 7). 


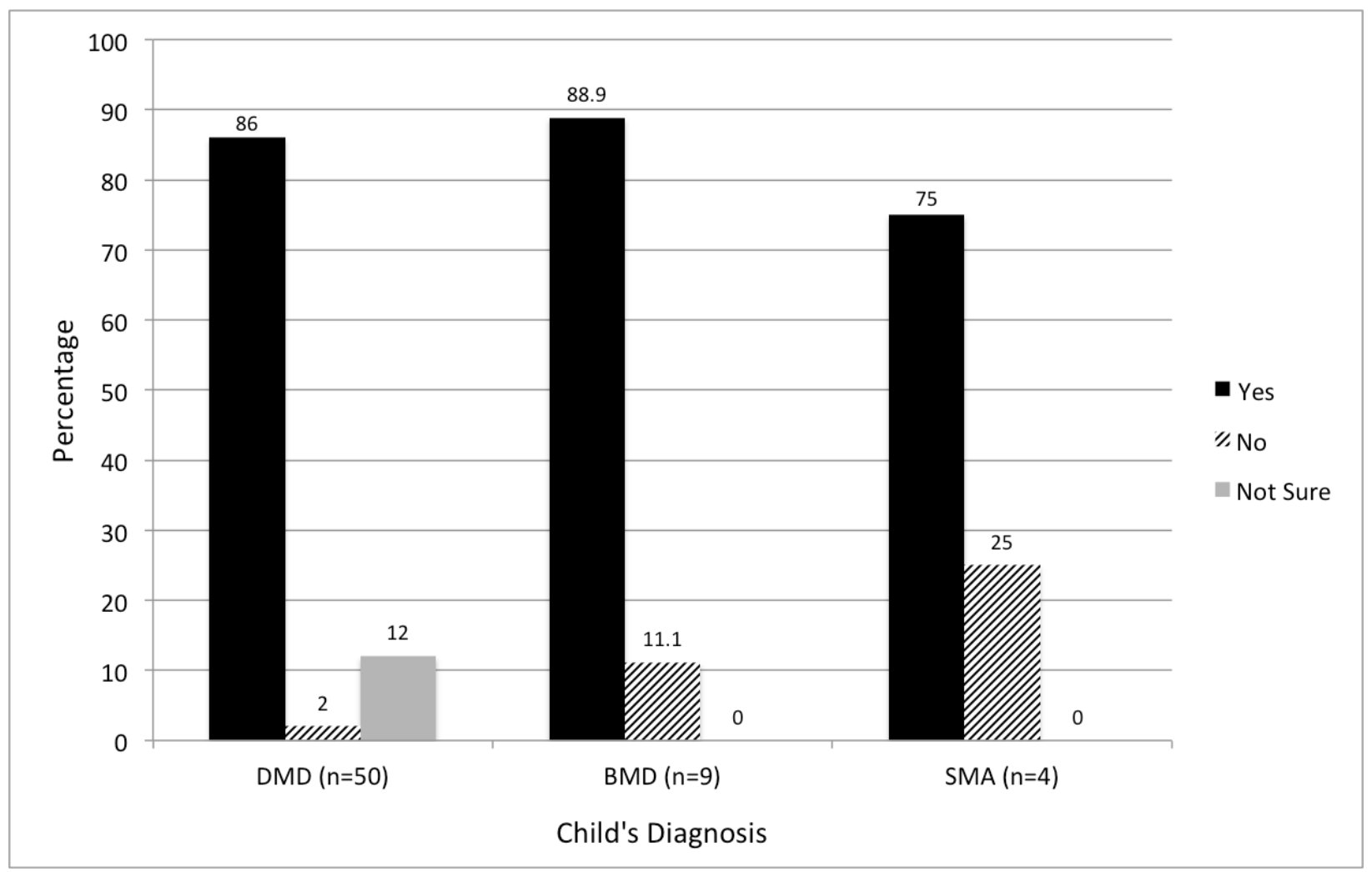

Figure 4: Parental support for NBS stratified by child's diagnosis.

Parents responded to the question, "Would you want future children screened for muscular dystrophy and spinal muscular atrophy?" with responses, "Yes," "No," and "Not sure." DMD=Duchenne muscular dystrophy, BMD=Becker muscular dystrophy, SMA=spinal muscular atrophy. 


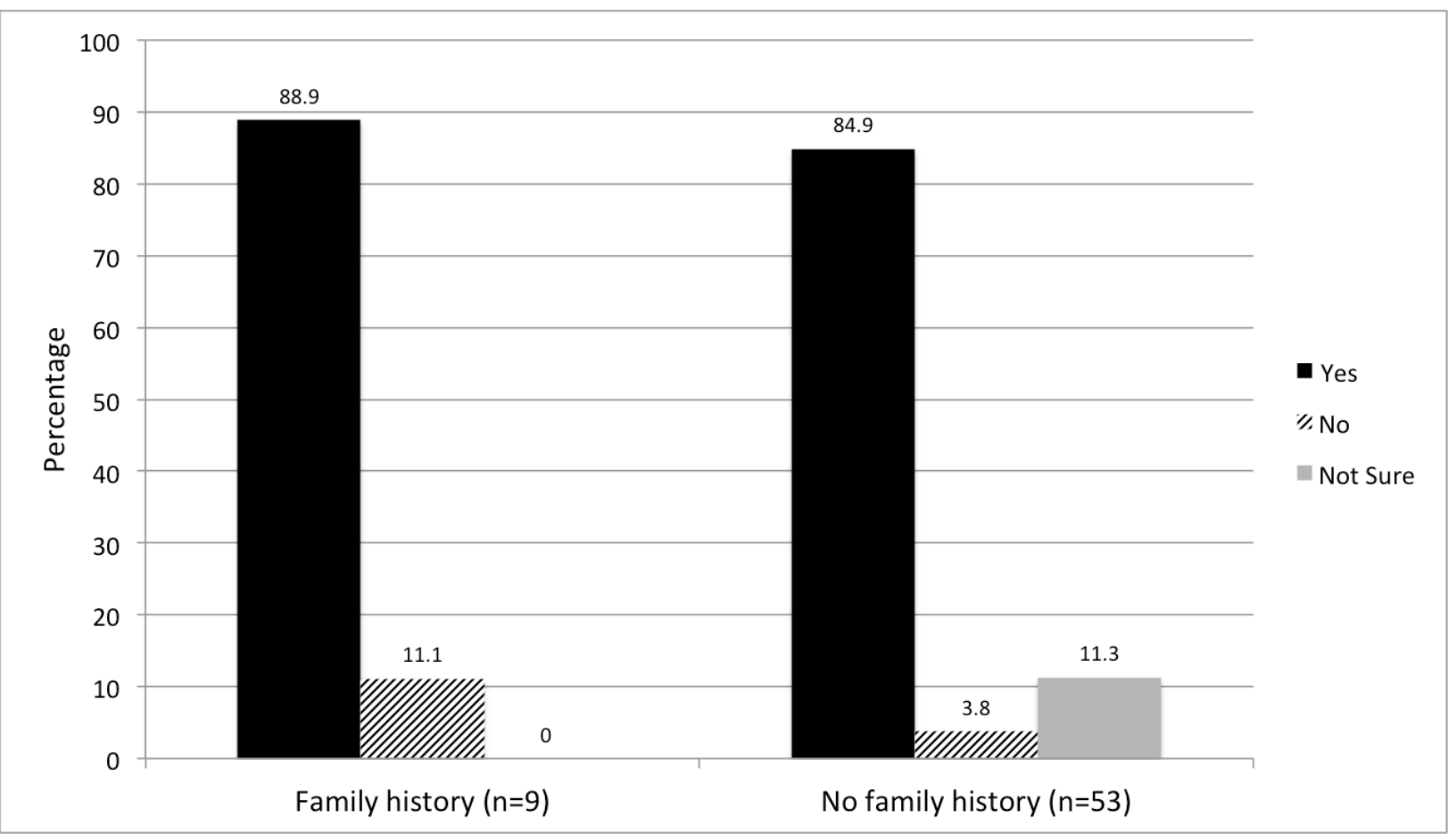

Figure 5: Parental support for NBS stratified by the presence or absence of a family history.

Parents responded to the question, "Would you want future children screened for muscular dystrophy and spinal muscular atrophy?" with responses, "Yes," "No," and "Not sure." 


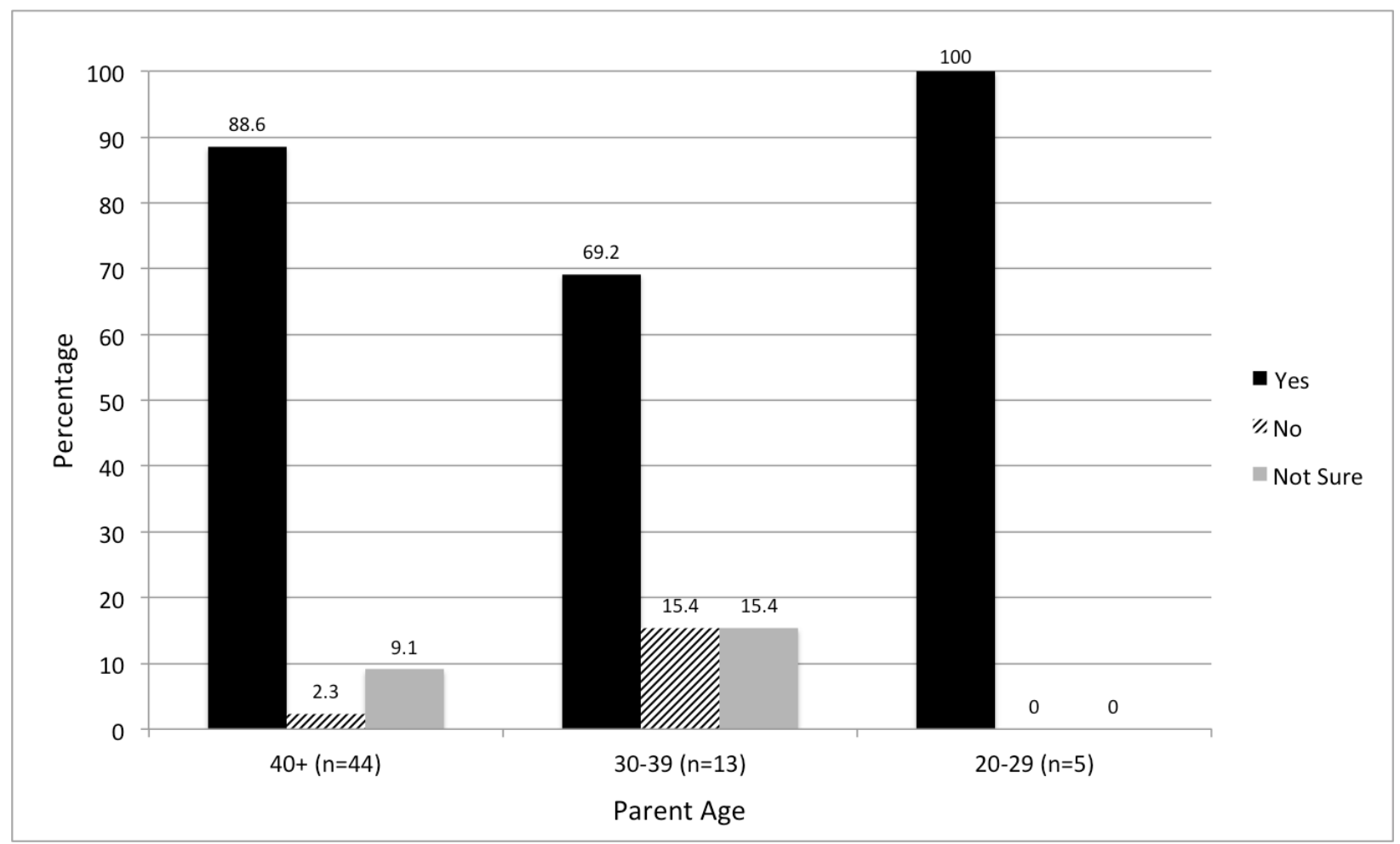

Figure 6: Parental support for NBS stratified by parental age.

Parents responded to the question, "Would you want future children screened for muscular dystrophy and spinal muscular atrophy?" with responses, "Yes," "No," and "Not sure." 


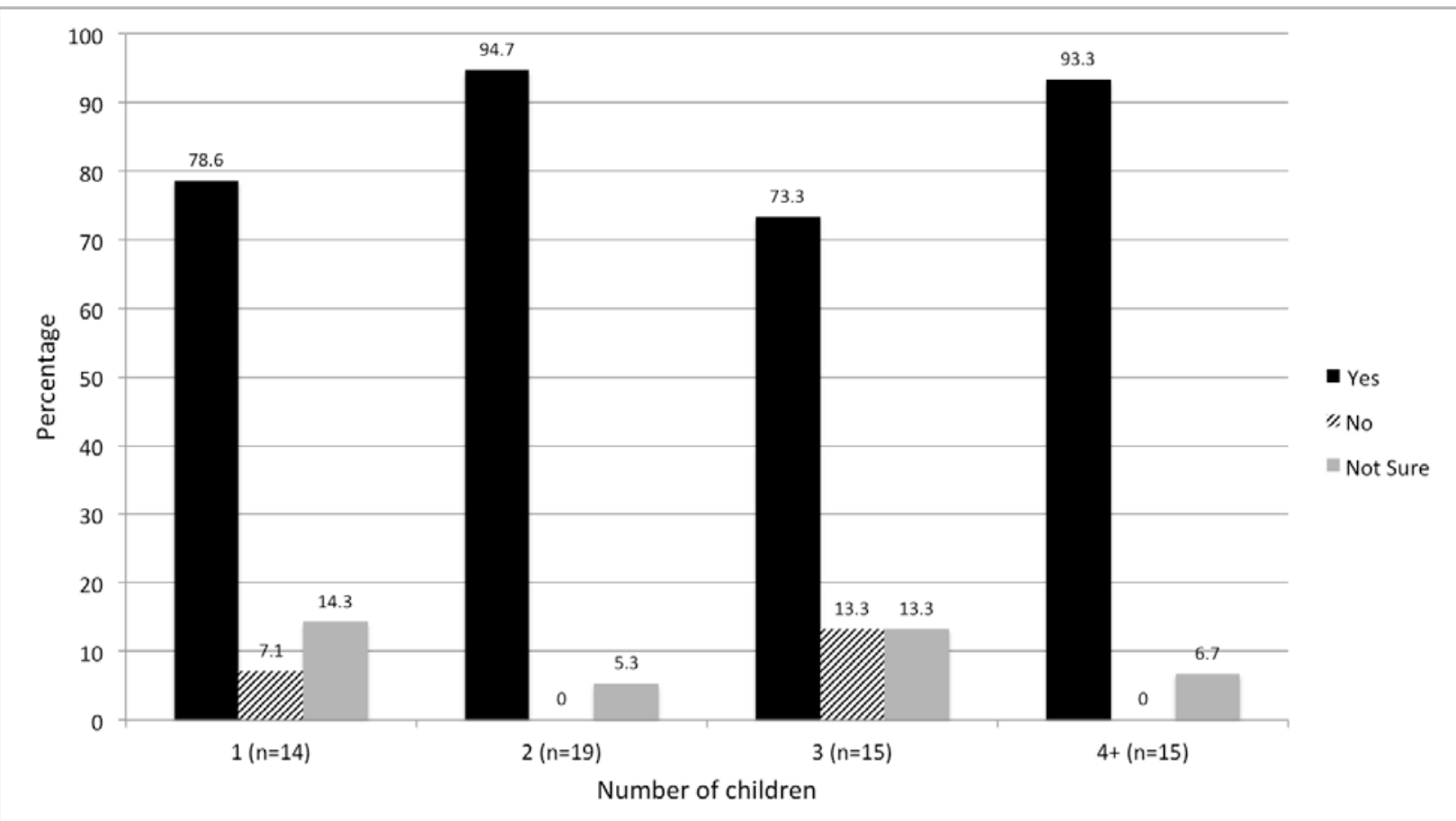

Figure 7: Parental support for NBS stratified by the number of children a parent has.

Parents responded to the question, "Would you want future children screened for muscular dystrophy and spinal muscular atrophy?" with responses, "Yes," "No," and "Not sure."

\subsubsection{Additional Comments}

Parents were given the option of leaving additional comments after filling out the survey. Some highlighted comments are included in Table 3: 
Table 3: Selected comments from parents of children with DMD, BMD, or SMA.

\begin{tabular}{|c|c|}
\hline \multicolumn{1}{|c|}{ Comment } & Parent \\
\hline $\begin{array}{c}\text { "We needed to put [our child] through 1 year of unnecessary testing: } \\
\text { MRI x2, blood test, etc. when a simple blood test could have } \\
\text { given us an answer much sooner." }\end{array}$ & $\begin{array}{c}\text { D-15, mother of 2.5 } \\
\text { year-old with SMA. }\end{array}$ \\
\hline $\begin{array}{c}\text { "If treatments become available in [the] future, then absolutely [there] } \\
\text { should be pre-screening." }\end{array}$ & $\begin{array}{c}\text { D-28, mother of 10 } \\
\text { year-old with DMD. }\end{array}$ \\
$\begin{array}{c}\text { "Screening should be done only if there is a family history of the } \\
\text { disease." }\end{array}$ & $\begin{array}{c}\text { D-31, father of 26 year- } \\
\text { old with BMD. }\end{array}$ \\
\hline $\begin{array}{c}\text { "An early diagnosis may have hindered his progress as we strived to } \\
\text { "catch up" to developmental milestones. A diagnosis may have }\end{array}$ & $\begin{array}{c}\text { D-61, mother of 23 } \\
\text { year-old with DMD. }\end{array}$ \\
\hline $\begin{array}{c}\text { "[Screening is] very important because of other situations that may } \\
\text { happen and need surgery... at birth or before diagnosis." }\end{array}$ & $\begin{array}{c}\text { D-64, mother of 10 } \\
\text { year-old with DMD. }\end{array}$ \\
$\begin{array}{c}\text { adopted I would hope that additional screening wouldn't decrease } \\
\text { the number of children being matched with families." }\end{array}$ & $\begin{array}{c}\text { D-11, adoptive mother } \\
\text { of 17 year-old with } \\
\text { DMD. }\end{array}$ \\
\hline $\begin{array}{c}\text { "I think it would have been easier on us as parents to know what was } \\
\text { wrong early on." }\end{array}$ & $\begin{array}{c}\text { D-9, mother of 5 year- } \\
\text { old with DMD. }\end{array}$ \\
\hline
\end{tabular}

\subsection{MAGEE COHORT}

A total of 400 expectant parents were surveyed at the time of data analysis. Three-hundred eighty participants identified a gender, including 212 expectant mothers and 168 expectant fathers. Of the 400 participants, $5(1.3 \%)$ were less than 20 years old, $154(38.5 \%)$ were between $20-29$ years old, $218(54.5 \%)$ were between 30-39 years old, 21 (5.3\%) were between 40-49 years old, and $2(0.5 \%)$ were 50 years or older. Three-hundred ninety eight participants self-identified their racial background; $351(88.2 \%)$ identified as White or Caucasian, 19 (4.8\%) identified as Black or African-American, 27 (6.8\%) identified as Asian, none identified as Native Hawaiian or Other Pacific Islander, and $1(0.3 \%)$ identified as American Indian or Alaska Native. Out of 351 
participants that self-identified an ethnicity, 11 (3.1\%) identified as Hispanic or Latino. Of the 400 participants, 325 (81.3\%) were expecting to be first-time parents.

On a scale from 1-7, with 1 meaning conservative and 7 meaning liberal, we asked participants to self-identify their economic views, social/political values, and spiritual views. As a whole, respondents self-reported to be moderate, with an average of 3.77 for economic views, 4.16 for social/political values, and 4.08 for spiritual views.

Three hundred ninety nine participants indicated if they personally knew anyone with muscular dystrophy; 75 (18.8\%) did. Three hundred ninety eight participants indicated if they personally knew anyone with a genetic diagnosis; 144 (36.2\%) did. Three hundred ninety three participants indicated if they knew of anyone (such as a celebrity, athlete, or politician) with a genetic diagnosis; $169(43.0 \%)$ did.

\subsubsection{Specific Aim 2}

The second specific aim was to assess how expectant parents feel about adding DMD/BMD/SMA to the NBS program.

To analyze how expectant parents feel about NBS for DMD/BMD/SMA, we first analyzed how they felt about NBS in general. This was done through their overall awareness of the NBS program, as well as through directed questions about whether they felt screening babies for genetic diseases was necessary or wrong. Overall, expectant parents were not aware of the NBS program (37.6\% awareness), as shown in Figure 8. Parents who already had children were more likely to be aware than first-time parents, but this was not found to be statistically significant using Fisher's exact test ( $\mathrm{p}=0.1833$ ) (Figure 9). 


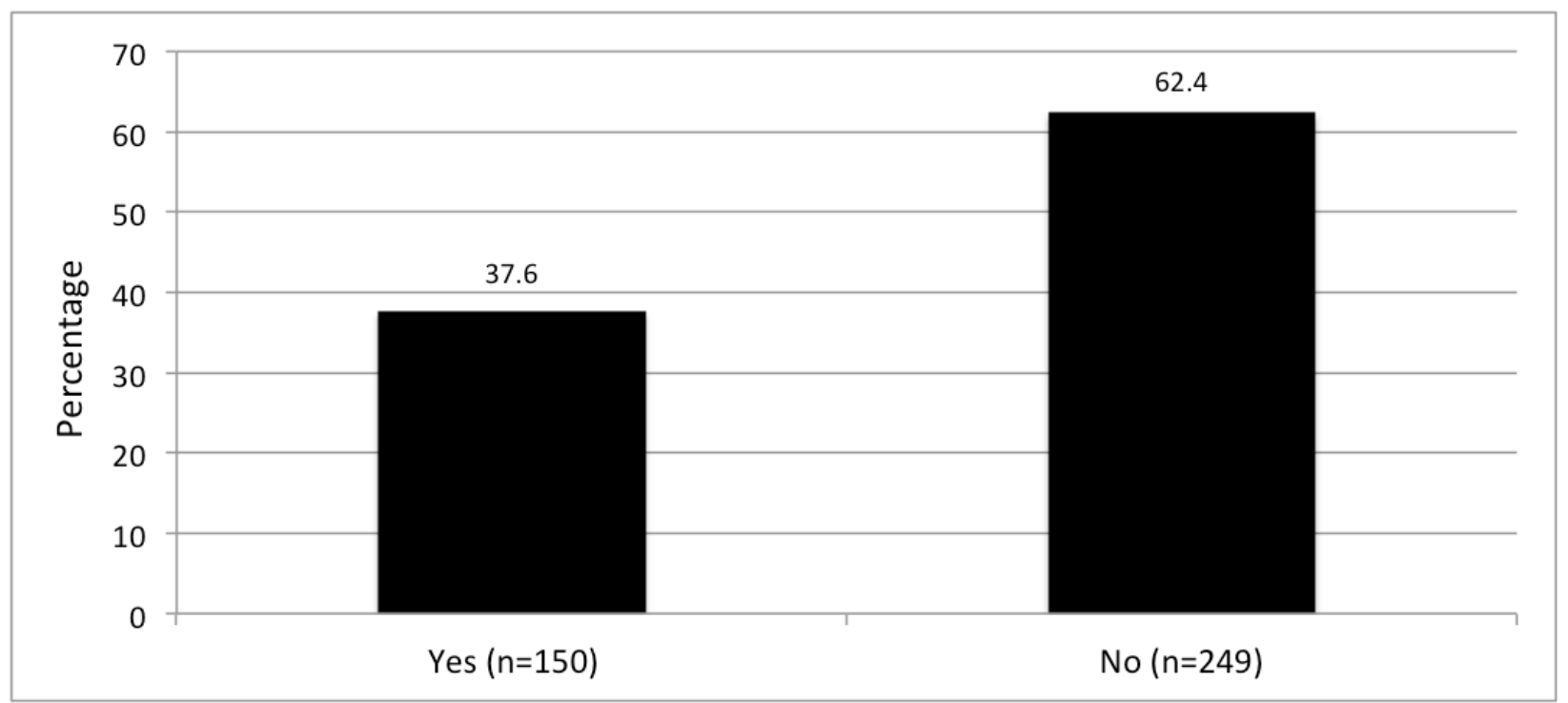

Figure 8: Awareness of NBS in expectant parents.

Expectant parents responded to the question, "Are you aware that all newborns are screened for over 20 treatable genetic diseases through the Pennsylvania Newborn Screening Program before they leave the hospital?" with responses, "Yes," or "No." 


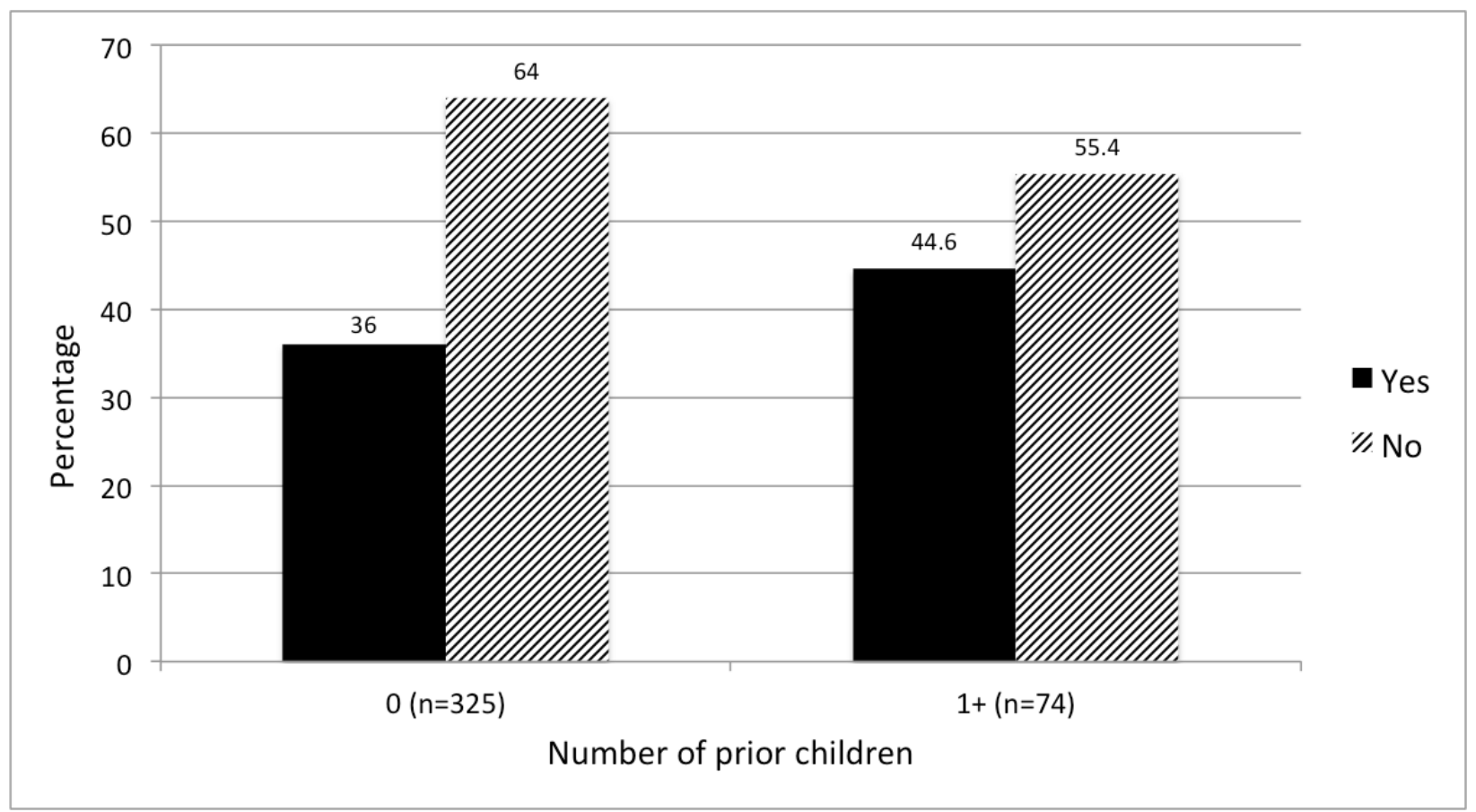

Figure 9: Awareness of NBS in expectant parents with and without prior children.

Expectant parents responded to the question, "Are you aware that all newborns are screened for over 20 treatable genetic diseases through the Pennsylvania Newborn Screening Program before they leave the hospital?" with responses, "Yes," or "No." 
We next asked if they felt that screening babies for genetic diseases was necessary. Overall, parents did not feel strongly that NBS was necessary, as shown in Figure 10. Fifty-three percent either agreed or agreed completely with the statement, "Screening babies for genetic diseases is necessary." Thirty-eight percent neither agreed nor disagreed. Nine percent either disagreed or disagreed completely.

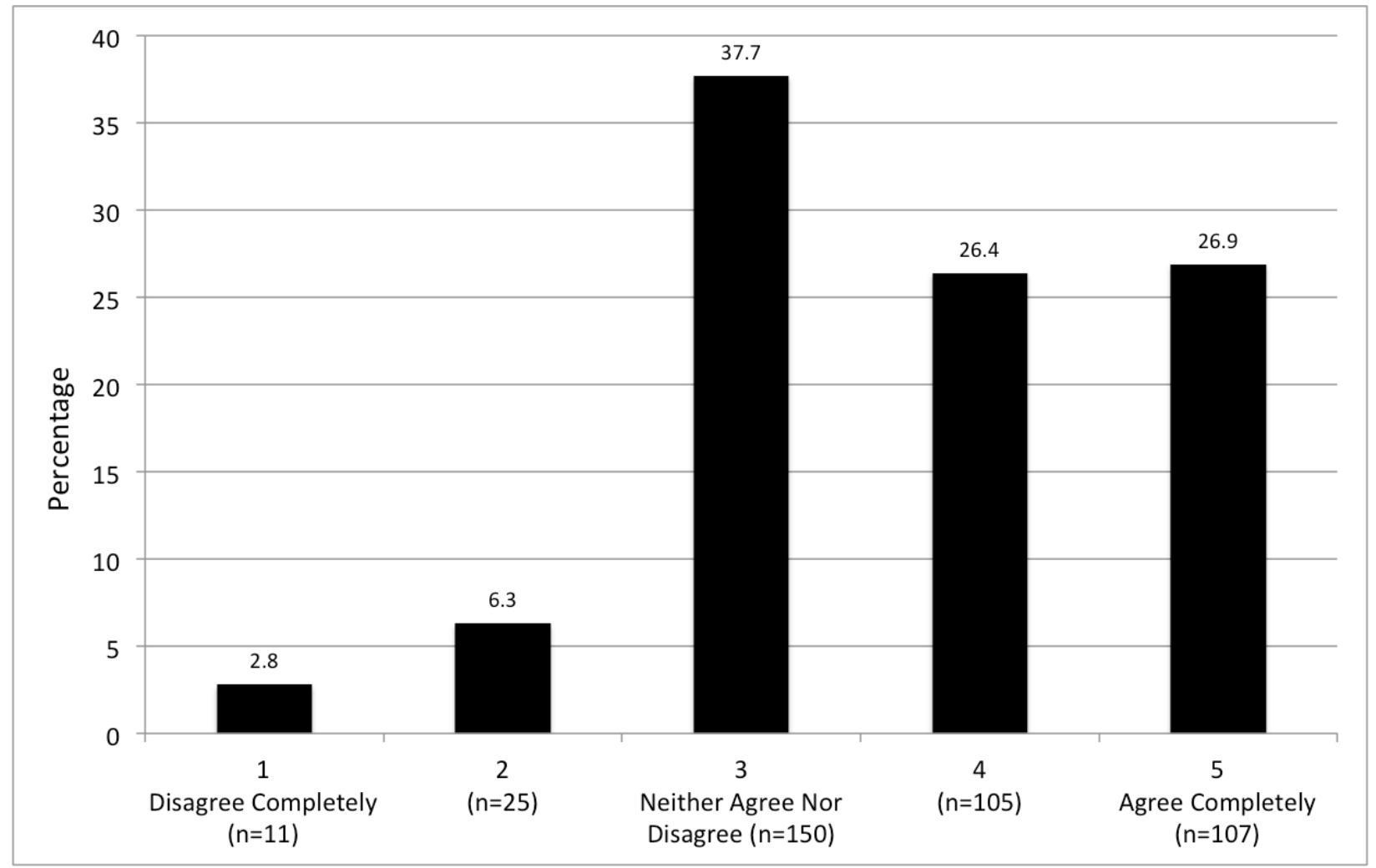

Figure 10: Expectant parents' opinions on the necessity of screening for genetic diseases.

Expectant parents responded to the statement, "Screening babies for genetic diseases is necessary." on a 5-point scale, where 1, 3, and 5 were defined as, "Disagree Completely," "Neither Agree nor Disagree," and "Agree Completely," respectively. 
We next asked if screening babies for genetic diseases was wrong. Overall, parents felt strongly that it was not wrong, as shown in Figure 11. Eighty-eight percent either disagreed or disagreed completely with the statement, "Screening babies for genetic diseases is wrong." One percent agreed, no parents agreed completely, and 11\% neither agreed nor disagreed.

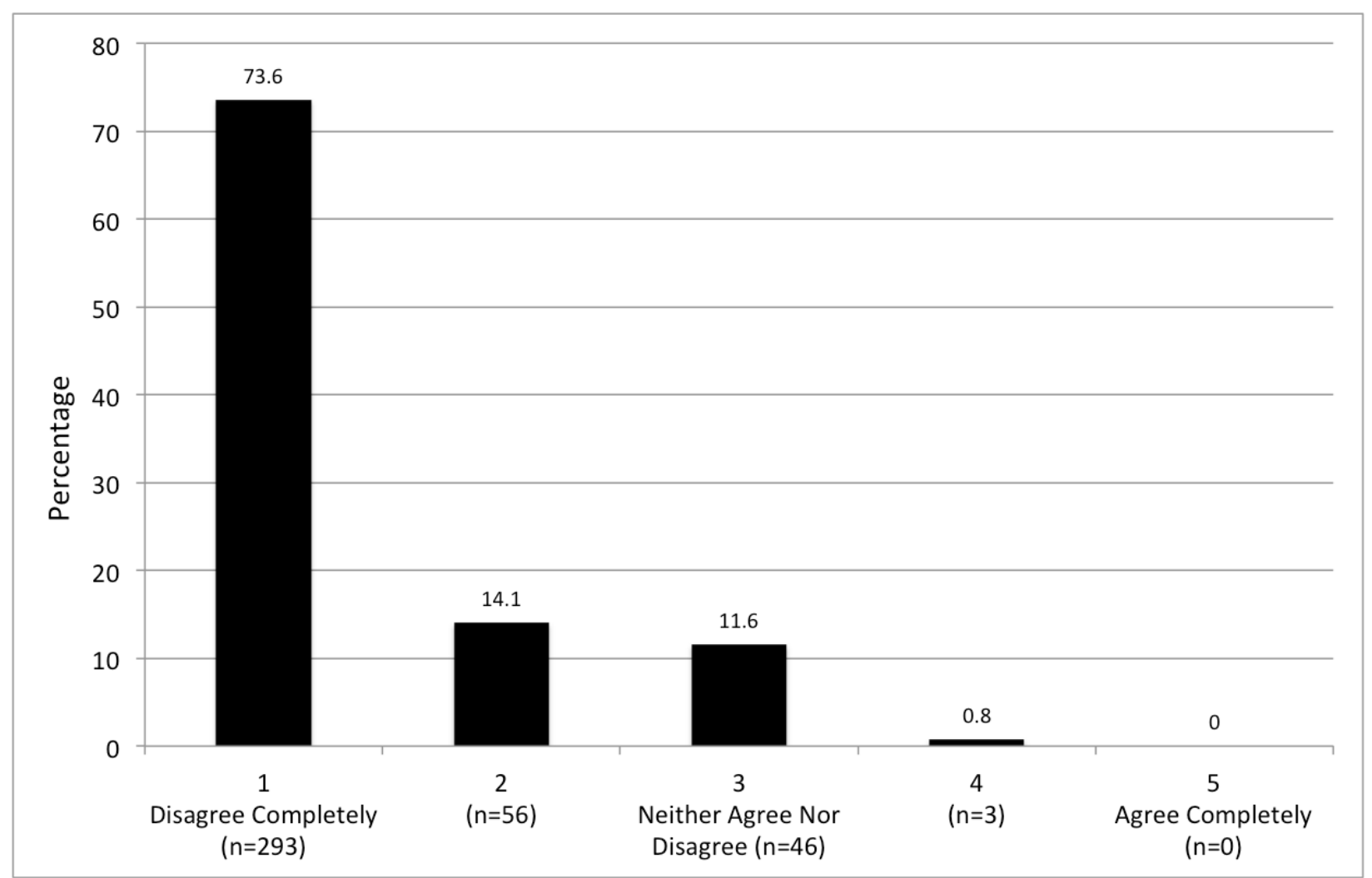

Figure 11: Expectant parents' opinions on whether screening for genetic disease is wrong.

Expectant parents responded to the statement, "Screening babies for genetic diseases is wrong." on a 5-point scale, where 1, 3, and 5 were defined as, "Disagree Completely," "Neither Agree nor Disagree," and "Agree Completely," respectively. 
After evaluating overall opinions of NBS, we considered whether parents wanted to know if their child had an incurable disease that would shorten his/her lifespan. $\mathrm{DMD} / \mathrm{BMD} / \mathrm{SMA}$ fit this model of disease. When asked, "If there were a disease without a cure that would affect your child's health and shorten his/her lifespan, would you want to know at birth?" 92.5\% of parents said yes, as shown in Figure 12.

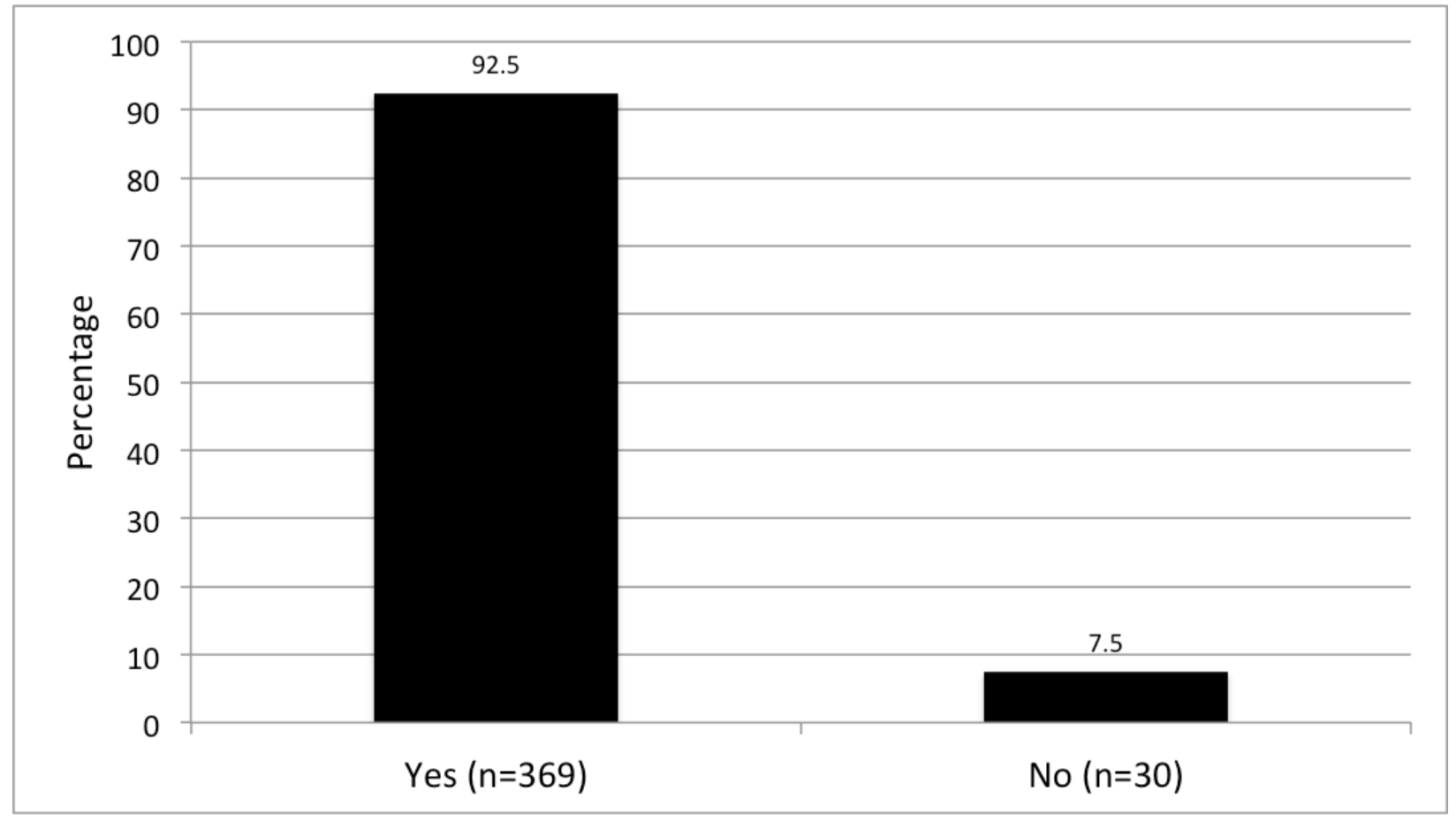

Figure 12: Support for NBS among expectant parents.

Expectant parents were asked, "If there were a disease without a cure that would affect your child's health and shorten his/her lifespan, would you want to know at birth?" with responses, "Yes," or "No." This presents a general model for which DMD/BMD/SMA are specific examples.

The proportion of expectant parents who would choose to screen their child did not change with personal knowledge of a person with muscular dystrophy $(\mathrm{p}=0.9697)$, personal knowledge of a person with a genetic diagnosis $(\mathrm{p}=0.994)$, or knowledge of a person (such as a 
celebrity, athlete, or politician) with a genetic diagnosis $(\mathrm{p}=0.1745)$, calculated using Fisher's exact test (Figures 13, 14, and 15).

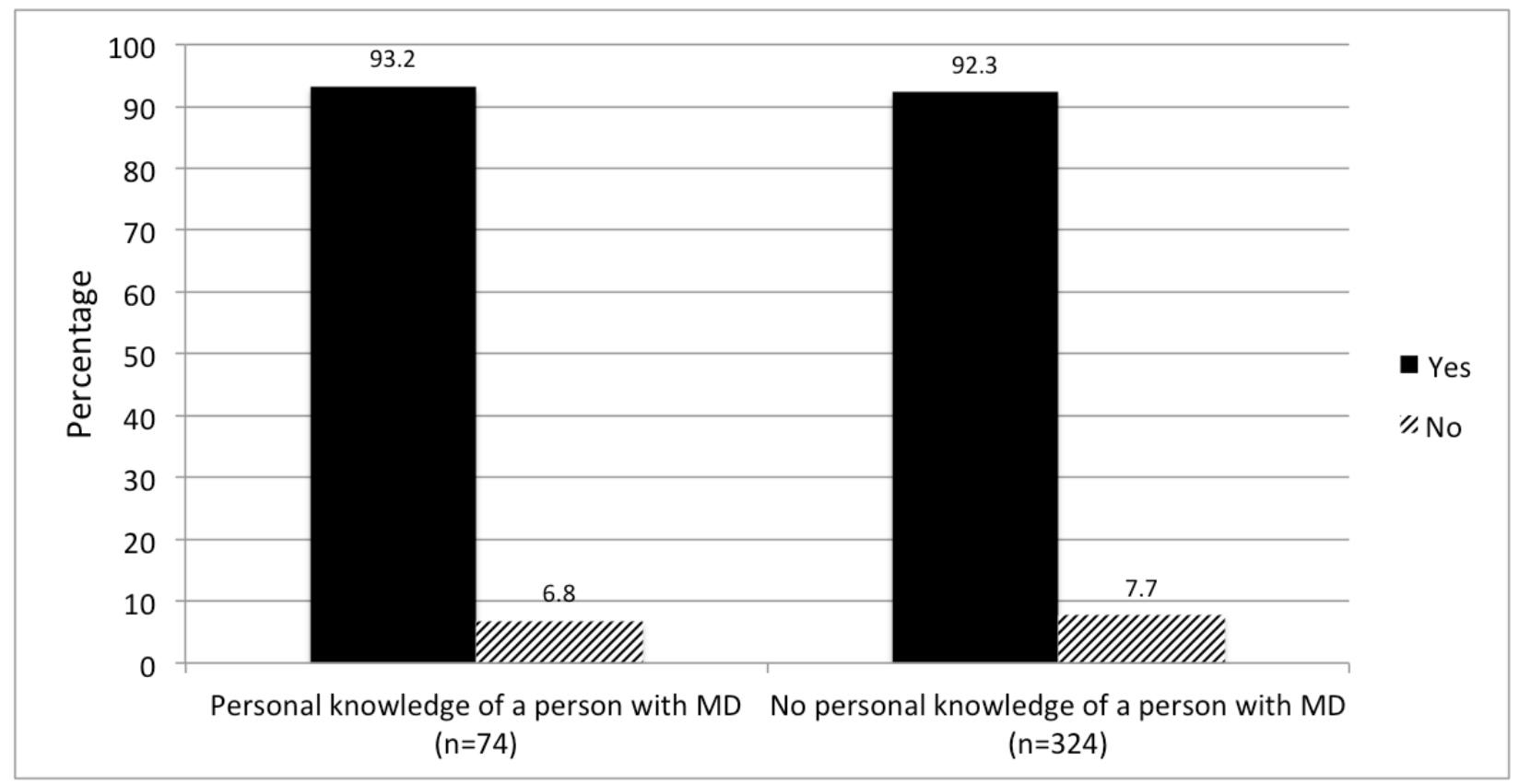

Figure 13: Support for NBS among expectant parents with and without personal knowledge of a person with muscular dystrophy.

Expectant parents were asked, "If there were a disease without a cure that would affect your child's health and shorten his/her lifespan, would you want to know at birth?" with responses, "Yes," or "No." $\mathrm{MD}=$ muscular dystrophy 


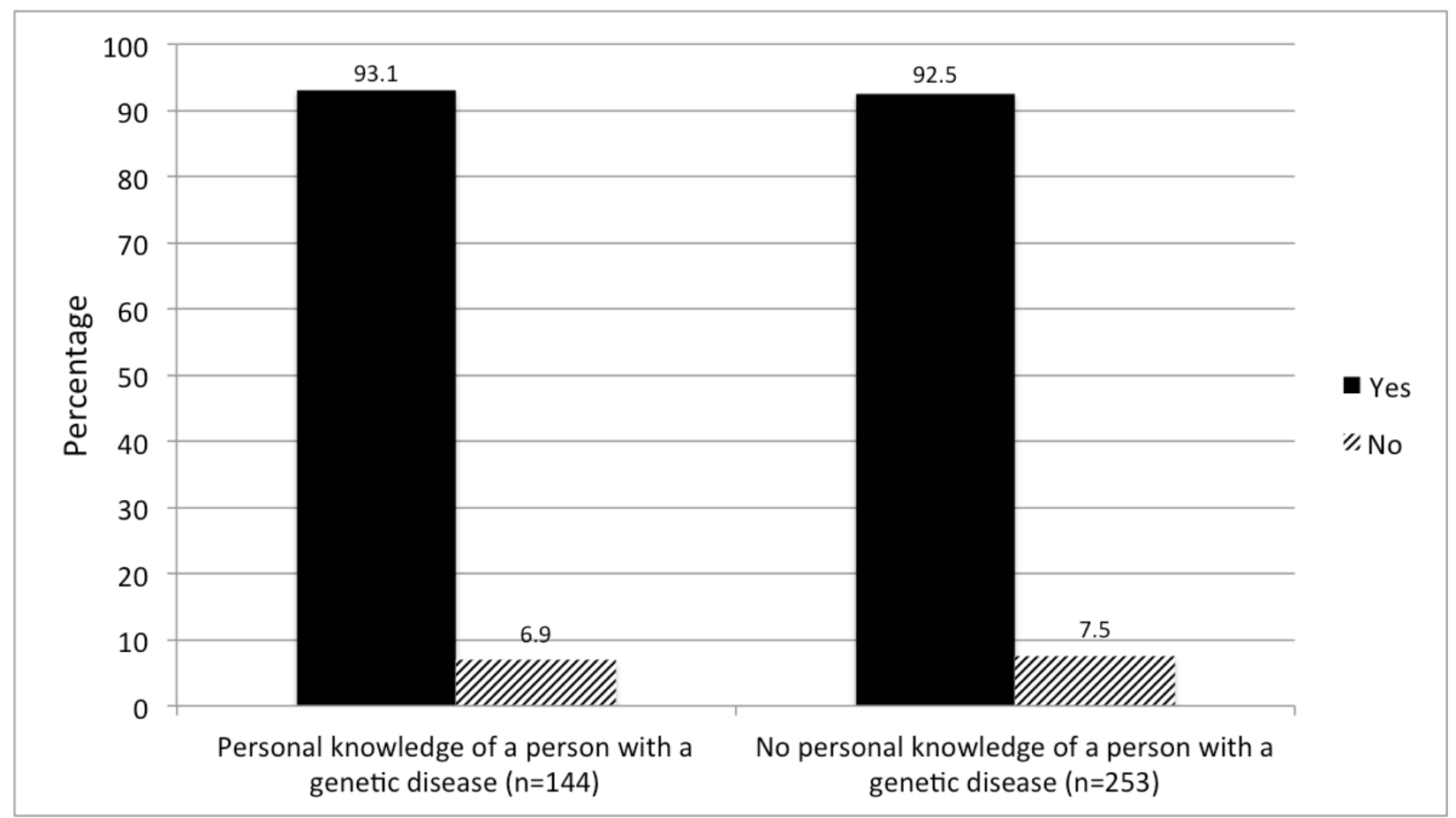

Figure 14: Support for NBS among expectant parents with and without personal knowledge of a person with a genetic disease.

Expectant parents were asked, "If there were a disease without a cure that would affect your child's health and shorten his/her lifespan, would you want to know at birth?" with responses, "Yes," or "No." 


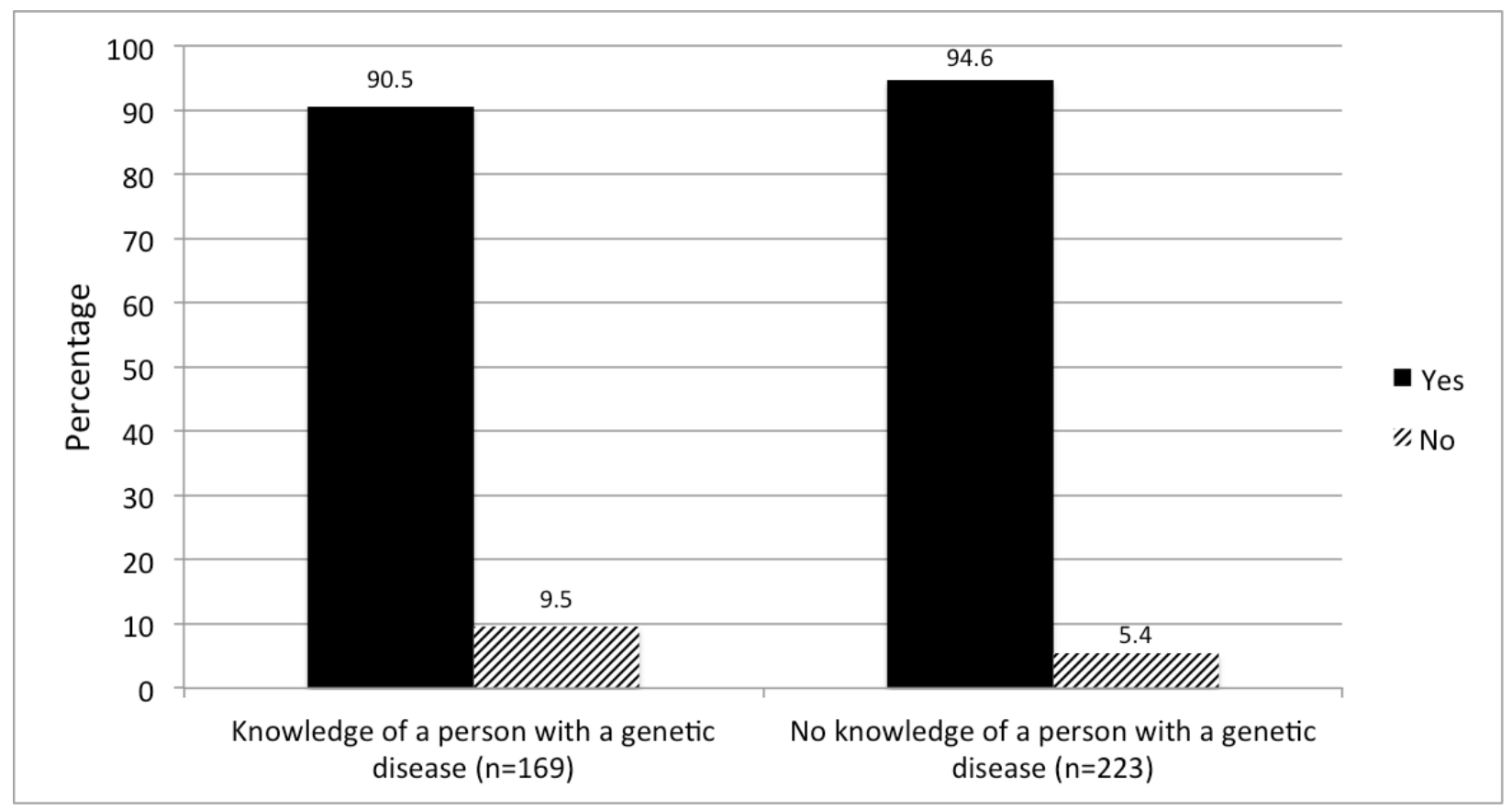

Figure 15: Support for NBS among expectant parents with and without knowledge of a person (such as a celebrity, athlete, or politician) with a genetic disease.

Expectant parents were asked, "If there were a disease without a cure that would affect your child's health and shorten his/her lifespan, would you want to know at birth?" with responses, "Yes," or "No."

\subsubsection{Specific Aim 3}

The third specific aim was to assess what factors influence expectant parents' feelings about NBS for DMD/BMD/SMA.

We divided the survey questions into 6 factor categories: bonding, anxiety, decision regret, time to prepare, family planning, and early diagnosis. Expectant parents were then asked to rank these 6 factors by which was most influential in their opinions about NBS for DMD/BMD/SMA. 348 parents responded, 205 (59\%) of which answered that an early diagnosis was the most influential factor, as shown in Figure 16. Seventy-seven (22\%) felt that time to prepare for the disease was the most influential factor. 


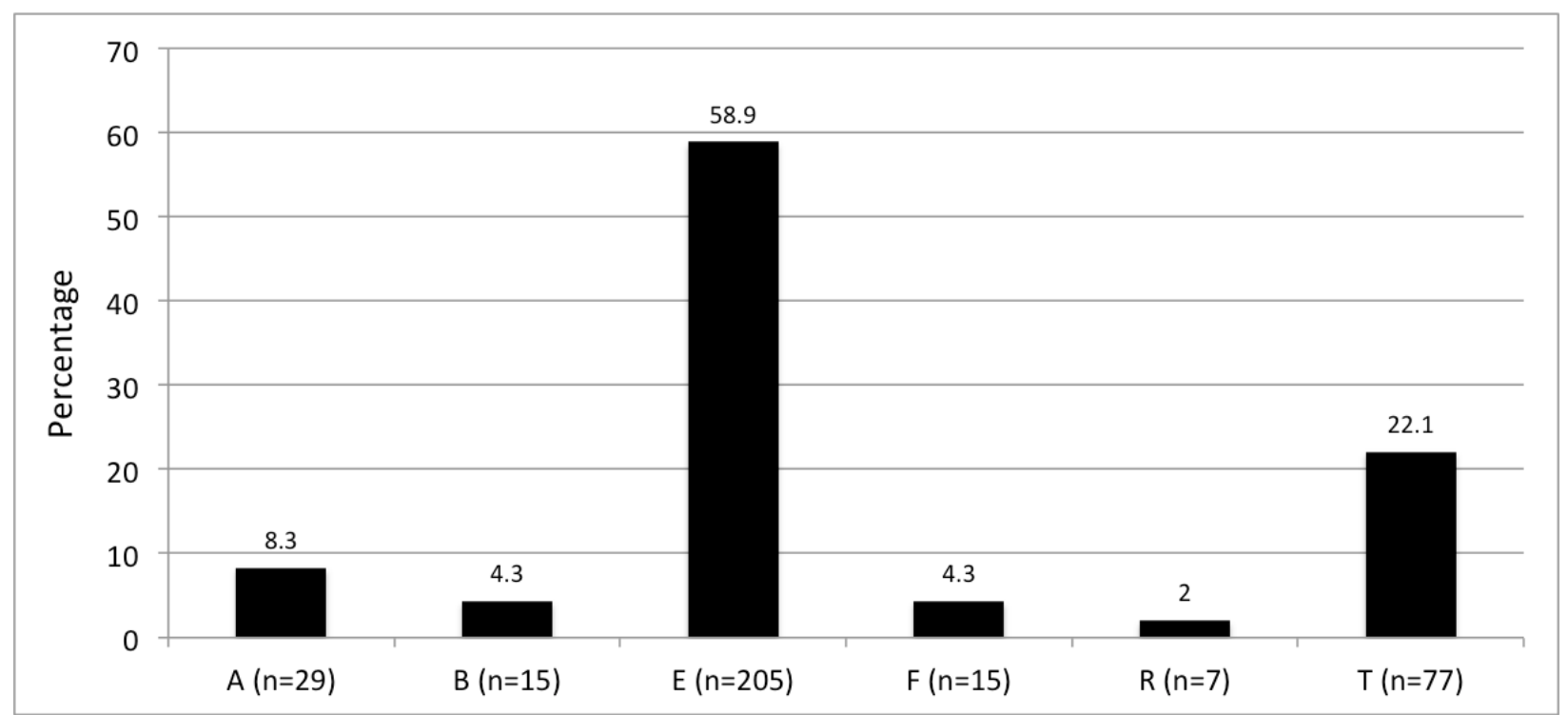

Figure 16: Factors that play a primary role in expectant parents' opinions of NBS for DMD/BMD/SMA.

*A=Anxiety, $B=$ Bonding, $E=$ Early diagnosis, $F=$ Family planning, $\mathbf{R}=$ Decision regret, $T=$ Time to prepare.

When the influencing factors of the expectant parents who would choose to screen their child were separated from the expectant parents who would choose not to screen their child, the most influential factor remains early diagnosis in both groups; however, anxiety was the second most influential factor for parents who would choose not to screen their child, as shown in Table 4 and Figure 17. Bonding and time to prepare both received equal rankings as the third most influential factors for parents who would choose not to have their child screened. 
Table 4: The most influential factors for expectant parents who would screen their child, compared to the most influential factors for expectant parents who would not screen their child.

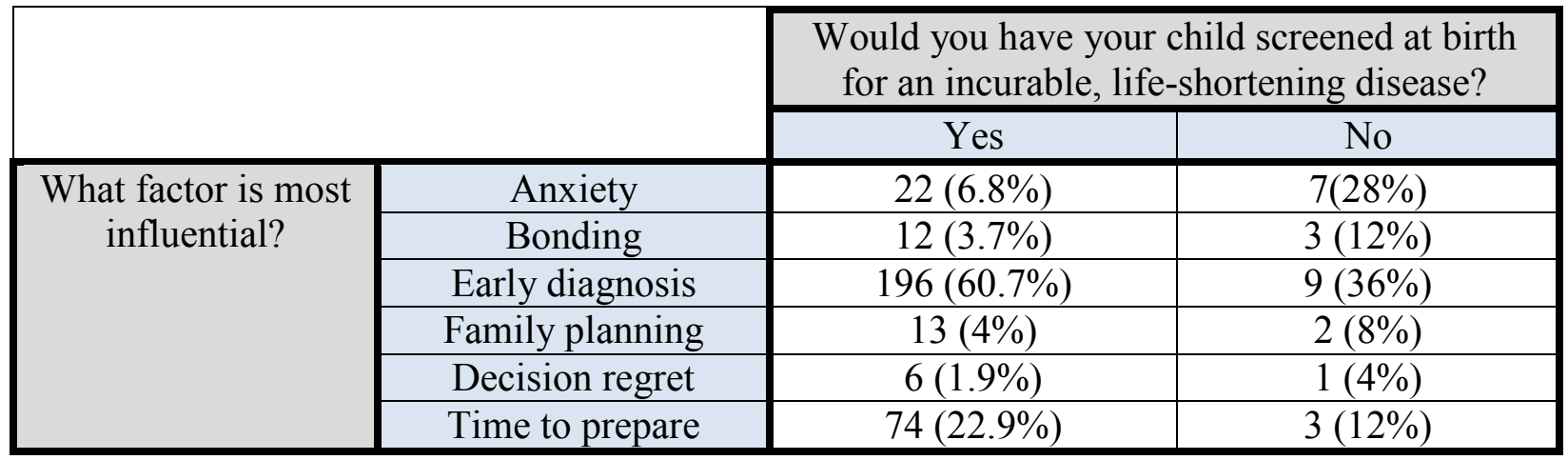

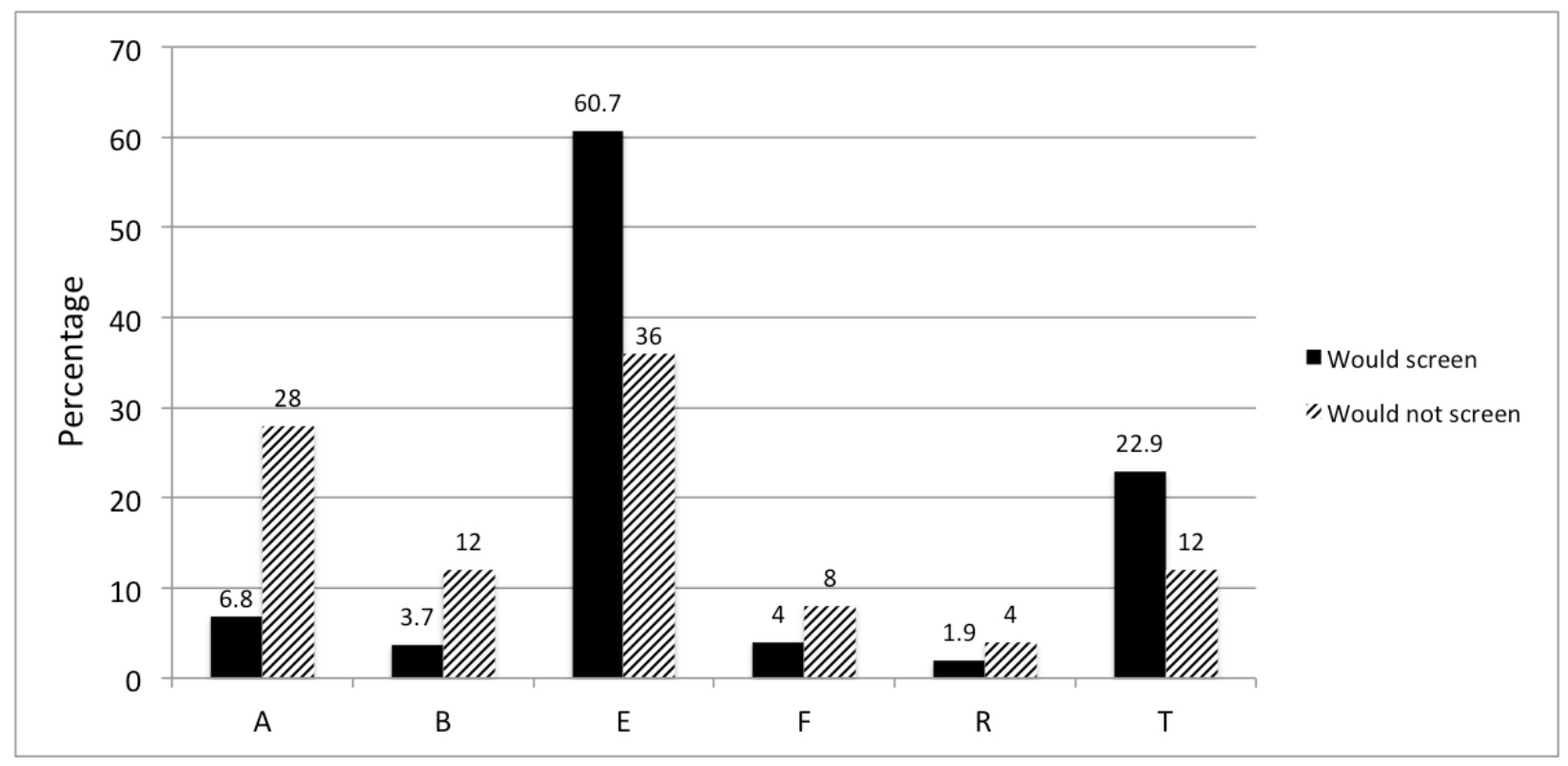

Figure 17: Factors that play a primary role in expectant parents' opinions of NBS for DMD/BMD/SMA, stratified by whether an expectant parent would choose to screen his/her child.

${ }^{*} \mathrm{~A}=$ Anxiety, $\mathrm{B}=$ Bonding, $\mathrm{E}=$ Early diagnosis, $\mathrm{F}=$ Family planning, $\mathrm{R}=$ Decision regret, $\mathrm{T}=\mathrm{Time}$ to prepare.

To determine expectant parents' consistency in their answers, we asked a number of inverse question pairs regarding influential factors. Participants were asked to indicate on a scale from 1-5 their feelings about a statement, with 1 meaning, "disagree completely," 5 meaning, “agree completely," and 3 meaning, "neither agree nor disagree." Concordance was calculated as 
the number of expectant parents that responded equally and oppositely between a question and its inverse. Of the expectant parents that were surveyed, $67.3 \%$ were consistent regarding their opinions on bonding, $44.5 \%$ were consistent regarding their opinions on anxiety, and 36.8\% were consistent regarding their opinions on time to prepare, as shown in Table 5.

Table 5: Concordance rates in paired questions.

Expectant parents responded to each statement on a 5-point scale, where 1, 3, and 5 were defined as, "Disagree Completely," "Neither Agree nor Disagree," and "Agree Completely," respectively.

\begin{tabular}{|c|c|c|c|}
\hline Category & Question & $\begin{array}{l}\text { Average } \\
\text { response }\end{array}$ & $\begin{array}{c}\text { Number of } \\
\text { concordant pairs }(\%)\end{array}$ \\
\hline \multirow[t]{2}{*}{ Anxiety } & "Screening would increase my anxiety level." & 3.20 & \multirow[t]{2}{*}{$178 / 400(44.5 \%)$} \\
\hline & "Screening would decrease my anxiety level." & 2.79 & \\
\hline \multirow[t]{2}{*}{ Bonding } & $\begin{array}{l}\text { "Screening would affect how I bond with my } \\
\text { child." }\end{array}$ & 1.81 & \multirow[t]{2}{*}{$269 / 400(67.3 \%)$} \\
\hline & $\begin{array}{l}\text { "Screening would not affect how I bond with my } \\
\text { child." }\end{array}$ & 3.88 & \\
\hline \multirow[t]{2}{*}{ Time } & $\begin{array}{l}\text { "Screening would allow me to enjoy the time } \\
\text { with my child before he/she shows symptoms, if } \\
\text { my child's results were abnormal." }\end{array}$ & 3.48 & \multirow[t]{2}{*}{$147 / 400(36.8 \%)$} \\
\hline & $\begin{array}{l}\text { "Screening would take away the first few happy } \\
\text { years with my child, if my child's results were } \\
\text { abnormal." }\end{array}$ & 1.80 & \\
\hline $\begin{array}{l}\text { Early } \\
\text { diagnosis }\end{array}$ & $\begin{array}{l}\text { "Screening would allow doctors to make a } \\
\text { diagnosis sooner." }\end{array}$ & 4.36 & $\mathrm{~N} / \mathrm{A}$ \\
\hline $\begin{array}{l}\text { Family } \\
\text { planning }\end{array}$ & $\begin{array}{l}\text { "Screening would affect my decision to have } \\
\text { more children." }\end{array}$ & 2.38 & $\mathrm{~N} / \mathrm{A}$ \\
\hline $\begin{array}{l}\text { Decision } \\
\text { regret }\end{array}$ & $\begin{array}{l}\text { "I would be sorry that I decided to have my baby } \\
\text { screened, if my child's results were abnormal." }\end{array}$ & 1.60 & $\mathrm{~N} / \mathrm{A}$ \\
\hline
\end{tabular}

\subsubsection{Additional comments}

Expectant parents were given the option of leaving additional comments after filling out the survey. Highlighted comments are included in Table 6. 
Table 6: Selected comments from expectant parents.

\begin{tabular}{|c|c|}
\hline Comment & Participant \\
\hline $\begin{array}{l}\text { "The concern that I would have for screening for these illnesses is that } \\
\text { there is no cure for [them]. Often children that have these illnesses } \\
\text { present very early. The test would need to have a very high } \\
\text { specificity or parents may be put through an incredible degree of } \\
\text { anxiety over the possibility of a false positive test." }\end{array}$ & $\begin{array}{l}\text { C-30, expectant father } \\
\text { with family history } \\
\text { of MD. }\end{array}$ \\
\hline $\begin{array}{l}\text { "So much research shows potential benefits for early diagnosis of many } \\
\text { conditions that I feel we should screen for everything possible to } \\
\text { give the best potential outcomes for our child." }\end{array}$ & $\begin{array}{l}\text { C-100, expectant } \\
\text { mother. }\end{array}$ \\
\hline $\begin{array}{l}\text { "I am in favor of screening. An abnormal result would allow us to } \\
\text { prepare and also I would be more likely to try and have my child } \\
\text { experience as many activities/events/places as possible before they } \\
\text { lose any physical ability. I would also begin a more aggressive } \\
\text { savings plan for future costs associated with treatments and my } \\
\text { child's life." }\end{array}$ & $\begin{array}{l}\text { C-121, gender } \\
\text { unspecified. }\end{array}$ \\
\hline $\begin{array}{l}\text { "I believe screening is up to the parents if they choose and for me I'd } \\
\text { want to be sure my child would not be put in any pain to be tested!" }\end{array}$ & $\begin{array}{l}\text { C-163, expectant } \\
\text { father. }\end{array}$ \\
\hline $\begin{array}{l}\text { "Like with most things, I believe screening is a choice parents should } \\
\text { have the option to make." }\end{array}$ & $\begin{array}{l}\text { C-241, expectant } \\
\text { father with family } \\
\text { history of MD. }\end{array}$ \\
\hline $\begin{array}{l}\text { "Really \#3-6 [anxiety, family planning, bonding, regret] are not an } \\
\text { influence at all." }\end{array}$ & $\begin{array}{l}\text { C-264, expectant } \\
\text { father with family } \\
\text { history of MD. }\end{array}$ \\
\hline $\begin{array}{l}\text { "Screening would not negatively impact my bond with my children - } \\
\text { regardless of the results. I would raise them and love them } \\
\text { unconditionally. I believe it would help me prepare for the future } \\
\text { and allow me an opportunity to research the conditions to get the } \\
\text { best care possible for my children." }\end{array}$ & $\begin{array}{l}\text { C-282, expectant } \\
\text { mother with family } \\
\text { history of MD. }\end{array}$ \\
\hline $\begin{array}{l}\text { "I would prefer to not know for the first month. But I would not delay } \\
\text { interminably. All these tests are too overwhelming the first day or } \\
\text { two. They should happen month 2." }\end{array}$ & $\begin{array}{l}\text { C-328, gender } \\
\text { unspecified. }\end{array}$ \\
\hline $\begin{array}{l}\text { "While I find screenings stressful, the benefits outweigh the risk, } \\
\text { especially if you are already screening for } 20 \text { other conditions." }\end{array}$ & $\begin{array}{l}\text { C-371, expectant } \\
\text { father. }\end{array}$ \\
\hline $\begin{array}{l}\text { "My husband and I feel very strongly that genetic testing - for us - } \\
\text { would only be used if it helped us to prepare differently (or our } \\
\text { doctors)." }\end{array}$ & $\begin{array}{l}\text { C-385, expectant } \\
\text { mother. }\end{array}$ \\
\hline $\begin{array}{l}\text { "I am a big believer in knowing as much as possible as soon as } \\
\text { possible. Ignorance is NOT bliss!" }\end{array}$ & $\begin{array}{l}\text { C-389, expectant } \\
\text { mother. }\end{array}$ \\
\hline
\end{tabular}




\subsection{HOW DO THE MDA AND MAGEE COHORTS COMPARE?}

\subsubsection{Specific Aim 4}

Our fourth specific aim was to compare parental support in the two cohorts.

Overall, both cohorts supported NBS for DMD, BMD, and SMA. All 65 parents surveyed from the MDA cohort answered the question "Should newborns be screened for DMD/BMD/SMA?" as discussed above. Without further developments in treatment, 97\% of parents supported NBS. Three-hundred ninety nine expectant parents answered the question "If there were a disease without a cure that would affect your child's health and shorten his/her lifespan, would you want to know at birth?" as discussed above. A total of $92.5 \%$ of participants supported NBS. Although a higher percentage of the MDA cohort supported NBS, it was not statistically significant based on Fisher's exact test $(\mathrm{p}=.295)$, as shown in Table 7.

Table 7: Comparison of NBS support in MDA and Magee cohorts.

NBS=Newborn screening, MDA=Muscular Dystrophy Association.

\begin{tabular}{|c|c|c|c|}
\hline Support NBS? & Yes (\%) & No (\%) & Total \\
\hline MDA & $63(97 \%)$ & $2(3 \%)$ & 65 \\
\hline Magee & $369(92.5 \%)$ & $30(7.5 \%)$ & 399 \\
\hline Total & 432 & 32 & 464 \\
\hline
\end{tabular}




\subsection{DISCUSSION}

\subsection{MDA COHORT}

Supportive of our hypothesis, parents of children with DMD/BMD/SMA strongly supported NBS for these conditions. Ninety-seven percent felt that NBS should be implemented, even without further therapeutic advances; however, only $85.7 \%$ would want their next child screened. This difference can be explained by the strong minority of parents $(40.0 \%)$ who felt that NBS for $\mathrm{DMD} / \mathrm{BMD} / \mathrm{SMA}$ should only be implemented with parental consent. It is reasonable to speculate that some parents who support optional NBS would choose not to have their own child screened.

In consideration of the broader implications of the opinions expressed through the survey responses, if parents who have already had an affected child, express a desire to not have their next child screened, then it seems reasonable to avoid implementing a mandatory screen for the general population. This means that the remaining options should include an opt-in screen at birth, an opt-out screen at birth, and an optional screen offered at a later time.

Our data is in accordance with previous studies done on parental opinions of NBS for DMD. Parsons et al. retrospectively evaluated parents' opinions on NBS for DMD after having a child screen positive during the implementation of NBS for DMD in Wales (Parsons, 2002). They found that $85-89 \%$ of parents supported NBS, whether the result was found to be a false 
positive or their child received a diagnosis of DMD. Another study surveyed parents of children with DMD who were diagnosed symptomatically and found that $90 \%$ of those who responded were in favor of NBS (Firth, 1983).

Qualitatively, parents' comments echo a number of alternatives to a universal NBS that have been mentioned in past discussions of NBS for DMD/BMD/SMA. One parent mentioned that screening should occur if and when there is a treatment developed; this, along with evidence that early intervention for DMD provides a better outcome than symptomatic diagnosis and treatment, would mean DMD would meet the original Wilson and Jungner screening criteria. Another parent brought up screening when there is a family history of one of these diseases. Parents also brought up several influential factors assessed in the second part of this study: the benefits and drawbacks of early diagnosis, and the benefits of time for both family and medical staff to prepare for the child's medical needs.

\subsection{MAGEE COHORT}

Consistent with our hypothesis, expectant parents supported NBS for DMD/BMD/SMA, as demonstrated by the $92.5 \%$ of parents who would want to know at birth if their child had a lifeshortening, incurable genetic disorder. This was considered a model for DMD/BMD/SMA for several reasons. DMD/BMD/SMA currently do not have a cure, and convey varying degrees of disability throughout the lifespan. We anticipated a low level of background knowledge of $\mathrm{DMD} / \mathrm{BMD} / \mathrm{SMA}$ and their associated complexities in the general population. By asking about parents' feelings before describing each disease, we can confidently say that this high level of support is applicable to many diseases that fit the above descriptors. Additionally, by asking 
about parents' opinions on screening for an incurable disorder, we can conclude that our respondents support NBS for DMD/BMD/SMA without further therapeutic development.

We expected that the most influential factor on parents' opinions of NBS would be time to prepare, both emotionally and practically. Although several comments reflected the importance of preparing for the child's diagnosis, the majority of parents responded that an early diagnosis was the most influential factor. Both early diagnosis and time to prepare are closely related concepts, and ranked first and second in the list of influential factors in parents who would choose to screen their child.

Our data supports previous studies done on parental opinions of NBS for DMD with no selection for family history. One study divided NBS into 3 categories: treatable (PKU), less treatable (CF), and untreatable (DMD) (Plass, 2010). Parental support was $73.3 \%$ for the inclusion of untreatable diseases into mandatory NBS. Smith et al. evaluated mothers' opinions on NBS for DMD and found that $94 \%$ felt that screening was acceptable despite the lack of an available treatment (Smith, 1990). Other studies have qualitatively evaluated parents' opinions of NBS for DMD. Campbell and Ross used focus groups to compare parental opinions of NBS for PKU and DMD; although parents were strongly supportive of NBS for PKU, many psychosocial concerns were brought up regarding NBS for DMD (Campbell, 2003).

Additional comments from expectant parents also gave a unique perspective into the thought processes that influenced parents' opinions. Several parents expressed that screening should be a choice for parents. Other parents outlined thoughtful reasons both for screening and for not screening. Parents who supported screening listed emotional, medical, and financial preparation for the child. Parents who did not support screening cited both the anxiety of false positive results, and the acceptability of a symptomatic diagnosis. 


\subsection{LIMITATIONS}

One major limitation in our ability to compare the two cohorts was the distribution of two different questionnaires. Although some data can be interpreted between both cohorts, it would be interesting to see how the influencing factors compared between expectant parents, and parents of children with DMD, BMD, or SMA.

In the MDA questionnaire, parents were asked to respond to the statement, "Newborn babies should be screened for muscular dystrophy and spinal muscular atrophy," with one of the following responses: "Yes, as a routine procedure," "Yes, but only if treatable," "Yes, but only with parental permission," "No," or "Not sure." A limitation of this question is that parents were not allowed to choose more than one response. For example, it is possible that some parents felt that screening should be mandatory, if treatment becomes available. This question would force parents to choose which response is most important, and may lead to an underestimation of the importance of therapeutic development to parents of children with DMD, BMD, or SMA when considering NBS for DMD/BMD/SMA.

After analyzing the data, there was a lower than anticipated awareness of the current NBS program in the Magee cohort. Several expectant parents expressed in their comments that their opinions of screening would depend on how invasive the screen was, or if screening would hurt the child. This confusion could have been avoided by including a paragraph about the current NBS procedures, and that screening for DMD/BMD/SMA should not require any additional blood. The invasiveness of a screen could potentially have a large impact on whether a parent considers the screen acceptable or not.

When assessing the most influential factors in expectant parents' opinions of NBS, the

terms "early diagnosis" and "time to prepare" may have been difficult to separate from one 
another. In past studies, "early diagnosis" has been used as a term to describe the avoidance of a diagnostic odyssey, or a reduction in time between when a parent first notices the child's symptoms and an eventual diagnosis. Naturally, an early diagnosis gives the family (and doctors) time to prepare, and thus may have confounded parent's ranking.

It is interesting to note that the majority of expectant parents who identified a well-known figure with a genetic disease named someone with a multifactorial disease, such as Parkinson's disease or amyotrophic lateral sclerosis (ALS). Although only a small fraction of these 2 conditions are due to single-gene defects, there is a genetic component to each, and the phrasing of the question does not exclude them.

When naming a well-known figure with a genetic disease, popular answers included Michael J. Fox, Ryan Clark (Pittsburgh Steeler), Stephen Hawking, Muhammad Ali, Chris Burke (actor from Life Goes On), and Lauren Potter (actress from Glee). However, this data may have been skewed by concurrent news events. Early in data collection, a Pittsburgh football player (Ryan Clark) was not allowed to play in an important game in Denver, Colorado, because doctors were concerned that his sickle cell anemia trait would cause him to have a blood crisis in Denver's high altitudes. This news event coincided with an observed influx of respondents naming Ryan Clark as a celebrity with a genetic disease.

\subsection{IMPLICATIONS FOR RE-IMPLEMENTING OPT-IN, OR INITIATING OPT- OUT NBS FOR DMD}

The lack of a proven improvement in long-term outcome that could be afforded by early identification and treatment of DMD, BMD, and SMA is a deterrent for their inclusion in the 
established mandatory NBS. Although current exon-skipping clinical trials for DMD are promising, there is no evidence yet that a greater benefit will be reaped if treatment is started presymptomatically, rather than upon symptomatic diagnosis. This also applies to current SMA clinical trials, although these trials are limited in their ability to demonstrate the benefits of presymptomatic treatment without enrolling participants through NBS. Without such evidence, the majority of benefit for the inclusion of DMD, BMD, and SMA in NBS is most relevant to the parents, not the child. As such, parental choice should be considered a higher priority than in current NBS practice, which centers on the child's right to a healthy life.

When considering parental choice in NBS, there are two options: an opt-in program, where parents must consent for their child to be screened, and an opt-out program, where parents must be aware of the implications of the screen and actively disagree in order for their child not to be screened. Given the high majority of support for NBS for DMD/BMD/SMA in both cohorts, an opt-out screen may be more practical. Those who are aware of the screen and do not wish to know such information may make their wishes known, and those who are not aware of the screen are statistically likely to want to know. Ideally, all parents would be made aware of such a screen, but currently, the majority of expectant parents are not aware of the mandatory NBS panel, making the likelihood of awareness for an optional screen low. An opt-in screen would give the most autonomy to the parents, but would limit the general utility of NBS for these conditions.

With an opt-in screen, informed consent becomes another key issue. Previous data has shown a high opt-in rate when the decision is made in the hospital shortly after birth (Bradley, 1993). As discussed above, the environment right after the birth of a child is not necessarily the best time for an autonomous, informed consent. Additionally, if an opt-in screen were to be done 
before parents leave the hospital, hospital time and resources would need to be allocated for informed consent. Such resources have a cost and are not always available. Opt-in rates have been shown to drop dramatically when parents are asked about screening even one month after the birth of a child (Scheuerbrandt, 1986; Scheuerbrandt, 2009); however, the interpretation of this finding is complex.

For SMA, the young age of diagnosis and early onset of irreversible symptoms suggest consideration of an opt-out screen. Early enrollment in a clinical trial could have a direct benefit for the child's overall health, thus elevating benefit to the child above parental choice. However, current knowledge and resources to predict prognosis of SMA based on SMN2 copy number are limited, and are not sufficient to predict which affected children will require early intervention. Ethically, a nebulous benefit to the child is not compelling evidence to override parental consideration. 


\subsection{CONCLUSION}

There is considerable current interest within families affected by muscular dystrophy and medical teams who care for them for the inclusion of DMD in the NBS panel. This interest is significantly supported by the promising gene therapy approaches for DMD treatment currently in clinical trials. The field is encouraged by the real potential for effective treatments for DMD to emerge from ongoing clinical research. None-the-less, this study provides strong support for the implementation of NBS for DMD/BMD/SMA without any further medical developments.

Our specific aims in this study were to assess how expectant parents and parents of children with $\mathrm{DMD} / \mathrm{BMD} / \mathrm{SMA}$ felt about adding $\mathrm{DMD} / \mathrm{BMD} / \mathrm{SMA}$ to the NBS program, to assess what factors influence these opinions, and to compare the opinions of expectant parents with the opinions of parents of children with DMD/BMD/SMA. We have evaluated parents' attitudes toward the inclusion of DMD/BMD/SMA in the standard NBS panel. Although there is strong support for screening, timing and importance of specific informed consent remain controversial. A majority of parents of children with DMD, BMD, or SMA supported mandatory screening, but a strong minority felt that screening should only be done with parental permission. Expectant parents supported screening for incurable, life-shortening diseases, such as DMD/BMD/SMA. The most influential factor in expectant parents' opinions was the benefit of an early diagnosis. Both expectant parents and parents of children with DMD, BMD, or SMA supported screening, but support was not significantly higher in either cohort. 
This study demonstrates that the addition of diseases that were not previously screened to the standard NBS program invokes the need to consider the beneficence of screening for these diseases in the context of parental opinions. Although there is currently no direct medical benefit of early diagnosis in $\mathrm{DMD} / \mathrm{BMD} / \mathrm{SMA}$, parents responded that early diagnosis could have other, less tangible benefits. These benefits would be preserved in a voluntary screening program, and an optional screen after the newborn period would allow parents the most autonomy in their decision. 
APPENDIX A

QUESTIONNAIRES

A.1 QUESTIONNAIRE FOR EXPECTANT PARENTS OR PARENTS OF NORMAL NEWBORNS 
Parental Attitudes Toward Newborn Screening for DMD/BMD/SMA

\section{THE FOLLOWING QUESTIONS ARE ABOUT YOU:}

Gender: $\quad$ a. Female b. Male

Age (years):
a. less than 20
b. $20-29$
c. $30-39$
d. $40-49$
e. $50+$

Race:

a. White or Caucasian

b. Black or African-American

c. Asian

d. Native Hawaiian/Other Pacific Islander
Education:
a. Some high school
b. High school graduate
c. Some college
d. College graduate
d. Master's degree
e. Doctoral degree
f. Other

e. American Indian or Alaska Native
a. Married
b. Single

Marital Status:

d. Separated

Ethnicity:

e. Not Married
a. Hispanic/Latino
b. Non-Hispanic

How do you consider your economic views:

Conservative 1----------2--------3-

3----------4 $-5$ $-6$

Liberal

How do you consider your social/political values:

Conservative 1----------2----------3----------4----------5----------6----------7 Liberal

How do you consider your spiritual views:

Conservative 1----------2----------3 $-3-$ $-4-$ $-5$ $-6--------7$ Liberal

What number child is this for you?
a. $1^{\text {st }}$
b. $2^{\text {nd }}$
c. $3^{\text {rd }}$
d. $4^{\text {th }}$
e. $5^{\text {th }}+$

Do you personally know anyone with muscular dystrophy?
a. Yes
b. No 
Do you personally know anyone with a genetic disease, such as cystic fibrosis, sickle-cell anemia, or Down syndrome?
a. Yes
Diagnosis:
b. No

Do you know of a person (for example, a celebrity, athlete, or politician) with a genetic disease?
a. Yes
b. No

Person:

Are you aware that all newborns are screened for over 20 treatable genetic diseases through the Pennsylvania Newborn Screening Program before they leave the hospital?
a. Yes
b. No

If there were a disease without a cure that would affect your child's health and shorten his/her lifespan, would you want to know at birth?
a. Yes
b. No 
Duchenne muscular dystrophy (DMD) is a genetic disease that causes muscle weakness beginning in the upper legs and arms. The muscles grow weaker as the child ages. DMD affects only boys, and these boys begin to show symptoms between ages 3-5 years. Most boys with DMD need wheelchairs by age 12 , and their lifespans are much shorter than a person without DMD. Treatment of DMD includes physical therapy, medications, and special medical care for heart and lung problems. There is no cure for DMD.

Becker muscular dystrophy (BMD) is another genetic disease that is caused by changes in the same gene as DMD. There is similar muscle weakness, but the weakness does not happen as quickly. BMD also affects only boys, but they begin to show symptoms at a later age. Lifespan is often shortened, but usually not as much as DMD. Treatment is similar to treatment of DMD. There is no cure for BMD.

Spinal muscular atrophy (SMA) is a genetic disease with a wide range of symptoms. Over time, muscles of people with SMA get smaller and weaker due to poor communication between the spinal cord and the muscles. This weakness can be very mild, or it can be very severe. Age of onset ranges from early infancy to adulthood. There is no cure for SMA.

We do not currently screen newborns for any of the above (DMD, BMD or SMA). We may soon have good screening tests for these but no cure to treat them. The following questions will help us decide how parents feel about screening newborns for these conditions. 
Please indicate how each factor influences your opinion of newborn screening for DMD, BMD, and SMA by circling a number, 1-5, with 1 meaning, "disagree completely," and 5 meaning, "agree completely."

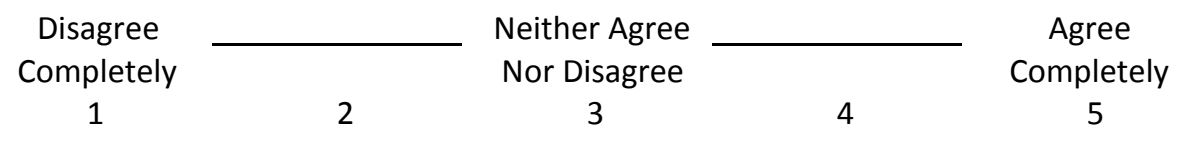

1. Screening would affect how I bond with my child:

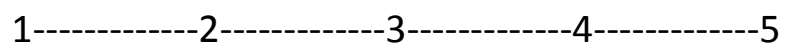

2. Screening would increase my anxiety level:

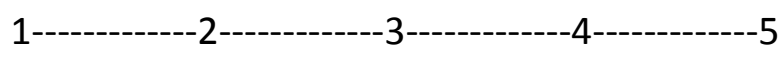

3. Screening would affect my decision to have more children:

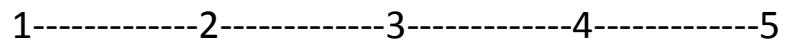

4. Screening babies for genetic diseases is wrong:

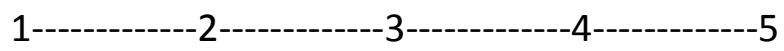

5. I would be sorry that I decided to have my baby screened, if my child's results were abnormal:

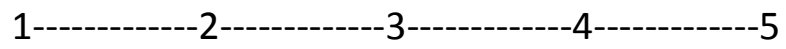

6. Screening would allow me to enjoy the time with my child before he/she shows symptoms, if my child's results were abnormal:

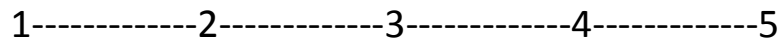

7. Screening would affect how I raise my child:

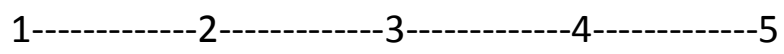

8. Screening would not affect how I bond with my child:

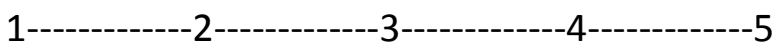




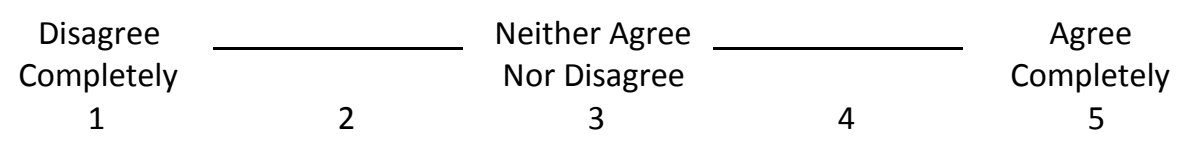

9. Screening would take away the first few happy years with my child, if my child's results were abnormal:

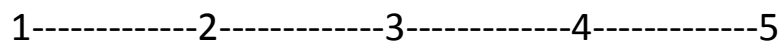

10. Screening would decrease my anxiety level:

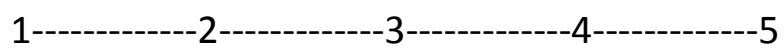

11. Screening would allow me to prepare emotionally for my child's disease, if my child's results were abnormal:

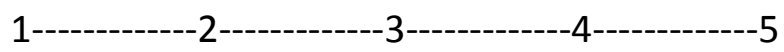

12. Screening babies for genetic diseases is necessary:

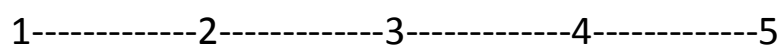

13. Screening would allow doctors to make a diagnosis sooner:

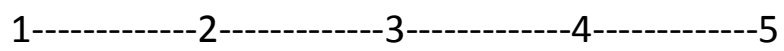

14. Please rank the following factors based on how much they influence your opinion on newborn screening, with 1 being the most influential and 6 being the least influential:

Anxiety
Bonding
Decision to have more children
Early diagnosis
Time to prepare
Potential for regret

Additional comments: 
A.2 QUESTIONNAIRE FOR PARENTS OF CHILDREN WITH D/BMD OR SMA 
QUESTIONNAIRE FOR PARENTS OF CHILDREN WITH MUSCULAR DYSTROPHY OR SPINAL MUSCULAR ATROPHY

THE FOLLOWING QUESTIONS ARE ABOUT YOU

Relationship:

Father
Mother
Other

$\underline{\text { Age (years): }}$

Education (highest level):

less than 20
$20-29$
$30-39$
over 40

8th Grade 12th Grade College Master's Degree Doctoral Degree Other

Number of Children:

$\underline{\text { Religion: }}$

One
Two
Three
Four or more

\begin{tabular}{l} 
Jewish \\
Catholic \\
\hline Protestant \\
Other
\end{tabular}

Race or Ethnicity:

Marital Status:

White
Black
Asian
Hispanic
Other

\begin{tabular}{l} 
Married \\
\hline Single \\
Divorced \\
Separated \\
Not Married
\end{tabular}

THE FOLLOWING QUESTIONS ARE ABOUT YOUR CHILD

Child's diagnosis:

Duchenne Muscular Dystrophy Becker Muscular Dystrophy Spinal Muscular Atrophy Other Muscular Dystrophy (LGMD, congenital), specify: 
Age of child when the diagnosis of muscular dystrophy or spinal muscular atrophy was confirmed:

Less than 4 weeks

$1-6$ months

Older than 6 months

Age at which YOU first suspected something might be wrong:

Less than 1 month

$1-12$ months

$1-5$ years

5-10 years

Older than 10 years

Current age of child:

Who informed you about the diagnosis of your child?

Pediatrician

Obstetrician

Family doctor

Pediatric Neurologist/Neurologist

Physician at MDA Clinic

Other

Are there other members of your family with muscular dystrophy or spinal muscular atrophy?

Yes If Yes, How many?

No Brothers or sisters

Other relative

Was your child screened for muscular dystrophy or spinal muscular atrophy at birth?

Yes

No

Don't know

PLEASE ANSWER THE FOLLOWING QUESTIONS REGARDING MUSCULAR DYSTROPHY, SPINAL MUSCULAR ATROPHY, AND NEWBORN SCREENING TO THE BEST OF YOUR KNOWLEDGE

(1) Newborn screening for muscular dystrophy and spinal muscular atrophy is:

a) currently performed nationwide in the United States

b) offered by a small number of hospitals in the United States

c) not in use at all at the present time

d) not sure 
PLEASE ANSWER THE FOLLOWING QUESTIONS REGARDING MUSCULAR DYSTROPHY, SPINAL MUSCULAR ATROPHY, AND NEWBORN SCREENING TO THE BEST OF YOUR KNOWLEDGE

(2) Newborn babies should be screened for inherited disorders through state mandated newborn screening programs:
a) Yes, as a routine procedure
b) Yes, but only if treatable
c) Yes, but only with parental consent
d) No
e) Not sure

(3) Newborn babies should be screened for muscular dystrophy and spinal muscular atrophy:
a) Yes, as a routine procedure
b) Yes, but only if treatable
c) Yes, but only with parental permission
d) $\mathrm{No}$
e) Not sure

(4) If your child was not detected through newborn screening, would you have wanted your child to have been screened for muscular dystrophy or spinal muscular atrophy:
a) Yes
b) No
c) Not sure

(5) If your child was screened as a newborn, are you glad that was child was screened for muscular dystrophy or spinal muscular atrophy:
a) Yes
b) No
c) Not sure

(6) Would you want future children screened for muscular dystrophy and spinal muscular atrophy:
a) Yes
b) No
c) Not sure

\section{Comments:}




\section{APPENDIX B}

\section{SCRIPTS}

\section{B.1 SCRIPT FOR MDA CLINICS}

The purpose of this research study is to evaluate current attitudes towards newborn screening for Spinal Muscular Atrophy (SMA) and Duchenne/Becker Muscular Dystrophy (D/BMD). For that reason, we will be surveying parents of newborns and parents of children with these muscle conditions and asking them to complete a brief questionnaire. The questionnaire will take approximately 5 minutes to complete. If you are willing to participate, our questionnaire will ask basic demographic information such as age, race, years of education, religion; your feelings about newborn screening, and your experience with your child's diagnosis. The risks associated with participating in this survey are minimal, and there are no direct benefits to you. This is an entirely anonymous questionnaire, and so your responses will not be identifiable in any way. All responses are confidential. Your participation is voluntary. This study is being conducted by Dr. Abdel-Hamid, who is a pediatric neuromuscular specialist.

\section{B.1.1 Parent Letter for MDA Clinic}

\section{Dear Parent of}

We are writing to you regarding a new research study being conducted by the Muscular Dystrophy Association (MDA) clinics at the University of Pittsburgh Medical Center (UPMC). It is a questionnaire-based study that will evaluate current attitudes toward newborn screening for Duchenne/Becker muscular dystrophy (D/BMD) and spinal muscular atrophy (SMA). We are approaching both expectant parents and parents of children with these muscle conditions and asking them to complete a brief questionnaire (enclosed). 
If you are willing to participate, the questionnaire will take approximately 5 minutes to complete. It will ask basic demographic information, your feelings toward newborn screening, and your experience with your child's diagnosis. This is an entirely anonymous questionnaire, and all identifying information will be removed prior to data entry. Your responses are confidential, and your participation is voluntary.

The risks associated with filling out the questionnaire are expected to be minimal, and there are no direct benefits to you. However, your responses will be important for future discussions about newborn screening for D/BMD and SMA.

To participate, please fill out the enclosed questionnaire and return it in the enclosed addressed envelope. By mailing the questionnaire, you are consenting to participate in this research study. If you have any questions about this research study, please contact Kate Hughes at the phone number below. Thank you for your consideration!

Sincerely, Molly Wood, B.A. Hoda Abdel-Hamid, M.D. Genetic Counseling Intern Pediatric Neurologist University of Pittsburgh '12 Children's Hospital of Pittsburgh of UPMC

Kate Hughes, M.S., C.G.C.

Genetic Counselor, Clinical Research Coordinator

University of Pittsburgh

\#\#\#-\#\#\#-\#\#\#\#.

\section{B.2 SCRIPT FOR EXPECTANT PARENTS}

The purpose of this research study is to evaluate current attitudes towards newborn screening for Spinal Muscular Atrophy (SMA) and Duchenne/Becker Muscular Dystrophy (D/BMD). All three diseases have onset of symptoms in childhood with varying degrees of muscle weakness, and convey a shortened lifespan. For that reason, we will be surveying expectant parents and/or parents of newborns and asking them to complete a brief questionnaire. The questionnaire will take approximately 10 minutes to complete. If you are willing to participate, our questionnaire will ask basic demographic information such as: age, race, years of education, religion; as well as your feelings about newborn screening. There are no foreseeable risks associated with this study, nor are there any direct benefits to you. This is an entirely anonymous questionnaire, and so your responses will not be identifiable in any way. All responses are confidential. Your participation is voluntary. This study is being conducted by Molly Wood, a genetic counseling intern, who can be reached at (\#\#\#) \#\#\#-\#\#\#\#. 
APPENDIX C

\section{IRB APPROVALS}

\section{University of Pittsburgh \\ Institutional Review Board}

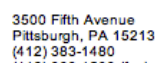

Pittsburgh, PA 15213
$(412) 383-1480$

(412) $383-1508$ (fax)
http: $/ /$ www.irb. pitt.ed

\section{Memorandum}

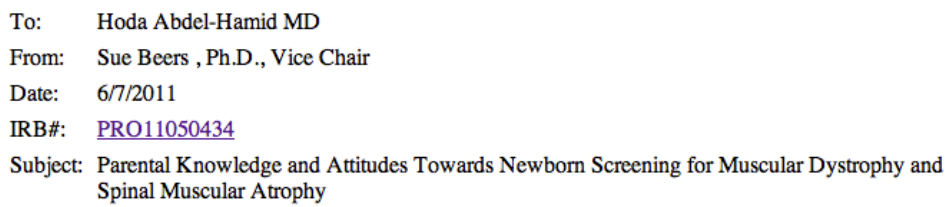

Subject: Parental Knowledge and Attitudes Towards Newborn Screening for Muscular Dystrophy and Spinal Muscular Atrophy

The above-referenced project has been reviewed by the Institutional Review Board. Based on the information provided, this project meets all the necessary criteria for an exemption, and is hereby designated as "exempt" under section

45 CFR 46.101(b)(2) Tests, surveys, interviews, observations of public behavior

Please note the following information:

- If any modifications are made to this project, use the "Send Comments to IRB Staff" process from the project workspace to request a review to ensure it continues to meet the exempt category.

- Upon completion of your project, be sure to finalize the project by submitting a "Study Completed" report from the project workspace.

Please be advised that your research study may be audited periodically by the University of Pittsburgh Research Conduct and Compliance Office. 


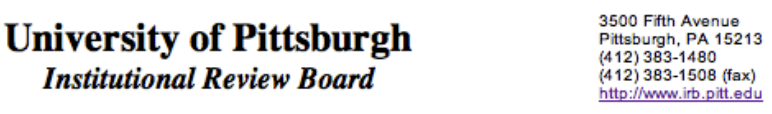

Memorandum

To: $\quad$ Molly Wood

From: Sue Beers, $\mathrm{PhD}$, Vice Chair

Date: $\quad 10 / 19 / 2011$

IRB\#: $\quad \underline{\text { PRO11090369 }}$

Subject: Parental Attitudes Toward Newborn Screening for Incurable Diseases

The above-referenced project has been reviewed by the Institutional Review Board. Based on the information provided, this project meets all the necessary criteria for an exemption, and is hereby designated as "exempt" under section

45 CFR 46.101(b)(2).

Please note the following information:

- If any modifications are made to this project, use the "Send Comments to IRB Staff" process from the project workspace to request a review to ensure it continues to meet the exempt category.

- Upon completion of your project, be sure to finalize the project by submitting a "Study Completed" report from the project workspace.

Please be advised that your research study may be audited periodically by the University of Pittsburgh Research Conduct and Compliance Office. 


\section{BIBLIOGRAPHY}

Anthony, K., Cirak, S., Torelli, S., Tasca, G., Feng, L., Arechavala-Gomeza, V., Armaroli, A., et al. (2011). Dystrophin quantification and clinical correlations in Becker muscular dystrophy: implications for clinical trials. Brain: A Journal of Neurology, 134(Pt 12), 3547-3559. doi:10.1093/brain/awr291

Aoki, Y., Nakamura, A., Yokota, T., Saito, T., Okazawa, H., Nagata, T., \& Takeda, S. (2010). In-frame dystrophin following exon 51-skipping improves muscle pathology and function in the exon 52-deficient mdx mouse. Molecular Therapy: The Journal of the American Society of Gene Therapy, 18(11), 1995-2005. doi:10.1038/mt.2010.186

Becker, P. E. (1962). Two families of benign sex-linked recessive muscular dystrophy. Revue Canadienne De Biologie / Éditée Par l’Université De Montréal, 21, 551-566.

Bellayou, H., Hamzi, K., Rafai, M. A., Karkouri, M., Slassi, I., Azeddoug, H., \& Nadifi, S. (2009). Duchenne and Becker muscular dystrophy: contribution of a molecular and immunohistochemical analysis in diagnosis in Morocco. Journal of Biomedicine \& Biotechnology, 2009, 325210. doi:10.1155/2009/325210

Blau, N., Hennermann, J. B., Langenbeck, U., \& Lichter-Konecki, U. (2011). Diagnosis, classification, and genetics of phenylketonuria and tetrahydrobiopterin (BH4) deficiencies. Molecular Genetics and Metabolism, 104 Suppl, S2-9. doi:10.1016/j.ymgme.2011.08.017

Bodamer, O. A. (2010). Screening for Phenylketonuria. Annales Nestlé (English ed.), 68(2), 5357. doi:10.1159/000312812

Bradley, D. M., Parsons, E. P., \& Clarke, A. J. (1993). Experience with screening newborns for Duchenne muscular dystrophy in Wales. BMJ (Clinical Research Ed.), 306(6874), 357-360.

Bradley, W. G., Jones, M. Z., Mussini, J. M., \& Fawcett, P. R. (1978). Becker-type muscular dystrophy. Muscle \& Nerve, 1(2), 111-132. doi:10.1002/mus.880010204

Brolin, C., \& Shiraishi, T. (2011). Antisense mediated exon skipping therapy for duchenne muscular dystrophy (DMD). Artificial DNA, PNA \& XNA, 2(1), 6-15. doi:10.4161/adna.2.1.15425 
Bürglen, L., Lefebvre, S., Clermont, O., Burlet, P., Viollet, L., Cruaud, C., Munnich, A., et al. (1996). Structure and organization of the human survival motor neurone (SMN) gene. Genomics, 32(3), 479-482. doi:10.1006/geno.1996.0147

Bushby, K., Finkel, R., Birnkrant, D. J., Case, L. E., Clemens, P. R., Cripe, L., Kaul, A., et al. (2010a). Diagnosis and management of Duchenne muscular dystrophy, part 1: diagnosis, and pharmacological and psychosocial management. Lancet Neurology, 9(1), 77-93. doi:10.1016/S1474-4422(09)70271-6

Bushby, K., Finkel, R., Birnkrant, D. J., Case, L. E., Clemens, P. R., Cripe, L., Kaul, A., et al. (2010b). Diagnosis and management of Duchenne muscular dystrophy, part 2: implementation of multidisciplinary care. Lancet Neurology, 9(2), 177-189. doi:10.1016/S1474-4422(09)70272-8

Bushby, K. M., \& Gardner-Medwin, D. (1993). The clinical, genetic and dystrophin characteristics of Becker muscular dystrophy. I. Natural history. Journal of Neurology, 240(2), 98-104.

Bushby, K. M., Gardner-Medwin, D., Nicholson, L. V., Johnson, M. A., Haggerty, I. D., Cleghorn, N. J., Harris, J. B., et al. (1993). The clinical, genetic and dystrophin characteristics of Becker muscular dystrophy. II. Correlation of phenotype with genetic and protein abnormalities. Journal of Neurology, 240(2), 105-112.

Bushby, K. M., Hill, A., \& Steele, J. G. (1999). Failure of early diagnosis in symptomatic Duchenne muscular dystrophy. Lancet, 353(9152), 557-558.

Campbell, E., \& Ross, L. F. (2003). Parental attitudes regarding newborn screening of PKU and DMD. American Journal of Medical Genetics. Part A, 120A(2), 209-214.

doi:10.1002/ajmg.a.20031

CDC. (2004). CDC - Duchenne/Becker Muscular Dystrophy (DBMD), Reports - Newborn Screening Report. Retrieved March 23, 2012, from http://www.cdc.gov/ncbddd/duchenne/documents/nbs_lay_report.pdf

Chelly, J., Kaplan, J. C., Maire, P., Gautron, S., \& Kahn, A. (1988). Transcription of the dystrophin gene in human muscle and non-muscle tissue. Nature, 333(6176), 858-860. doi: $10.1038 / 333858 \mathrm{a} 0$

Ciafaloni, E., Fox, D. J., Pandya, S., Westfield, C. P., Puzhankara, S., Romitti, P. A., Mathews, K. D., et al. (2009). Delayed diagnosis in duchenne muscular dystrophy: data from the Muscular Dystrophy Surveillance, Tracking, and Research Network (MD STARnet). The Journal of Pediatrics, 155(3), 380-385. doi:10.1016/j.jpeds.2009.02.007

D’Amico, A., Mercuri, E., Tiziano, F. D., \& Bertini, E. (2011). Spinal muscular atrophy. Orphanet Journal of Rare Diseases, 6, 71. doi:10.1186/1750-1172-6-71 
Davies, K. E., \& Nowak, K. J. (2006). Molecular mechanisms of muscular dystrophies: old and new players. Nature Reviews. Molecular Cell Biology, 7(10), 762-773. doi:10.1038/nrm2024

Do, T. (2002). Orthopedic management of the muscular dystrophies. Current Opinion in Pediatrics, 14(1), 50-53.

Doglio, L., Pavan, E., Pernigotti, I., Petralia, P., Frigo, C., \& Minetti, C. (2011). Early signs of gait deviation in Duchenne muscular dystrophy. European Journal of Physical and Rehabilitation Medicine, 47(4), 587-594.

Drousiotou, A., Ioannou, P., Georgiou, T., Mavrikiou, E., Christopoulos, G., Kyriakides, T., Voyasianos, M., et al. (1998). Neonatal screening for Duchenne muscular dystrophy: a novel semiquantitative application of the bioluminescence test for creatine kinase in a pilot national program in Cyprus. Genetic Testing, 2(1), 55-60.

Eagle, M., Baudouin, S. V., Chandler, C., Giddings, D. R., Bullock, R., \& Bushby, K. (2002). Survival in Duchenne muscular dystrophy: improvements in life expectancy since 1967 and the impact of home nocturnal ventilation. Neuromuscular Disorders: NMD, 12(10), 926-929.

Emery, A. E. (1991). Population frequencies of inherited neuromuscular diseases--a world survey. Neuromuscular Disorders: NMD, 1(1), 19-29.

Emery, A. E., \& Skinner, R. (1976). Clinical studies in benign (Becker type) X-linked muscular dystrophy. Clinical Genetics, 10(4), 189-201.

Engel, A. G., Franzini-Armstrong, C. (Eds.). (2004). Myology (3rd ed.). New York, NY: McGraw-Hill.

Ervasti, J. M. (2007). Dystrophin, its interactions with other proteins, and implications for muscular dystrophy. Biochimica Et Biophysica Acta, 1772(2), 108-117. doi:10.1016/j.bbadis.2006.05.010

Finsterer, J., \& Stöllberger, C. (2008). Cardiac involvement in Becker muscular dystrophy. The Canadian Journal of Cardiology, 24(10), 786-792.

Firth, M. A., \& Wilkinson, E. J. (1983). Screening the newborn for Duchenne muscular dystrophy: parents' views. British Medical Journal (Clinical Research Ed.), 286(6382), 1933-1934.

Fragall, C. T., Adams, A. M., Johnsen, R. D., Kole, R., Fletcher, S., \& Wilton, S. D. (2011). Mismatched single stranded antisense oligonucleotides can induce efficient dystrophin splice switching. BMC Medical Genetics, 12, 141. doi:10.1186/1471-2350-12-141

Gérard, B., Ginet, N., Matthijs, G., Evrard, P., Baumann, C., Da Silva, F., Gérard-Blanluet, M., et al. (2000). Genotype determination at the survival motor neuron locus in a normal 
population and SMA carriers using competitive PCR and primer extension. Human Mutation, 16(3), 253-263. doi:10.1002/1098-1004(200009)16:3<253::AID-HUMU8>3.0.CO;2-8

Giliberto, F., Ferreiro, V., Dalamon, V., \& Szijan, I. (2004). Dystrophin deletions and cognitive impairment in Duchenne/Becker muscular dystrophy. Neurological Research, 26(1), 83-87.

Goemans, N. M., Tulinius, M., van den Akker, J. T., Burm, B. E., Ekhart, P. F., Heuvelmans, N., Holling, T., et al. (2011). Systemic administration of PRO051 in Duchenne's muscular dystrophy. The New England Journal of Medicine, 364(16), 1513-1522. doi:10.1056/NEJMoa1011367

Goyenvalle, A., Seto, J. T., Davies, K. E., \& Chamberlain, J. (2011). Therapeutic approaches to muscular dystrophy. Human Molecular Genetics, 20(R1), R69-78. doi:10.1093/hmg/ddr105

Goyenvalle, A., Wright, J., Babbs, A., Wilkins, V., Garcia, L., \& Davies, K. E. (2012). Engineering Multiple U7snRNA Constructs to Induce Single and Multiexon-skipping for Duchenne Muscular Dystrophy. Molecular Therapy: The Journal of the American Society of Gene Therapy. doi:10.1038/mt.2012.26

Griffet, J., Decrocq, L., Rauscent, H., Richelme, C., \& Fournier, M. (2011). Lower extremity surgery in muscular dystrophy. Orthopaedics \& Traumatology, Surgery \& Research: OTSR, 97(6), 634-638. doi:10.1016/j.otsr.2011.04.010

Hendrickson, B. C., Donohoe, C., Akmaev, V. R., Sugarman, E. A., Labrousse, P., Boguslavskiy, L., Flynn, K., et al. (2009). Differences in SMN1 allele frequencies among ethnic groups within North America. Journal of Medical Genetics, 46(9), 641-644. doi:10.1136/jmg.2009.066969

Hiraki, S., Ormond, K. E., Kim, K., \& Ross, L. F. (2006). Attitudes of genetic counselors towards expanding newborn screening and offering predictive genetic testing to children. American Journal of Medical Genetics. Part A, 140(21), 2312-2319. doi:10.1002/ajmg.a.31485

Hoffman, E. P., Brown, R. H., Jr, \& Kunkel, L. M. (1987). Dystrophin: the protein product of the Duchenne muscular dystrophy locus. Cell, 51(6), 919-928.

Holloway, S. M., Wilcox, D. E., Wilcox, A., Dean, J. C. S., Berg, J. N., Goudie, D. R., Denvir, M. A., et al. (2008). Life expectancy and death from cardiomyopathy amongst carriers of Duchenne and Becker muscular dystrophy in Scotland. Heart (British Cardiac Society), 94(5), 633-636. doi:10.1136/hrt.2007.125948

Hsu, J. D., \& Furumasu, J. (1993). Gait and posture changes in the Duchenne muscular dystrophy child. Clinical Orthopaedics and Related Research, (288), 122-125. 
Jansen, M., de Groot, I. J., van Alfen, N., \& Geurts, A. C. (2010). Physical training in boys with Duchenne Muscular Dystrophy: the protocol of the No Use is Disuse study. BMC Pediatrics, 10, 55. doi:10.1186/1471-2431-10-55

Jinks, D. C., Minter, M., Tarver, D. A., Vanderford, M., Hejtmancik, J. F., \& McCabe, E. R. (1989). Molecular genetic diagnosis of sickle cell disease using dried blood specimens on blotters used for newborn screening. Human Genetics, 81(4), 363-366.

Kashima, T., \& Manley, J. L. (2003). A negative element in SMN2 exon 7 inhibits splicing in spinal muscular atrophy. Nature Genetics, 34(4), 460-463. doi:10.1038/ng1207

Kaspar, R. W., Allen, H. D., \& Montanaro, F. (2009). Current understanding and management of dilated cardiomyopathy in Duchenne and Becker muscular dystrophy. Journal of the American Academy of Nurse Practitioners, 21(5), 241-249. doi:10.1111/j.17457599.2009.00404.x

Kemper, A. R., \& Wake, M. A. (2007). Duchenne muscular dystrophy: issues in expanding newborn screening. Current Opinion in Pediatrics, 19(6), 700-704. doi:10.1097/MOP.0b013e3282f19f65

Kinali, M., Main, M., Eliahoo, J., Messina, S., Knight, R. K., Lehovsky, J., Edge, G., et al. (2007). Predictive factors for the development of scoliosis in Duchenne muscular dystrophy. European Journal of Paediatric Neurology: EJPN: Official Journal of the European Paediatric Neurology Society, 11(3), 160-166. doi:10.1016/j.ejpn.2006.12.002

Koch, R., Burton, B., Hoganson, G., Peterson, R., Rhead, W., Rouse, B., Scott, R., et al. (2002). Phenylketonuria in adulthood: a collaborative study. Journal of Inherited Metabolic Disease, 25(5), 333-346.

Komanapalli, C. B., Sera, V., Slater, M. S., Burdette, M., Tripathy, U., Brady, G., Hegnell, L., et al. (2006). Becker's muscular dystrophy and orthotopic heart transplantation: perioperative considerations. The Heart Surgery Forum, 9(2), E604-606.

Lefebvre, S., Bürglen, L., Reboullet, S., Clermont, O., Burlet, P., Viollet, L., Benichou, B., et al. (1995). Identification and characterization of a spinal muscular atrophy-determining gene. Cell, 80(1), 155-165.

Lorson, C. L., Rindt, H., \& Shababi, M. (2010). Spinal muscular atrophy: mechanisms and therapeutic strategies. Human Molecular Genetics, 19(R1), R111-118. doi:10.1093/hmg/ddq147

Lu, Q.-L., Yokota, T., Takeda, S., Garcia, L., Muntoni, F., \& Partridge, T. (2011). The status of exon skipping as a therapeutic approach to duchenne muscular dystrophy. Molecular Therapy: The Journal of the American Society of Gene Therapy, 19(1), 9-15. doi:10.1038/mt.2010.219 
MacKenzie, A. (2012). Sense in antisense therapy for spinal muscular atrophy. The New England Journal of Medicine, 366(8), 761-763. doi:10.1056/NEJMcibr1114629

Mailman, M. D., Heinz, J. W., Papp, A. C., Snyder, P. J., Sedra, M. S., Wirth, B., Burghes, A. H. M., et al. (2002). Molecular analysis of spinal muscular atrophy and modification of the phenotype by SMN2. Genetics in Medicine: Official Journal of the American College of Medical Genetics, 4(1), 20-26.

Main, M., Mercuri, E., Haliloglu, G., Baker, R., Kinali, M., \& Muntoni, F. (2007). Serial casting of the ankles in Duchenne muscular dystrophy: can it be an alternative to surgery? Neuromuscular Disorders: NMD, 17(3), 227-230. doi:10.1016/j.nmd.2006.12.002

Manzur, A. Y., Kuntzer, T., Pike, M., \& Swan, A. (2008). Glucocorticoid corticosteroids for Duchenne muscular dystrophy. Cochrane Database of Systematic Reviews (Online), (1), CD003725. doi:10.1002/14651858.CD003725.pub3

Manzur, A. Y., \& Muntoni, F. (2009). Diagnosis and new treatments in muscular dystrophies. Postgraduate Medical Journal, 85(1009), 622-630. doi:10.1136/jnnp.2008.158329

Martigne, L., Salleron, J., Mayer, M., Cuisset, J.-M., Carpentier, A., Neve, V., Tiffreau, V., et al. (2011). Natural evolution of weight status in Duchenne muscular dystrophy: a retrospective audit. The British Journal of Nutrition, 105(10), 1486-1491.

doi:10.1017/S0007114510005180

McDonald, C. M. (2002). Physical activity, health impairments, and disability in neuromuscular disease. American Journal of Physical Medicine \& Rehabilitation / Association of Academic Physiatrists, 81(11 Suppl), S108-120. doi:10.1097/01.PHM.0000029767.43578.3C

Mehler, M. F. (2000). Brain dystrophin, neurogenetics and mental retardation. Brain Research. Brain Research Reviews, 32(1), 277-307.

Melacini, P., Fanin, M., Danieli, G. A., Villanova, C., Martinello, F., Miorin, M., Freda, M. P., et al. (1996). Myocardial involvement is very frequent among patients affected with subclinical Becker's muscular dystrophy. Circulation, 94(12), 3168-3175.

Mendell, J. R., Shilling, C., Leslie, N. D., Flanigan, K. M., Al-Dahhak, R., Gastier-Foster, J., Kneile, K., et al. (2012). Evidence-based path to newborn screening for Duchenne muscular dystrophy. Annals of Neurology, 71(3), 304-313. doi:10.1002/ana.23528

Menezes, M. P., \& North, K. N. (2011). Inherited neuromuscular disorders: Pathway to diagnosis. Journal of Paediatrics and Child Health. doi:10.1111/j.1440-1754.2011.02210.x

Merlini, L., Cicognani, A., Malaspina, E., Gennari, M., Gnudi, S., Talim, B., \& Franzoni, E. (2003). Early prednisone treatment in Duchenne muscular dystrophy. Muscle \& Nerve, 27(2), 222-227. doi:10.1002/mus.10319 
Monaco, A. P., Bertelson, C. J., Liechti-Gallati, S., Moser, H., \& Kunkel, L. M. (1988). An explanation for the phenotypic differences between patients bearing partial deletions of the DMD locus. Genomics, 2(1), 90-95.

Muntoni, F., Torelli, S., \& Ferlini, A. (2003). Dystrophin and mutations: one gene, several proteins, multiple phenotypes. Lancet Neurology, 2(12), 731-740.

Nakamura, A., \& Takeda, S. (2009). Exon-skipping therapy for Duchenne muscular dystrophy. Neuropathology: Official Journal of the Japanese Society of Neuropathology, 29(4), 494501. doi:10.1111/j.1440-1789.2009.01028.x

National Institutes of Health Consensus Development Conference Statement: phenylketonuria: screening and management, October 16-18, 2000. (2001).Pediatrics, 108(4), 972-982.

Naylor, E. W., \& Chace, D. H. (1999). Automated tandem mass spectrometry for mass newborn screening for disorders in fatty acid, organic acid, and amino acid metabolism. Journal of Child Neurology, 14 Suppl 1, S4-8.

Naylor, E. W., Hoffman, E. P., Paulus-Thomas, J., Wessel, H. B., Reid, K. S., Mitchell, B., \& Schmidt, B. J. (1992). Neonatal screening for Duchenne/Becker muscular dystrophy; Reconsideration based on molecular diagnosis and potential therapeutics. Screening, 1(2), 99-113. doi:10.1016/0925-6164(92)90002-M

Norman, A. M., Thomas, N. S., Kingston, H. M., \& Harper, P. S. (1990). Becker muscular dystrophy: correlation of deletion type with clinical severity. Journal of Medical Genetics, 27(4), 236-239.

Ogino, S., \& Wilson, R. B. (2002). Genetic testing and risk assessment for spinal muscular atrophy (SMA). Human Genetics, 111(6), 477-500. doi:10.1007/s00439-002-0828-x

Ogino, S., \& Wilson, R. B. (2004). Spinal muscular atrophy: molecular genetics and diagnostics. Expert Review of Molecular Diagnostics, 4(1), 15-29. doi:10.1586/14737159.4.1.15

Pangalila, R. F., van den Bos, G. A. M., Stam, H. J., van Exel, N. J. A., Brouwer, W. B. F., \& Roebroeck, M. E. (2011). Subjective caregiver burden of parents of adults with Duchenne muscular dystrophy. Disability and Rehabilitation. doi:10.3109/09638288.2011.628738

Parsons, E. P., Clarke, A. J., Hood, K., Lycett, E., \& Bradley, D. M. (2002). Newborn screening for Duchenne muscular dystrophy: a psychosocial study. Archives of Disease in Childhood. Fetal and Neonatal Edition, 86(2), F91-95.

Partridge, T. A. (2011). Impending therapies for Duchenne muscular dystrophy. Current Opinion in Neurology, 24(5), 415-422. doi:10.1097/WCO.0b013e32834aa3f1

Pearce, J. M. S. (2000). Gowers' sign. Journal of Neurology, Neurosurgery \& Psychiatry, 68(2), 149-149. doi:10.1136/jnnp.68.2.149 
Pearn, J. (1978). Incidence, prevalence, and gene frequency studies of chronic childhood spinal muscular atrophy. Journal of Medical Genetics, 15(6), 409-413.

Pichavant, C., Aartsma-Rus, A., Clemens, P. R., Davies, K. E., Dickson, G., Takeda, S., Wilton, S. D., et al. (2011). Current status of pharmaceutical and genetic therapeutic approaches to treat DMD. Molecular Therapy: The Journal of the American Society of Gene Therapy, 19(5), 830-840. doi:10.1038/mt.2011.59

Plass, A. M. C., van El, C. G., Pieters, T., \& Cornel, M. C. (2010). Neonatal screening for treatable and untreatable disorders: prospective parents' opinions. Pediatrics, 125(1), e99106. doi:10.1542/peds.2009-0269

Prior, T. W. (2010). Spinal muscular atrophy: a time for screening. Current Opinion in Pediatrics, 22(6), 696-702. doi:10.1097/MOP.0b013e32833f3046

Prior, T. W., Snyder, P. J., Rink, B. D., Pearl, D. K., Pyatt, R. E., Mihal, D. C., Conlan, T., et al. (2010). Newborn and carrier screening for spinal muscular atrophy. American Journal of Medical Genetics. Part A, 152A(7), 1608-1616. doi:10.1002/ajmg.a.33474

Pyatt, R. E., Mihal, D. C., \& Prior, T. W. (2007). Assessment of liquid microbead arrays for the screening of newborns for spinal muscular atrophy. Clinical Chemistry, 53(11), 1879-1885. doi:10.1373/clinchem.2007.092312

Rose, K. J., Burns, J., Wheeler, D. M., \& North, K. N. (2010). Interventions for increasing ankle range of motion in patients with neuromuscular disease. Cochrane Database of Systematic Reviews (Online), (2), CD006973. doi:10.1002/14651858.CD006973.pub2

Ross, L. F. (2002). Predictive genetic testing for conditions that present in childhood. Kennedy Institute of Ethics Journal, 12(3), 225-244.

Ross, L. F. (2006). Screening for conditions that do not meet the Wilson and Jungner criteria: the case of Duchenne muscular dystrophy. American Journal of Medical Genetics. Part A, 140(8), 914-922. doi:10.1002/ajmg.a.31165

Sadler, W. A., Lynskey, C. P., \& Legge, M. (1978). Radioimmunoassay of thyroxine in dried blood spots. Australian Paediatric Journal, 14(3), 154-162.

Scheuerbrandt, G., Lundin, A., Lövgren, T., \& Mortier, W. (1986). Screening for Duchenne muscular dystrophy: an improved screening test for creatine kinase and its application in an infant screening program. Muscle \& Nerve, 9(1), 11-23. doi:10.1002/mus.880090103

Scheuerbrandt, G. (2009). The progress reports on the development of therapies of Duchenne muscular dystrophy. Acta Myologica: Myopathies and Cardiomyopathies: Official Journal of the Mediterranean Society of Myology / Edited by the Gaetano Conte Academy for the Study of Striated Muscle Diseases, 28(2), 62-65. 
Seguy, D., Michaud, L., Guimber, D., Cuisset, J.-M., Devos, P., Turck, D., \& Gottrand, F. (2002). Efficacy and tolerance of gastrostomy feeding in pediatric forms of neuromuscular diseases. JPEN. Journal of Parenteral and Enteral Nutrition, 26(5), 298-304.

Smith, R. A., Williams, D. K., Sibert, J. R., \& Harper, P. S. (1990). Attitudes of mothers to neonatal screening for Duchenne muscular dystrophy. BMJ (Clinical Research Ed.), 300(6732), 1112.

Spurney, C. F. (2011). Cardiomyopathy of Duchenne muscular dystrophy: current understanding and future directions. Muscle \& Nerve, 44(1), 8-19. doi:10.1002/mus.22097

Su, Y.-N., Hung, C.-C., Lin, S.-Y., Chen, F.-Y., Chern, J. P. S., Tsai, C., Chang, T.-S., et al. (2011). Carrier screening for spinal muscular atrophy (SMA) in 107,611 pregnant women during the period 2005-2009: a prospective population-based cohort study. PloS One, 6(2), e17067. doi:10.1371/journal.pone.0017067

Takaso, M., Nakazawa, T., Imura, T., Okada, T., Fukushima, K., Ueno, M., Takahira, N., et al. (2010). Surgical management of severe scoliosis with high risk pulmonary dysfunction in Duchenne muscular dystrophy: patient function, quality of life and satisfaction. International Orthopaedics, 34(5), 695-702. doi:10.1007/s00264-010-0957-0

Trefz, F., Maillot, F., Motzfeldt, K., \& Schwarz, M. (2011). Adult phenylketonuria outcome and management. Molecular Genetics and Metabolism, 104 Suppl, S26-30. doi:10.1016/j.ymgme.2011.08.025

Tyler, K. L. (2003). Origins and early descriptions of "Duchenne muscular dystrophy." Muscle \& Nerve, 28(4), 402-422. doi:10.1002/mus.10435

Van Opstal, N., Verlinden, C., Myncke, J., Goemans, N., \& Moens, P. (2011). The effect of Luque-Galveston fusion on curve, respiratory function and quality of life in Duchenne muscular dystrophy. Acta Orthopaedica Belgica, 77(5), 659-665.

Voit, T., Neuen-Jacob, E., Mahler, V., Jauch, A., \& Cremer, M. (1992). Somatic mosaicism for a deletion of the dystrophin gene in a carrier of Becker muscular dystrophy. European Journal of Pediatrics, 151(2), 112-116.

Wang, C. H., Finkel, R. S., Bertini, E. S., Schroth, M., Simonds, A., Wong, B., Aloysius, A., et al. (2007). Consensus statement for standard of care in spinal muscular atrophy. Journal of Child Neurology, 22(8), 1027-1049. doi:10.1177/0883073807305788

Watson, M. S., Mann, M., \& Lloyd-Puryear, M. (2006). Newborn screening: toward a uniform screening panel and system. Genetics in Medicine: Official Journal of the American College of Medical Genetics, 8 Suppl 1, 1S-252S. doi:10.1097/01.gim.0000223891.82390.ad 
Wee, C. D., Kong, L., \& Sumner, C. J. (2010). The genetics of spinal muscular atrophies. Current Opinion in Neurology, 23(5), 450-458. doi:10.1097/WCO.0b013e32833e1765

Wilcken, B., \& Wiley, V. (2008). Newborn screening. Pathology, 40(2), 104-115. doi:10.1080/00313020701813743

Wilson, J. M., \& Jungner, Y. G. (1968). Principles and practice of mass screening for disease. Boletín De La Oficina Sanitaria Panamericana. Pan American Sanitary Bureau, 65(4), 281393.

Yazaki, M., Yoshida, K., Nakamura, A., Koyama, J., Nanba, T., Ohori, N., \& Ikeda, S. (1999). Clinical characteristics of aged Becker muscular dystrophy patients with onset after 30 years. European Neurology, 42(3), 145-149.

Yilmaz, O., Karaduman, A., \& Topaloglu, H. (2004). Prednisolone therapy in Duchenne muscular dystrophy prolongs ambulation and prevents scoliosis. European Journal of Neurology: The Official Journal of the European Federation of Neurological Societies, 11(8), 541-544. doi:10.1111/j.1468-1331.2004.00866.x

Zatz, M., Rapaport, D., Vainzof, M., Passos-Bueno, M. R., Bortolini, E. R., Pavanello, R. de C., \& Peres, C. A. (1991). Serum creatine-kinase (CK) and pyruvate-kinase (PK) activities in Duchenne (DMD) as compared with Becker (BMD) muscular dystrophy. Journal of the Neurological Sciences, 102(2), 190-196.

Zellweger, H., \& Antonik, A. (1975). Newborn screening for Duchenne muscular dystrophy. Pediatrics, 55(1), 30-34. 